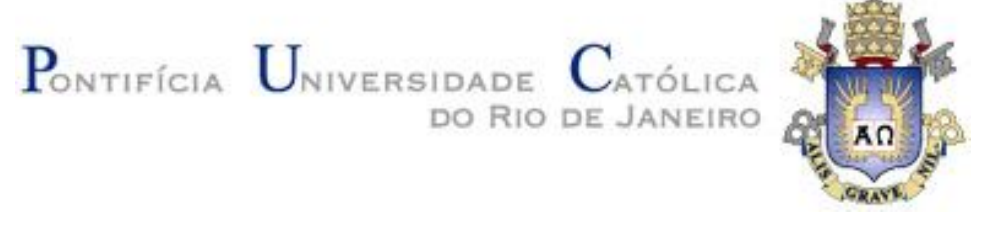

Sergio Libanio de Campos

\title{
Desenvolvimento de Sistema Climatizador Automotivo para Aquecimento e Resfriamento
}

\section{Tese de Doutorado}

Tese apresentada ao Programa de Pós-Graduação em Engenharia Mecânica da PUC-Rio como requisito parcial para obtenção do título de Doutor em Engenharia Mecânica.

Orientador: Prof. José Alberto dos Reis Parise 


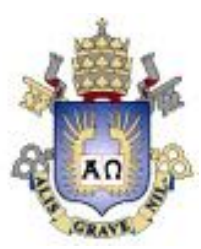

\section{Sergio Libanio de Campos}

Desenvolvimento de Sistema Climatizador Automotivo para Aquecimento e Resfriamento

Tese apresentada ao Programa de Pós-Graduação em Engenharia Mecânica da PUC-Rio como requisito parcial para obtenção do grau de Doutor em Engenharia Mecânica. Aprovada pela comissão Examinadora abaixo assinada.

Prof. José Alberto dos Reis Parise

Orientador Departamento de Engenharia Mecânica - PUC-Rio

Profa. Ana Rosa Fonseca de Aguiar Martins Instituto Tecnológico - PUC Rio

Prof. Mauro Speranza Departamento de Engenharia Mecânica - PUC-Rio

Prof. Enio Bandarra Filho UFU

Prof. Alcir de Faro Orlando Departamento de Engenharia Mecânica - PUC-Rio

Prof. José Luiz Fernandes CEFET-RJ

Prof. José Eugenio Leal Coordenador Setorial do Centro Técnico Científico - PUC-Rio 
Todos os direitos reservados. É proibida a reprodução total ou parcial do trabalho sem a autorização da universidade, do autor e do orientador.

\section{Sergio Libanio de Campos}

Graduou-se em Engenharia Mecânica na PUC-Rio em 1984. Obteve o título de Mestre em Tecnologia no CEFET-RJ em 2007. É professor do Curso Técnico de Manutenção Automotiva do CEFET-RJ, UnED de Maria da Graça, Rio de Janeiro, desde 2003.

Ficha Catalográfica

CDD: 621 


\section{Agradecimentos}

À minha família que sempre está do meu lado: À minha esposa, em especial, que soube entender a minha ausência até mesmo no período de oito meses em que participei de um estágio de doutorado na Universidade de Braunschweig, Alemanha, me apoiando em todo o momento, mesmo naqueles difíceis que juntos passamos.

Ao meu orientador, Prof. Parise, pelo ensinamento, colaboração, incentivo, paciência e apoio durante todo o período do programa.

Ao Professor Alcir Faro Orlando pela inestimável colaboração quanto a disponibilização dos laboratórios de temperatura e pressão para a calibração dos termopares utilizados no experimento, do seu orientado no curso de mestrado Daniel, que prestou uma grande colaboração para a calibração da célula de carga utilizada na balança de medição do peso de água condensada no evaporador.

Ao aluno de graduação em engenharia mecânica Felipe Portes Lanes, pela inestimável ajuda durante os trabalhos experimentais no laboratório.

Aos meus amigos do Laboratório de Termociências, do DEM, do ITUC e da PUC-Rio: Carlúcio, Roberta, Fabio, Rosely, Evemero, Marcelo, João, Alexandre e Leninaldo.

Aos Professores do Departamento de Engenharia Mecânica da PUC-Rio.

Ao CNPq, PUC-Rio, CAPES e à FAPERJ pelo apoio financeiro. 


\section{Resumo}

Campos, Sergio Libanio; Parise, José Alberto dos Reis. Desenvolvimento de sistema climatizador automotivo para aquecimento e resfriamento. Rio de Janeiro, 2014.119 p. Tese de Doutorado - Departamento de Engenharia Mecânica, Pontifícia Universidade Católica do Rio de Janeiro.

Sistemas condicionadores de ar automotivos têm sido extensivamente estudados, buscando melhor eficiência de resfriamento e redução do consumo de combustível. O presente trabalho tem como objetivo o estudo de um sistema condicionador de ar automotivo operando nos modos de resfriamento e aquecimento, este último atendendo às necessidades de conforto em dias frios nos veículos elétricos, os quais não apresentam calor de rejeito do motor, como nos veículos convencionais. Para tal foi projetado e montado, no Laboratório de Refrigeração, Condicionamento de Ar e Criogenia da PUC-Rio, um aparato experimental composto por duas câmaras de temperatura e umidade controladas, uma simulando o compartimento de passageiros e a outra, o ambiente externo. Um típico sistema condicionador de ar automotivo, composto por componentes comercialmente disponíveis e utilizados nos veículos atuais, foi dotado de válvulas direcionais, permitindo a inversão do ciclo de compressão de vapor do modo de resfriamento para o modo de aquecimento, operando neste último como bomba de calor. Dados experimentais foram levantados sob operação em regime permanente e transiente (período de partida), com temperaturas entre $-5^{\circ} \mathrm{C}$ e 45 ${ }^{\circ} \mathrm{C}$. Para o modo de resfriamento, seguiu-se a norma SAE J2765 e, para o de aquecimento, na ausência de normas, foram cobertas as operações em modos de recirculação do ar da cabine e de renovação com ar externo, entre as temperaturas de $-5{ }^{\circ} \mathrm{C}$ e $10{ }^{\circ} \mathrm{C}$. Foi também realizada uma simulação numérica, validada pelos dados experimentais, utilizando as equações fundamentais da termodinâmica e transferência de calor. O sistema testado mostrou-se viável na aplicação em veículos elétricos, uma vez que nestes o calor de rejeito previsto (regeneração de frenagem e efeito Joule na eletrônica de potência) não é suficiente para o conforto térmico em dias frios. Demonstrou-se que a bomba de calor consome menos energia que resistências as elétricas atualmente utilizadas.

\section{Palavras-chave}

Ar Condicionado Automotivo; Bomba de Calor Automotiva; Veículo Elétrico. 


\section{Abstract}

Campos, Sergio Libanio; Parise, José Alberto dos Reis (Advisor). Development of an automotive air conditioning system for heating and cooling. Rio de Janeiro, 2011. P 119. DSc. Thesis - Departamento de Engenharia Mecânica, Pontifícia Universidade Católica do Rio de Janeiro.

Automotive air conditioning systems have been extensively studied, searching for better cooling efficiency and reduced fuel consumption. The present work aims to study a system of automotive air conditioner operating in cooling and heating modes, the latter satisfies the needs of comfort on cold days in electrical vehicles, which do not include waste heat from the engine as the conventional vehicles. To this was designed and assembled in the Refrigeration, Air Conditioning and Cryogenics Laboratory, in Puc-Rio, an experimental apparatus consists of two chambers with temperature and humidity controlled, one, simulating the passenger compartment and the other, the external environment. A typical automotive air conditioning system, composed of commercially available components used in current vehicles is provided with a directional valve, allowing the inversion of vapor compression cooling mode to the heating mode cycle, the latter operating as a heat pump.

\section{Keywords}

Automotive air conditioner; Automotive Heat Pump; Electrical Vehicles. 


\section{Sumário}

1 Introdução 22

1.1 Operação básica dos atuais sistemas de ar condicionado veicular 22

1.1.1 Sistema de resfriamento 22

1.1.2 Sistema de aquecimento 26

1.2 Componentes dos sistemas climatizadores automotivo 27

1.2.1 Compressor 27

1.2.2 Condensador 29

1.2.3 Evaporador 30

1.2.4 Filtro secador acumulador 32

1.2.5 Dispositivo de expansão 34

1.2.6 Aquecedor de ar 36

1.2.7 Controle de temperatura interna do veículo 38

$\begin{array}{ll}1.3 \text { Organização do trabalho } & 38\end{array}$

2 Revisão Bibliográfica $\quad 39$

$\begin{array}{ll}2.1 \text { Resumo do estado da arte } & 39\end{array}$

2.2 Estado da Arte $\quad 40$

2.3 Contribuição da presente tese 58

3 Aparato Experimental $\quad 60$

3.1 Introdução $\quad 60$

3.2 Aparato experimental e medições 60

3.2.1 Câmaras climatizadas 60

3.2.2 Túneis de vento 63

3.2.3 Bancada de componentes 64

$\begin{array}{ll}3.3 \text { Instrumentação utilizada } & 69\end{array}$

$\begin{array}{ll}\text { 3.3.1 Medidas de pressão } & 69\end{array}$

3.3.2 Medidas de temperatura 70

3.3.3 Medidas dos escoamentos de ar $\quad 71$

$\begin{array}{ll}\text { 3.3.4 Peso do condensado no evaporador } & 73\end{array}$ 
3.3.5 Umidade relativa $\quad 74$

$\begin{array}{ll}\text { 3.4 Quadro elétrico de comando e potência } & 74\end{array}$

4 Procedimento Experimental $\quad 77$

4.1 Aquisição de dados $\quad 79$

4.2 Problemas operacionais com o aparato experimental 83

5 Aquisição e redução de dados 86

$\begin{array}{ll}5.1 \text { Redução dos dados } & 87\end{array}$

5.2 Análise de incertezas $\quad 90$

$\begin{array}{ll}5.2 .1 \text { Introdução } & 90\end{array}$

5.2.2 Avaliação da incerteza padrão tipo A 90

5.2.3 Avaliação da incerteza padrão tipo B 91

5.2.4 Determinação da incerteza de medição 91

5.2.5 Possíveis fontes de incerteza em calibrações de instrumentos
elétricos

5.2.6 Análise de incertezas utilizadas 93

6 Resultados 96

7 Conclusões e sugestões para futuros trabalhos 116

$\begin{array}{ll}7.1 \text { Conclusão } & 116\end{array}$

$\begin{array}{ll}\text { 7.2 Sugestões para futuros trabalhos } & 117\end{array}$

8 Referências Bibliograficas 118 


\section{Lista de figuras}

Figura 1: Tipos de sistemas de ar condicionado veicular. (Shah, 2009).

Figura 2: Diagrama ilustrativo do funcionamento de sistema de aquecimento dos veículos convencionais. 26

Figura 3: Compressor do tipo FDC (a) e Diagrama de funcionamento (b) (Sistema SETE de Ensino, 2013).

Figura 4:Compressor do tipo VDC (a) e diagrama de funcionamento (b) 28

Figura 5: Vista das volutas fixa e móvel (a); princípio de funcionamento (b).

Figura 6: Condensador de tubos e aletas, (DIDACTA, 2003) .................... 30

Figura 7: Condensador Modine, (DIDACTA, 2003).................................... 30

Figura 8: Condensador de fluxos paralelos.................................................. 30

Figura 9: Caixa evaporadora veicular, onde 1 - termostato; 2 de controle de velocidade e 3 - o eletro ventilador, (DIDACTA, 2003) .......... 31

Figura 10: Evaporador de tubos e aletas de alumínio, (DIDACTA,

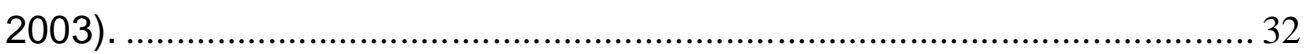

Figura 11: Evaporador de serpentina, (DIDACTA, 2003).......................... 32

Figura 12: Evaporador de placas brasadas e aletas (Sistema SETE de Ensino, 2013)

Figura 13: Filtro convencional vertical; 1 - Entrada; 2 - Saída; 3 -

Filtro secador; 4 - Tanque líquido refrigerante; 5 - Aspirador de líquido; 6 - Malhas filtrantes, (DIDACTA, 2003)........................................... 33

Figura 14: Filtro secador de líquido, (DIDACTA, 2003).............................. 34

Figura 15: Filtro secador acumulador de vapor (Sistema SETE de ensino, 2013).

Figura 16: Dispositivos de expansão do tipo tubo de orifício constante (Sistema SETE de Ensino, 2013).

Figura 17: Esquema de válvula termostática de expansão (DIDACTA, 2003).

Figura 18: Esquema de funcionamento de uma válvula de expansão termostática com controle interno, (Sistema SETE de Ensino, 2013)....... 36 
Figura 19: Módulo interno de resfriamento e aquecimento do veículo GM, Corsa (Apostila de treinamento GM, 2003).

Figura 20: Vistas do trocador de calor de aquecimento da cabine utilizado nos veículos convencionais.

Figura 21: Variação da capacidade de refrigeração (a) e capacidade de aquecimento (b), vs. velocidade do compressor. Hosoz e Direk (2006).

Figura 22: Variação do COP vs. velocidade do compressor, para operações em modo de refrigeração (a) e modo de aquecimento (b). Hosoz e Direk (2006)...

Figura 23: Variação da temperatura de descarga do compressor vs. velocidade do compressor, para operações em modo de refrigeração (a) e modo de aquecimento (b). Hosoz e Direk (2006).

Figura 24: Taxas de destruição total de exergia por unidade de capacidade, como uma função da velocidade do compressor para os modos de refrigeração (a) e de aquecimento (b). Hosoz e Direk (2006).

Figura 25: Taxas de exergia destruídas pelos componentes do circuito de refrigeração, como uma função da velocidade do compressor para os modos de refrigeração (a) e de aquecimento (b). Hosoz e Direk (2006).

Figura 26: (a) Variação da capacidade de refrigeração; (b) Capacidade de aquecimento, vs. temperatura de evaporação. Hosoz e Direk (2006).

Figura 27: Variação do COP vs. temperatura de evaporação para operações em modo de refrigeração (a) e modo de aquecimento (b). Hosoz e Direk (2006).

Figura 28: Variação da temperatura de descarga do compressor vs. temperatura de evaporação para operações em modo de refrigeração (a); e modo de aquecimento (b). Hosoz e Direk (2006).

Figura 29: (a) Variação da temperatura do ar registrado na saída frontal do compartimento de passageiros; (b) Alteração da temperatura média do ar no compartimento de passageiros vs. 
velocidade do compressor (ambas as temperaturas foram registradas no final do período de cinco minutos de operação). Direk, et al. (2011)... 45 Figura 30: (a) Variação da capacidade de aquecimento no final do período de cinco minutos de operação; (b) Capacidade de aquecimento no estado de equilíbrio vs. velocidade do compressor. Direk, et al. (2011)

Figura 31: (a) Variação do COP; (b) Aumento no consumo de combustível específico causado pela operação do sistema AHP vs. velocidade do compressor. Direk, et al. (2011). 46

Figura 32: Diagrama do sistema de bomba de calor automotiva, Scherer, et al. (2003).

'Tabela 3: Regime transiente de aquecimento por tempo (bomba de calor VS. sistema de base), Scherer, et al. (2003).

Figura 33a: Diagrama do sistema operando em modo de A/C. Meyer, et al. (2004).

Figura 33b: Diagrama do sistema operando em modo bomba de calor.

Meyer, et al. (2004).

Figura 34: Layout da instalação do sistema condicionador de ar em um micro-ônibus. Torregrosa, et al. (2013).

Figura 35: Validação da modelagem da cabine durante os testes de aquecimento e resfriamento. Torregrosa, et al. (2013)......

Figura 36: Consumo de energia durante uma hora de resfriamento.

Torregrosa, et al. (2013).

Figura 37: Desempenho da bomba de calor durante o aquecimento.

Torregrosa, et al. (2013).

Figura 38: Energia consumida durante uma hora de aquecimento.

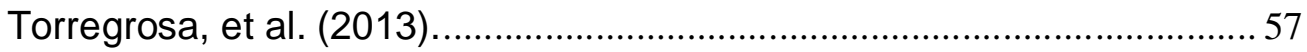

Figura 39: Diagrama ilustrativo da construção das câmaras......................... 61

Figura 40: Auto sintonia para o controle de aquecimento. ............................ 62

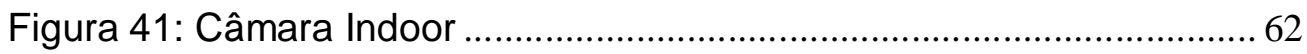

Figura 43: Visão geral da alocação das câmaras no laboratório. ................ 63

Figura 44: Diagrama llustrativo do Aparato Experimental. ........................... 63

Figura 45: (a) Túnel de vento Indoor, (b) Túnel de vento Outdoor............. 64 
Figura 46: (a) Estrutura da bancada, (b) bancada com os componentes instalados.

Figura 47: (a) Vista superior do sistema AC \& BC montado no laboratório, (b) Vista das válvulas de inversão do ciclo, do tipo esfera de comando manual.

Figura 48: Diagrama do sistema ar de condicionado e bomba de calor montado no laboratório.

Figura 49: (a) Vista da montagem no túnel de vento outdoor e (b)

Vista do condensador automotivo.

Figura 50: Circuitos do condensador utilizado.

Figura 51: Vista dos tubos planos e micro canais do condensador.

Figura 52: Válvula de expansão termostática do tipo bloco.

Figura 53: (a) Instalação da válvula TXV e "Check Valve" na câmara indoor e (b) Instalação da válvula TXV e "Check Valve" na câmara "outdoor".

Figura 54: Vista do evaporador automotivo instalado no túnel de vento "indoor".

Figura 55: Vista: (a) "manifold" inferior de entrada do refrigerante, (b) "maifold" superior de saída do refrigerante.

Figura 56: Vista dos filtros na linha de líquido e suas "check valves"

Figura 57: Grades de termopares do túnel "indoor".

Figura 58: Grade de termopares do túnel "outdoor".

Figura 59: (a) Diagrama de montagem dos manômetros de coluna d'água inclinado, (b) Anemômetro utilizado para medir as velocidades de face do ar na entrada dos túneis de vento.

Figura 60: Manômetro de coluna d'água inclinado range de 100mm........ 72

Figura 61: Vistas do bocal ASME com $75 \mathrm{~mm}$ de diâmetro de descarga, fabricado e instalado no túnel de vento "indoor".

Figura 62: Vistas do bocal ASME fabricado em fibra de vidro com 250 $\mathrm{mm}$ de diâmetro de descarga, instalado no túnel "outdoor".

Figura 63: Termo Higrômetro ICEL.

Figura 64: Termo

Higrômetro TFA. 
Figura 65: (a) Vista das chaves de comando; (b) Vista dos componentes no interior do painel.

Figura 66: Inversores CFW9 no interior do quadro e o CFW8 externo ao quadro

Figura 67: Quadro de controle da temperatura da câmara indoor.............. 76

Figura 68: Quadro de controle de temperatura da câmara "outdoor"......... 76

Figura 69: Sistema de aquisição de dados NI cDAQ 9178 ........................... 80

Figura 70: Tela de leitura dos dados no aplicativo labVIEW....................... 80

Figura 71: Dados experimentais do ensaio de ar condicionado. ................. 81

Figura 72: Pressões medidas no lado do refrigerante vs. tempo total do ensaio

Figura 73: Pressões medidas no lado do refrigerante vs. Intervalo de

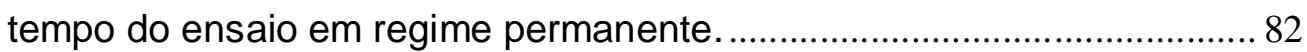

Figura 74: Dados experimentais do ensaio de bomba de calor.

Figura 75: Pressões do lado do refrigerante vs. tempo total do ensaio com regime transiente, operando como bomba de calor.

Figura 76: Pressões medidas no lado do refrigerante vs. Intervalo de tempo do ensaio em regime permanente.

Figura 77: Variação da taxa de transferência de calor interna vs. a variação da rotação do compressor e temperatura do ambiente externo.

Figura 78: Variação do $\mathrm{COP}$ elet. vs. rotação do compressor e temperatura do ambiente externo.

Figura 79: Variação da temperatura de insuflamento vs. rotação do compressor e temperatura do ambiente externo.

Figura 80: Variação da temperatura do ar na saída do evaporador vs. rotação do compressor e temperatura do ambiente externo.

Figura 81: Variação do trabalho do compressor vs. rotação do compressor e temperatura do ambiente externo.

Figura 82: Variação da taxa de transferência de calor no evaporador vs. rotação do compressor e temperatura do ambiente externo.

Figura 83: Variação do COP da bomba de calor vs. rotação do compressor e temperatura do ambiente externo. 
Figura 84: Variação da taxa de transferência de calor no ambiente interno vs. rotação do compressor e temperatura do ambiente externo. 101 Figura 85: Variação da taxa de transferência de calor do condensador vs. rotação do compressor e temperatura ambiente.

Figura 86: Variação do COP vs. diferença de temperatura entre o condensador e o evaporador.

Figura 87: Variação da temperatura do ar através do evaporador vs. rotação do compressor e temperatura do ar do ambiente externo.

Figura 88: Taxa de transferência de calor para o ar do condensador, vs. rotação do compressor e temperatura do ar do ambiente externo.... 103 Figura 89: Trabalho do compressor, vs. rotação e temperatura do ambiente externo

Figura 90: Variação do expoente politrópico do compressor vs. rotação do compressor e temperatura do ambiente externo.

Figura 91: variação do expoente politrópico do compressor vs. razão de compressão do compressor e temperatura do ambiente externo...... 104 Figura 92: Variação da eficiência isentrópica do compressor vs. razão de compressão e temperatura do ambiente externo. 105 Figura 93: Variação da queda de pressão na linha de sucção vs. rotação do compressor e temperatura do ambiente externo.

Figura 94: Variação da queda de pressão na linha de sucção vs. rotação do compressor e temperatura do ambiente externo.

Figura 95: Variação da efetividade do trocador indoor vs. rotação do compressor e temperatura do ambiente externo.

Figura 96: Variação da efetividade do trocador outdoor vs. rotação do compressor e temperatura do ambiente externo.

Figura 97: Variação da queda de pressão no condensador vs. rotação do compressor e temperatura do ambiente externo, sistema operando como bomba de calor.

Figura 98: Variação da queda de pressão no condensador vs. rotação do compressor e temperatura do ambiente externo, sistema operando como ar condicionado. 
Figura 99: Variação da efetividade do evaporador no modo bomba de calor vs. rotação do compressor e temperatura do ambiente externo. .. 110 Figura 100: Variação da efetividade do evaporador no modo ar condicionado vs. rotação do compressor e temperatura do ambiente externo.

Figura 101: Variação da queda de pressão no evaporador no modo bomba de calor vs. rotação do compressor e temperatura do ambiente externo.

Figura 102: Variação da queda de pressão no evaporador no modo ar condicionado vs. rotação do compressor e temperatura do ambiente externo.

Figura 103: Variação da queda de pressão no trocador indoor vs. rotação do compressor com temperatura do ambiente externo de $10^{\circ} \mathrm{C}$

Figura 104: Variação das pressões vs. tempo de ensaio em segundos. 114 Figura 105: Variação das pressões vs. tempo de ensaio em segundos. 115 


\section{Lista de Tabelas}

Tabela 1: Trabalhos sobre AC e BC encontrados na literatura................. 39

Tabela 2: Desempenho em regime permanente da bomba de calor a temperatura ambiente de $0^{\circ} \mathrm{F}$. (Sherer, et al. 2003) .................................... 48

'Tabela 3: Regime transiente de aquecimento por tempo (bomba de calor VS. sistema de base), Scherer, et al. (2003 ..................................... 49

Tabela 4: Resumo dos dados de desempenho. Meyer, et al. (2004)....... 52

Tabela 5: Matriz de testes da norma SAE J2765 .................................... 79

Tabela 6: Nomenclatura dos testes realizados com renovação de ar (OSA).

Tabela 7: Nomenclatura dos testes realizados com recirculação de ar (REC) 


\section{Lista de Equações}

Equação 1: Curva de calibração da balança de condensado

Equação 2: Taxa de transferência de calor fornecida ou retirada do ambiente interno

Equação 3: Vazão mássica do ar

Equação 4: Taxa de transferência de calor do ambiente

Equação 5: Taxa de realização de trabalho do compressor

Equação 6: Coeficiente de desempenho, $\mathrm{COP}_{\text {elt }}$

Equação 7: Coeficiente de desempenho, $\mathrm{COP}_{\mathrm{AC}}$

Equação 8: Coeficiente de desempenho, $\mathrm{COP}_{\mathrm{HP}}$

Equação 9: Expoente politrópico

Equação 10: Razão de pressão do compressor

Equação 11: Eficiência isentrópica do compressor

Equação 12: Queda de pressão na linha de sucção do compressor para AC

Equação 13: Queda de pressão na linha de sucção do compressor para $\mathrm{HP}$

Equação 14: Vazão mássica de refrigerante, esta foi calculada a partir do balanço de energia no lado do ar no condensador

Equação 15: Efetividades do condensador

Equação 16: Efetividades do evaporador com calor sensível e latente $\quad 90$

Equação 17: Cálculo da incerteza em uma medição 91

Equação 18: Cálculo da incerteza de distribuição retangular 92

Equação 19: Cálculo da incerteza de distribuição normal 92

Equação 20: Cálculo da incerteza de componente aleatória 92

Equação 21: Cálculo do desvio-padrão da média 92 
Equação 22: Cálculo da incerteza padrão para as avaliações Tipo A 93 Equação 23: Cálculo da Incerteza Padrão Combinada 93 Equação 24: Cálculo da Incerteza de correlação entre grandezas 93 Equação 25: Cálculo das incertezas das grandezas mencionadas 94 Equação 26: Cálculo da incerteza da grandeza temperatura 94 Equação 27: Cálculo da incerteza da grandeza pressão 95 Equação 28: Cálculo da incerteza das demais grandezas instrumentadas 95 


\section{Lista de Símbolos}

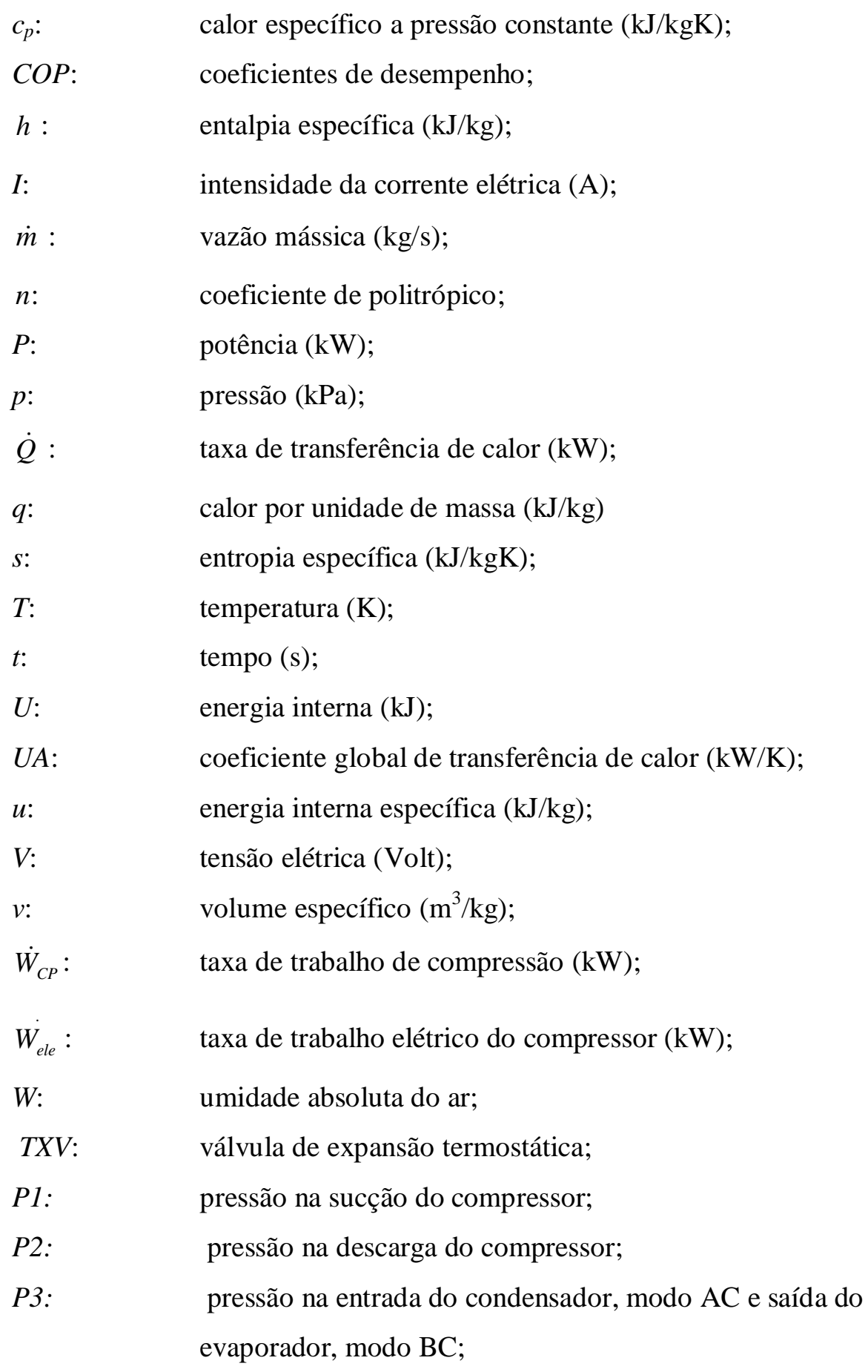



P4: $\quad$ pressão na saída do condensador, modo AC e entrada do evaporador, modo BC;
P5: $\quad$ pressão na entrada do evaporador, modo AC e saída do condensador, modo BC;
P6: $\quad$ pressão na saída do evaporador no modo AC e entrada do condensador, no modo BC.
T1: $\quad$ temperatura do refrigerante na sucção do compressor;
T2: $\quad$ temperatura do refrigerante na descarga do compressor;
T3: $\quad$ temperatura do refrigerante na entrada do condensador, modo AC e saída do evaporador, modo BC;
T4: $\quad$ temperatura do refrigerante na saída do condensador, modo $\mathrm{AC}$ e entrada do evaporador, modo $\mathrm{BC}$;
T5: $\quad$ temperatura do refrigerante na entrada do evaporador, modo AC e saída do condensador, modo BC;
T6: $\quad$ temperatura do refrigerante na saída do evaporador no modo AC e entrada do condensador, no modo BC.
$R: \quad$ razão.

Símbolos Gregos:

$\Delta T \quad$ diferença de temperaturas $(\mathrm{K})$;

$\Delta T_{\text {saq }}: \quad$ grau de superaquecimento do evaporador $(\mathrm{K})$;

$\Delta T_{\text {sub: }} \quad$ grau de subresfriamento do condensador $(\mathrm{K})$;

$\eta$ : $\quad$ eficiência;

$\varepsilon: \quad$ efetividade (trocadores de calor).

$\underline{\text { Subscritos: }}$

$\begin{array}{ll}a r: & \text { ar; } \\ a o: & \text { ambiente; } \\ a q c: & \text { referente ao aquecimento; } \\ c d: & \text { condensador; } \\ c p: & \text { compressor; } \\ \text { cond: } & \text { condensação; }\end{array}$




$\begin{array}{ll}\text { ev: } & \text { evaporador; } \\ \text { ele: } & \text { elétrico; } \\ \text { evap: } & \text { evaporador; } \\ \text { saq: } & \text { superaquecimento; } \\ \text { indoor: } & \text { ambiente interno (compartimento de passageiros); } \\ \text { outdoor: } & \text { ambiente externo (meio ambiente); } \\ \text { ele: } & \text { elétrico; } \\ \text { ac: } & \text { ar condicionado (refrigeração); } \\ h p: & \text { bomba de calor (aquecimento); } \\ s l: & \text { linha de sucção do compressor; } \\ r f: & \text { refrigerante; } \\ I: & \text { condições do ar a montante do trocador de calor externo; } \\ I I: & \text { condições do ar a jusantante do trocador de calor externo; } \\ I I I: & \text { condições do ar a montante do trocador de calor interno; } \\ I V: & \text { condições do ar a jusantante do trocador de calor interno } .\end{array}$




\section{1 \\ INTRODUÇÃO}

A presente tese está fundamentada no estudo experimental e teórico de tecnologia nos sistemas condicionadores de ar automotivos, aquecimento e refrigeração aplicada a veículos elétricos, buscando atender as diretrizes do Regulamento (CE) n ${ }^{\circ}$ 842/2006 do Parlamento Europeu e do Conselho, de 17 de Maio de 2006, relativas a determinados gases de efeito estufa fluorados.

Para o aquecimento da cabine dos veículos convencionais utiliza-se o calor de rejeito do motor de combustão interna, para tal é introduzido um trocador de calor na caixa HVAC (aquecimento, ventilação e ar condicionado), por onde se faz passar o líquido de arrefecimento do motor, quando o modo de aquecimento é solicitado.

Nos veículos elétricos o calor de rejeito do motor é ausente, logo para realizar o aquecimento da cabine os veículos elétricos atuais, aquecedores elétricos de resistência são utilizados. Tais equipamentos possuem, quando bem projetados, um coeficiente de desempenho (COP) unitário e consequentemente consomem energia das baterias que acionam o motor elétrico do veículo, reduzindo assim sua autonomia.

Para esta tese foi projetado, baseado na norma SAE J2765, e montado, no Laboratório de Refrigeração, Condicionamento de Ar e Criogenia da PUC-Rio, um aparato experimental de ensaio de sistemas automotivos de condicionamento de ar, que será melhor descrito a frente. Igualmente foi realizada uma simulação numérica do sistema estudado a fim de ampliar os dados estudados.

\section{1}

Operação Básica dos Atuais Sistemas de Climatização Veicular

\subsubsection{Sistema de Resfriamento}

Dois, são na maioria dos casos, os tipos de sistemas utilizados nos veículos: TXV-RD (dotados de válvula de expansão termostática e filtro acumulador na linha de líquido) e OT-AD (dotados de tubo de orifício permanente e filtro acumulador na linha de vapor). Os componentes destes tipos de sistema 
são mostra dos na figura 1 (a) e (b) respectivamente. No sistema TXV-RD a vazão de refrigerante

controlada por uma válvula de expansão termostática (TXV, válvula de expansão em bloco ou TEV, válvula de expansão de bulbo externo) por meio do monitoramento do grau de superaquecimento do refrigerante na saída do evaporador. O acumulador secador (RD) é instalado antes da TXV para a separação do refrigerante líquido/vapor e armazenar refrigerante necessário durante o resfriamento nos repentinos aumentos de carga térmica. Nos sistemas OT-AD, funções similares são alcançadas por um tubo de orifício constante (OT), instalado antes do evaporador e do acumulador secador (AD).

Presença de umidade no refrigerante nos ciclos dos sistemas de $\mathrm{A} / \mathrm{C}$ pode causar corrosão no evaporador, entupimento no orifício da TXV ou no tubo de orifício. Portanto uma bolsa contendo material dissecante é colocada no interior do $\mathrm{RD}$ e do $\mathrm{AD}$ dos sistemas já mencionados.

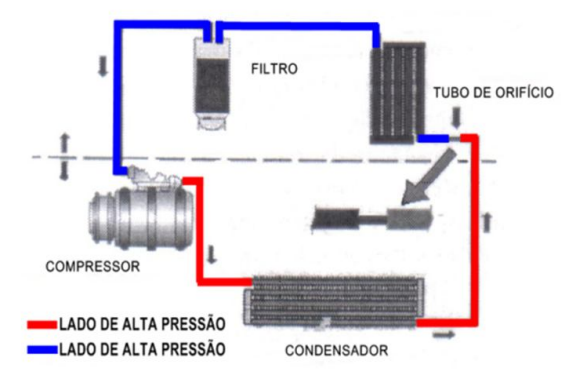

(a)

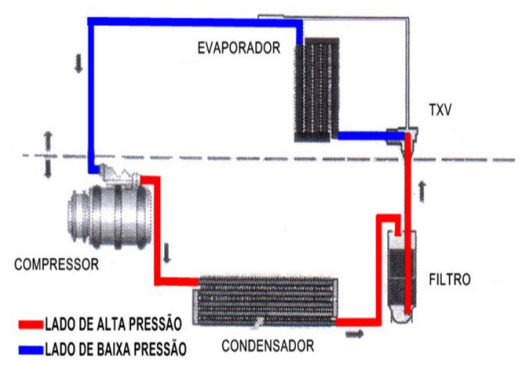

(b)

Figura 1: Tipos de sistemas de ar condicionado veicular. (Shah, 2009).

A operação básica destes sistemas será agora descrita, começando pelo compressor. A função primária do compressor é dupla: (1) comprimir e pressurizar o refrigerante gasoso relativamente frio vindo da saída do evaporador (linha de sucção) com a mínima potência de acionamento possível e (2) disponibilizar o máximo de refrigerante gasoso a alta pressão e temperatura para o condensador. Esses dois objetivos são quantificados pelas eficiências isentrópica e volumétrica do compressor, respectivamente. O compressor é acionado por correia que é ligada ao motor do veículo e sua velocidade rotacional (revoluções por minuto - rpm), em alguns casos, é mais alta que a do motor do veiculo. Tal diferença é definida pela razão dos diâmetros das respectivas polias. O 
compressor é acionado por meio de uma embreagem eletromagnética, permitindo assim seu acionamento ou desligamento (Shah, 2009).

O próximo componente é o condensador, no caminho do fluxo do refrigerante, ver figura 1 . O condensador é e deve ser instalado à frente do radiador do motor. Nos sistemas automotivos o condensador típico é do tipo fluxo cruzado (cross-flow), é um trocador de calor em que o fluxo de ar atravessa aletas, corrugada ou do tipo persianas e o refrigerante flui através de placas multiportas ou tubos redondos, com ou sem microaletas, em múltiplos passes na direção perpendicular a do fluxo de ar. O condensador resfria o refrigerante gasoso, vindo do compressor, a alta pressão e temperatura convertendo-o em líquido, geralmente com uma pequena queda de pressão, por meio do uso do ar ambiente (relativamente frio comparado com o refrigerante quente), soprado pelo ventilador do conjunto condensador/radiador. O refrigerante líquido que sai do condensador, na maioria dos casos subresfriado, é conduzido via tubo de menor diâmetro (linha de líquido) para o RD (aplicado nos sistemas de válvula de expansão). O RD é um recipiente de metal (aço) com um pacote de dissecante em seu interior e permite na sua saída somente refrigerante líquido. Normalmente está localizado perto da saída do condensador. Atualmente o RD é parte integral do condensador nos modelos modernos de alto desempenho de sistemas de ar condicionado veicular e este passa a ser denominado "condensador acumulador-secador" (IRDC). Neste caso o refrigerante passa pelo RD antes de sair do condensador, no ultimo passe, como líquido subresfriado. O objetivo é melhorar o grau de subresfriamento do refrigerante na saída do condensador permitindo apenas refrigerante líquido já condensado. Existe uma imperceptível alteração de pressão e temperatura do refrigerante no interior do $\mathrm{RD}$, o mesmo não ocorrendo com a umidade do refrigerante que é removida pelo dissecante (Shah, 2009).

Continuando com a operação do sistema, o refrigerante, na condição de líquido subresfriado, que deixa o condensador, chega à TXV ou OT que modulam a quantidade apropriada de vazão de refrigerante no sistema. Efetivamente, a TXV é um tubo de orifício de diâmetro variável e a OT é um tubo com orifício de diâmetro constante. Assim a TXV permite maior vazão de refrigerante em marcha lenta comparado com a fornecida pelo OT. Tem-se, então, maior resfriamento na condição de operação em marcha lenta. 
O ideal seria que ambos os sistemas fornecessem o mesmo desempenho de refrigeração nas condições de tráfego da cidade (velocidade do veículo entre 40$50 \mathrm{~km} / \mathrm{h}$ ), porém, o sistema TXV tem um desempenho de refrigeração ligeiramente melhor do que o sistema OT, comparando-se em um mesmo veiculo. Isto é porque o sistema OT-AD promove uma alta queda de pressão na linha do refrigerante (linha de sucção) entre o evaporador e o compressor, uma vez que o recipiente $\mathrm{AD}$ introduz queda de pressão adicional impactando no desempenho do sistema condicionador de ar.

Nos veículos em altas velocidades o sistema com TXV mantém o desejado grau de superaquecimento do refrigerante na saída do evaporador permitindo maior vazão de refrigerante no sistema para atender uma necessidade maior de arrefecimento. O sistema OT não controla as condições do refrigerante na saída do evaporador, porém o ponto de bolha, onde o refrigerante começa a evaporar se move dentro do OT a partir da entrada (condição de refrigeração do evaporador alta) para extremidade de saída do tubo no interior do OT (condição de refrigeração do evaporador baixa) para se obter a vazão de refrigerante necessária ao evaporador e ao sistema A/C. O líquido pressurizado passa através do dispositivo de expansão, com considerável redução de pressão e de temperatura correspondente (Shah, 2009).

A mistura fria, líquido/vapor de refrigerante, oriunda do dispositivo de expansão, alimenta o evaporador no módulo HVAC instalado na parte inferior do painel do veículo, no compartimento de passageiros. O gás refrigerante ou resfria o ar externo da atmosfera ou recircula o ar do ambiente interno, com fluxo de ar gerado por um ventilador montado no referido módulo, direcionando este fluxo para o interior da cabine resfriando-a. Como o ar que esta sendo arrefecido passa através das aletas do evaporador, lado ar, aquece a mistura liquido/vapor de refrigerante fazendo com que este se evapore totalmente. O gás refrigerante evaporado em seguida retorna por meio da linha de sucção que possui grande diâmetro (tubo e mangueiras) para o compressor na entrada de sucção iniciando todo o processo novamente para o sistema TXV-RD. No sistema OT-AD, um acumulador/secador é instalado entre o evaporador e o compressor. Ele separa e armazena qualquer refrigerante liquido que sai do evaporador antes de ir para o 
compressor uma vez que não existe superaquecimento na saída do evaporador neste sistema (Shah, 2009).

\subsubsection{Sistema de Aquecimento}

Veículos convencionais, dotados de motor a combustão interna, possuem um sistema de aquecimento da cabine que utiliza o líquido de arrefecimento do motor como fonte de calor. Nestes sistemas faz-se passar o líquido de arrefecimento por um trocador de calor instalado na caixa HVAC (aquecimento, ventilação e ar condicionado), montada no interior da cabine e, por meio de portas (dampers), o condutor pode selecionar a condição de conforto que melhor convier, resfriamento ou aquecimento.

Já nos veículos elétricos ou mesmo híbridos o calor de rejeito do motor é ausente, impossibilitando sua utilização para aquecer o compartimento de passageiros destes veículos. Atualmente tais veículos utilizam aquecedores elétricos que possuem um coeficiente de desempenho (COP) não superior à unidade, que produzem uma significativa redução da autonomia do veículo. Uma solução seria a utilização do ciclo reversível de compressão de vapor, podendo operar como ar condicionado e como bomba de calor (Pommé, 2012).

Um diagrama ilustrativo do sistema de aquecimento utilizado nos veículos convencionais é mostrado na figura 2.
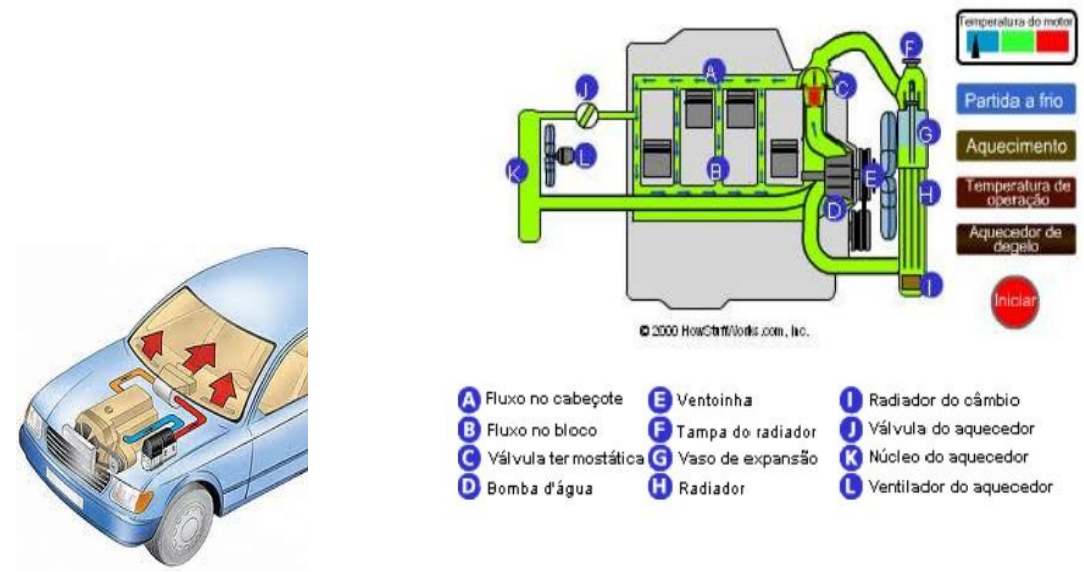

Figura 2: Diagrama ilustrativo do funcionamento de sistema de aquecimento dos veículos convencionais. 


\section{2}

Componentes dos Sistemas Climatizadores Automotivo

Os principais componentes dos sistemas condicionadores de ar automotivos são: i) Compressor; ii) Condensador; iii) Dispositivo de expansão; iv) Evaporador e v) Vaso receptor secador ou Acumulador secador, além de tubos, mangueiras, conectores e sensores, que serão descritos a seguir.

\subsubsection{Compressor}

Os principais tipos de compressores utilizados pela indústria automotiva em sistemas de ar condicionado são: compressores alternativos de deslocamento fixo (Fixed Displacement Compressor - FDC), alternativos de deslocamento variável (Variable Displacement Compressor - VDC), do tipo voluta (scroll), serão mostrados nas figuras 2,3 e 4 .

Os compressores de deslocamento fixo foram introduzidos no início do desenvolvimento dos sistemas de ar condicionado automotivo, nos anos 50 e pesavam cerca de $30 \mathrm{~kg}$. Atualmente eles possuem um peso entre 4 e $7 \mathrm{~kg}$, além da redução de peso suas eficiências isentrópicas e volumétricas, bem como sua durabilidade e confiabilidade foram aumentadas consideravelmente e os ruídos foram reduzidos significativamente (Shah, 2009).

Dentre os compressores utilizados em todo o mundo os alternativos representam $80 \%$ do mercado enquanto que os de voluta (scroll) e os rotativos representam 20\%. As características gerais dos compressores serão resumidas a seguir.

Em um compressor de deslocamento fixo (FDC), o movimento rotativo da placa oscilante montada no eixo é convertido em movimento alternativo dos pistões, produzindo curso fixo dos pistões. A taxa de vazão mássica de refrigerante é mantida pelo diferencial de pressão por meio do cilindro, entre o pleno de sucção e o pleno de descarga. Neste tipo de compressor o deslocamento, volume do cilindro não varia com a rotação, portanto a vazão mássica de refrigerante é função somente da rotação. 
A figura 3 mostra um compressor do tipo FDC, e um diagrama do seu funcionamento.

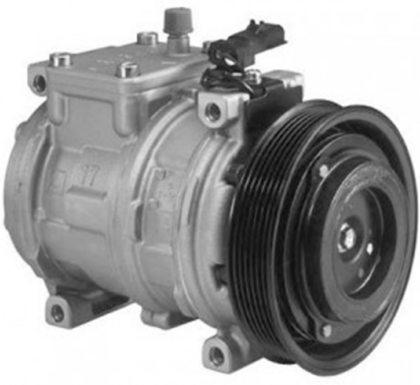

(a)

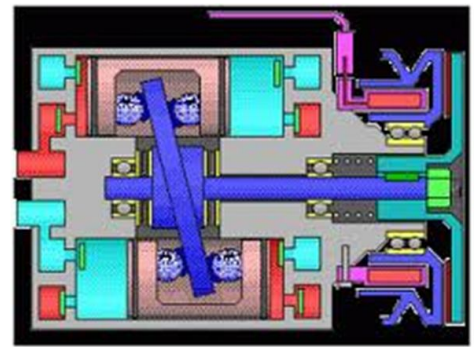

(b)

Figura 3: Compressor do tipo FDC (a) e Diagrama de funcionamento (b) (Sistema SETE de Ensino, 2013).

Nos compressores de deslocamento variável (VDC), o curso dos êmbolos varia com a carga térmica que o sistema está submetido e sua a rotação.

Estes compressores são dotados de uma válvula equalizadora de pressão que, ao ser atuada, permite uma variação da placa inclinada reduzindo assim o curso dos êmbolos, daí o nome compressores de deslocamento variável. Este tipo de compressores é mais eficiente do que os FDC sob as condições de climas amenos, como primavera, outono, dias nublados, noites de verão e longos percursos de deslocamento do veículo (Shah, 2009).

A figura 4 mostra um compressor do tipo VDC (a) e seu diagrama de funcionamento(b).

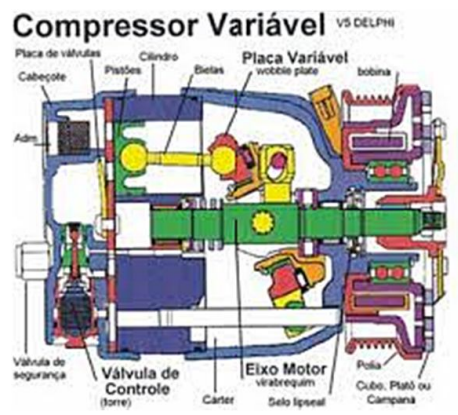

(a)

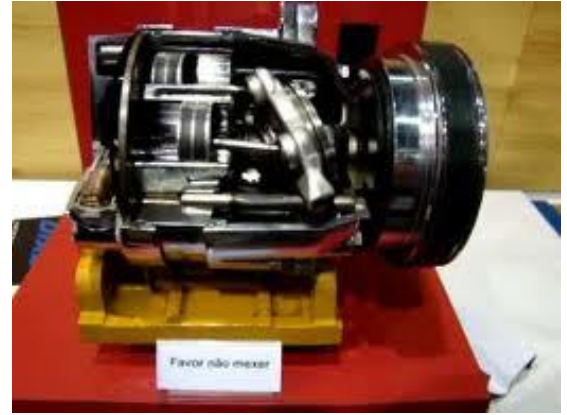

(b)

Figura 4: Compressor do tipo VDC (a) e diagrama de funcionamento (b). 
Compressores do tipo voluta (scroll) são do tipo orbital, como mostrado na figura 5. A voluta móvel executa um movimento orbital sobre a voluta fixa. $\mathrm{O}$ movimento orbital da voluta móvel empurra o refrigerante entre a voluta fixa e as paredes, promovendo uma compressão contínua em direção ao centro. Isto significa não existir reexpansão do gás comprimido como ocorre nos compressores do tipo FDC e VDC. Portanto sua eficiência volumétrica é elevada aproximadamente 85 a 95\%. As vantagens deste compressor sobre os FDC são: melhor desempenho a alta velocidade do compressor; maior eficiência volumétrica; são mais compactos e de menor peso e o processo de compressão contínua suaviza o fluxo de refrigerante gasoso.

As desvantagens deste compressor são: precisão requerida para seus componentes internos; a fabricação de peças com geometria complexa.

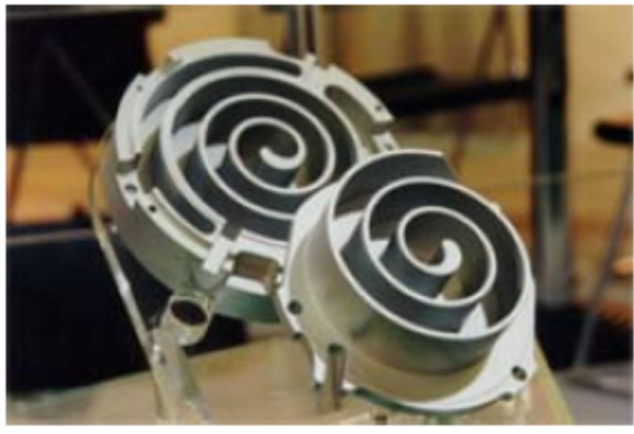

(a)

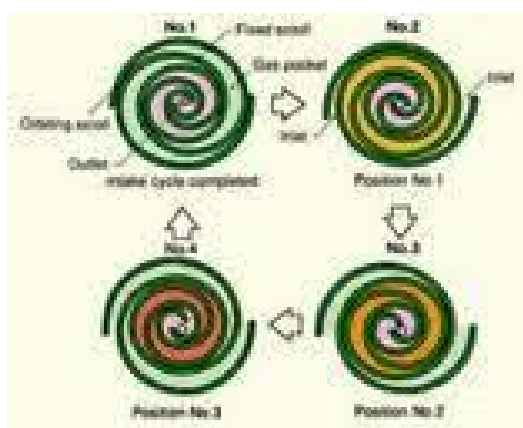

(b)

Figura 5: Vista das volutas fixa e móvel (a); princípio de funcionamento (b).

\subsubsection{Condensador}

O condensador é um trocador de calor que tem a função de dissipar calor proporcionando a mudança para o estado liquido do refrigerante superaquecido, proveniente do compressor. O ar é, neste caso, o fluído responsável pela troca de calor.

Os condensadores usados atualmente nas aplicações automobilísticas podem ser agrupados em três tipos:

1. De tubos e aletas: construído com tubos horizontais de cobre (ou alumínio) e aletas de alumínio, figura 6. 


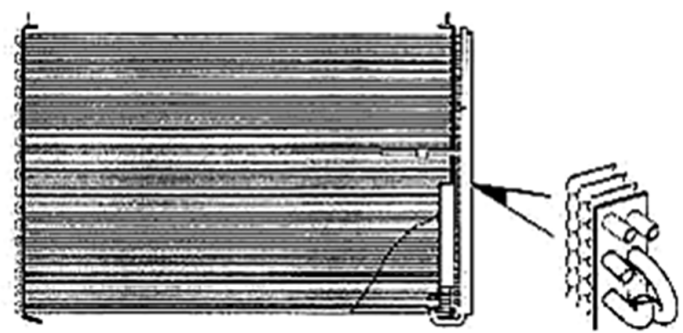

Figura 6: Condensador de tubos e aletas, (DIDACTA, 2003).

2. Tubo plano (Modine), figura 7, construídos com um perfil de seção plana multicanal, em uma configuração de serpentina, com aletas de alumínio; apresenta rendimento superior em relação aos tradicionais condensadores de tubos e aletas.

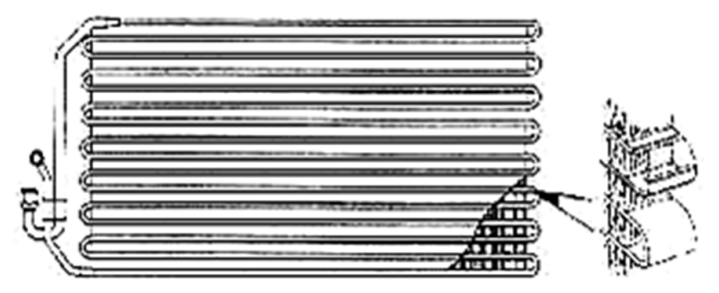

Figura 7: Condensador Modine, (DIDACTA, 2003).

3. Multifluxo, de fluxos paralelos, mostrado na figura 8 , são totalmente construídos em alumínio. Sua montagem é constituída por dois tubos coletores laterais que alimentam uma serie de tubos de perfil plano horizontais, contendo micro canais no seu interior.
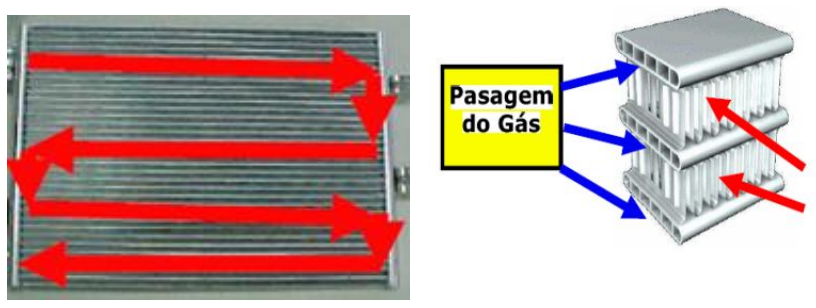

Passagem do Ar

Figura 8: Condensador de fluxos paralelos.

\subsubsection{Evaporador}

É um trocador de calor que tem como objetivo evaporar o fluido refrigerante, retirando calor do ar no ambiente a ser refrigerado. $\mathrm{O}$ evaporador deve possuir alguns requisitos, entre os quais é oportuno mencionar: 
- Superfície de troca de calor suficientemente extensa;

- Seções internas projetadas de modo a não exercer excessiva resistência à passagem do refrigerante reduzindo ao máximo a perda de carga;

Os evaporadores utilizados em sistemas condicionadores de ar automotivos são do tipo expansão seca, pois o fluido refrigerante se evapora completamente na parte interna dos tubos.

$\mathrm{Na}$ figura 9 está representado um evaporador típico utilizado no condicionamento de ar veicular. O ar a ser resfriado é deslocado por meio de um eletro ventilador de velocidade regulável, atravessa o evaporador, onde sua temperatura é reduzida, chegando finalmente chega à parte interna do compartimento de passageiros do veiculo. Os drenos do condensado, gerado pela desumidificação parcial do ar após ser resfriado, não são mostrados na figura.

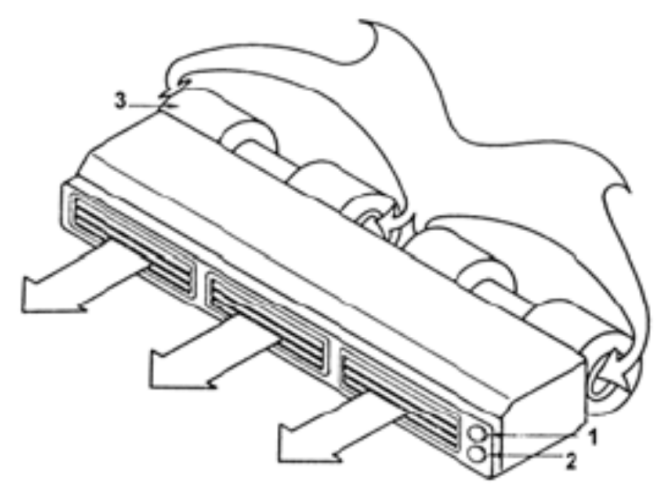

Figura 9: Caixa evaporadora veicular, onde 1 - termostato; 2 - controle de velocidade e 3 - o eletro ventilador, (DIDACTA, 2003).

Nas aplicações comerciais, o termostato, situado na parte interna do compartimento de passageiros, determina qual dos dois efeitos (resfriamento ou aquecimento) deve prevalecer.

Os evaporadores podem ser classificados em três categorias, segundo a geometria da superfície de troca de térmica, entre o fluido de trabalho e o ar a ser resfriado.

1. Evaporador de tubos e aletas, mostrado na figura 10, é constituído por tubos redondos de cobre com múltiplas passagens e aletas de alumínio. 


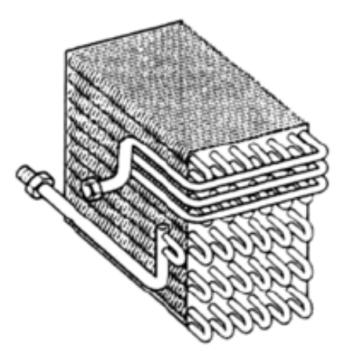

Figura 10: Evaporador de tubos e aletas de alumínio, (DIDACTA, 2003).

2. Evaporador de serpentina, figura 11, é constituído por tubos de alumínio de secção plana e aletas de alumínio.

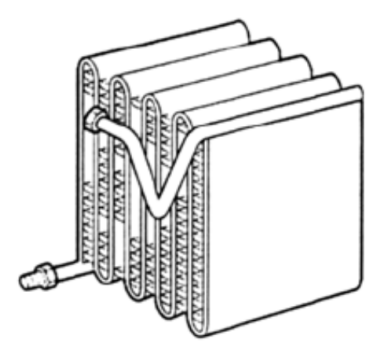

Figura 11: Evaporador de serpentina, (DIDACTA, 2003).

3. De placas brasadas e aletas, figura 12, constituído por uma série de tubos planos e paralelos formados por duas placas brasadas que são unidas nas extremidades. Apresentam ótima eficiência de troca de calor e baixas quedas de pressão no lado do refrigerante.
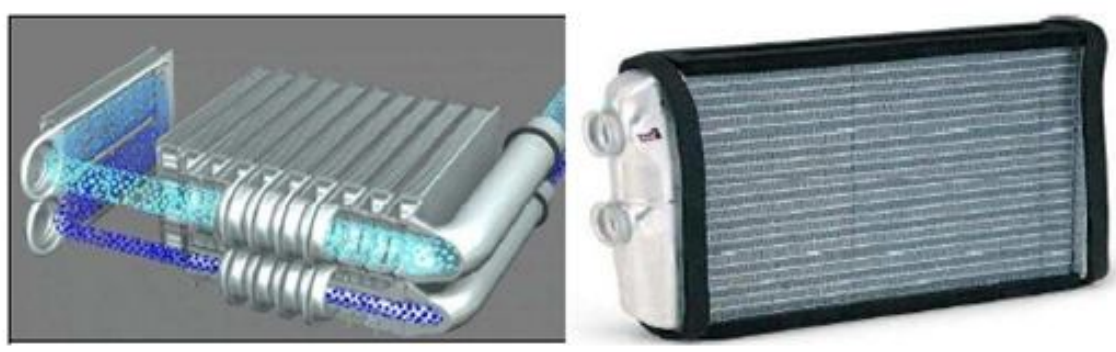

Figura 12: Evaporador de placas brasadas e aletas (Sistema SETE de Ensino, 2013).

\subsubsection{Filtro Secador Acumulador}

Possui três funções básicas: Remover a umidade do refrigerante e do óleo; filtrar os materiais estranhos (partículas sólidas) e atuar como separador de líquido. 
Existem dois tipos de filtros secadores mais utilizados em sistemas veiculares na linha de líquido:

1. Filtro convencional vertical, mostrado na figura $13 . \mathrm{O}$ refrigerante sai do condensador e entra no filtro secador onde o líquido e os vapores não condensados são separados; um tubo aspirador extrai o líquido da base do filtro assegurando o abastecimento contínuo de refrigerante em fase líquida à válvula de expansão;

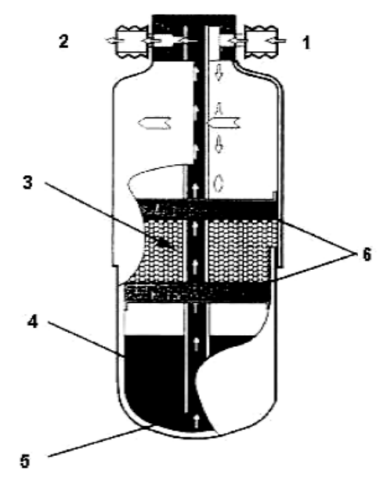

Figura 13: Filtro convencional vertical; 1 - Entrada; 2 - Saída; 3 - Filtro secador; 4 Tanque líquido refrigerante; 5 - Aspirador de líquido; 6 - Malhas filtrantes, (DIDACTA, 2003).

2. Filtro secador na linha de líquido, mostrado na figura 14. Montado na entrada do condensador vem sendo muito utilizado nos sistemas condicionadores de ar automotivos, pois protege o condensador de partículas sólidas normalmente geradas pelo funcionamento do compressor.

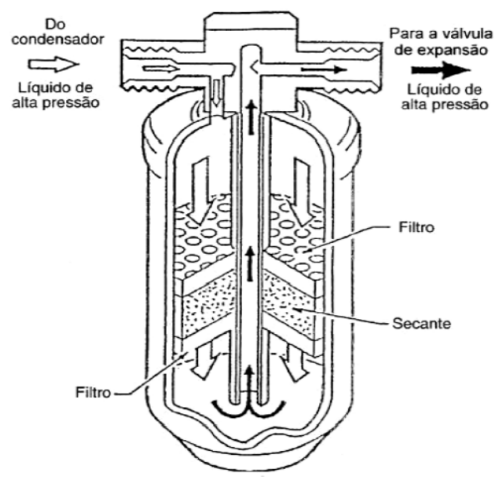


Figura 14: Filtro secador de líquido, (DIDACTA, 2003).

O elemento desidratante é constituído, geralmente, por sílicagel ou zeólito; o material é mantido na parte interna do reservatório por meio de telas, possuindo dispositivos de proteção a fim de evitar que o mesmo se impreguine de partículas, perdendo suas características.

Sistemas condicionadores de ar automotivos, que utilizam como dispositivo de expansão o tubo de orifício, utilizam um sistema de filtragem e secagem do refrigerante e óleo, na linha de baixa pressão, ou seja, na saída do evaporador, como mostrado na figura 15. Estes filtros, confeccionados em alumínio, também agem como um acumulador de líquido, garantindo a ausência de refrigerante na fase líquida na sucção do compressor, uma vez que o tubo de orifício não garante um grau de superaquecimento constante na saída do evaporador.
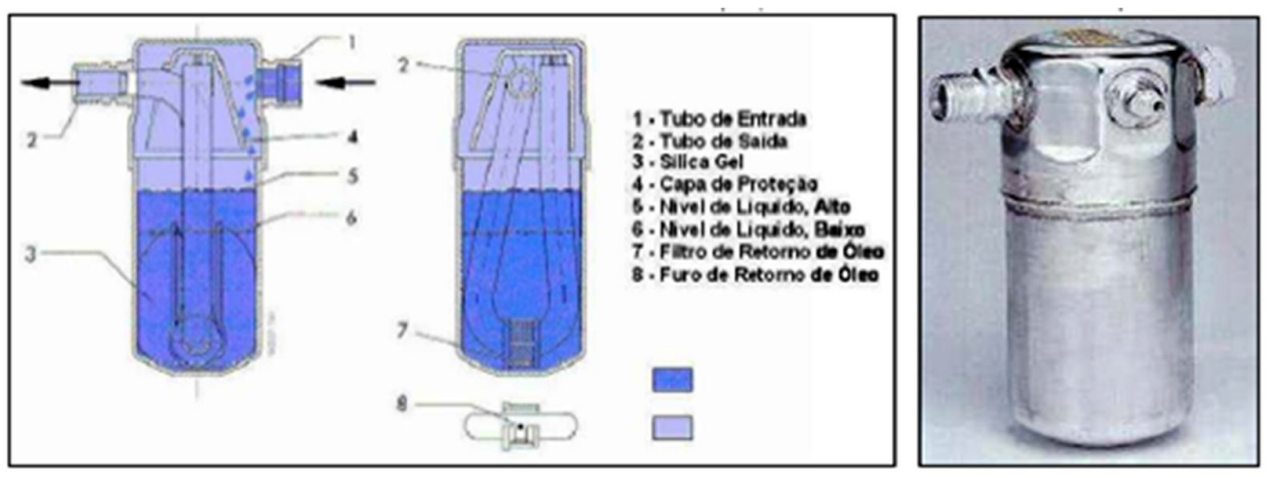

Figura 15: Filtro secador acumulador de vapor (Sistema SETE de ensino, 2013).

\subsubsection{Dispositivo de Expansão}

Existem diversos dispositivos usados para reduzir a pressão do refrigerante, antes da entrada no evaporador, desde a pressão de condensação (Pcd) até a pressão de evaporação (Pev), baixando assim, a temperatura do fluído refrigerante.

Tais dispositivos podem ser: tubo capilar, válvula de orifício calibrado, válvula de expansão pressostática e a válvula de expansão termostática (TXV). O objetivo dos dispositivos de expansão é diminuir a pressão do refrigerante na fase líquida, de maneira que, no evaporador, se realize a evaporação a temperatura 
suficientemente baixa para promover o resfriamento do ar que escoa para a cabine e um leve superaquecimento no refrigerante, geralmente de 5 a $8{ }^{\circ} \mathrm{C}$.

Na figura 16 é mostrado um dispositivo de expansão do tipo tubo de orifício, utilizado nos sistemas de ar condicionado e que vem sendo substituído pelas válvulas TXV compacta ou, como também são conhecidas, em bloco.

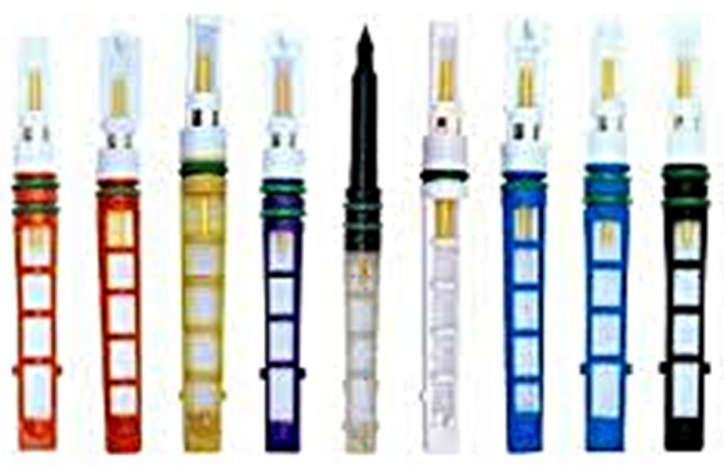

Figura 16: Dispositivos de expansão do tipo tubo de orifício constante (Sistema SETE de Ensino, 2013).

A válvula de expansão termostática (TXV) é um tipo de válvula que opera de acordo com a temperatura do refrigerante na saída do evaporador. A abertura da válvula é variada proporcionalmente à variação da temperatura do refrigerante, neste ponto.

A figura 17 apresenta o esquema de uma válvula de expansão termostática com controle externo.

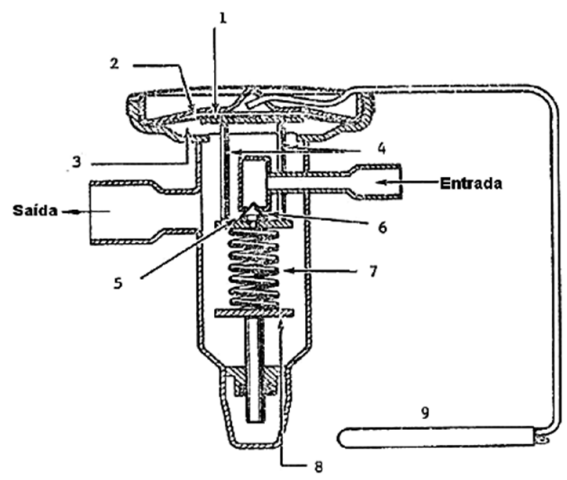

Figura 17: Esquema de válvula termostática de expansão (DIDACTA, 2003).

Onde: 1 - Ponto onde atua a pressão do fluído presente no bulbo situado na saída do evaporador; 2 - Diafragma sensível; 3 - Vácuo sobre o qual atua a pressão do 
evaporador; 4 - Porca de ajuste da pressão; 5 - Passagem da válvula; 6 - Assento da válvula; 7 - mola; 8 - Parafuso de regulagem da válvula; 9 - Bulbo sensor termostático.

A figura 18 mostra o esquema de funcionamento de uma válvula de expansão termostática com controle interno.

O funcionamento da válvula de expansão termostática é, em princípio, o seguinte: a passagem do fluido é regulada com base na temperatura do refrigerante na saída do evaporador.

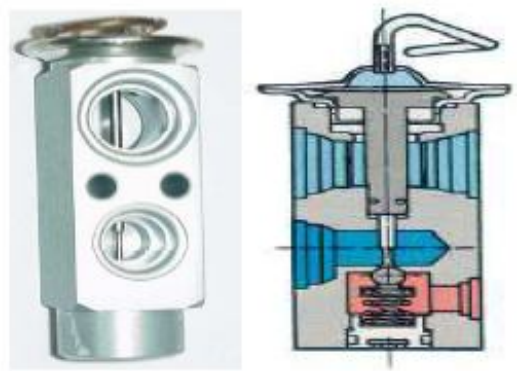

Figura 18: Esquema de funcionamento de uma válvula de expansão termostática com controle interno, (Sistema SETE de Ensino, 2013).

Quando esta grandeza assume valores superiores aos estabelecidos, um mecanismo dosador é acionado aumentando a vazão mássica de refrigerante a ser expandido.

Se, após a evaporação, na saída do evaporador, obtém-se um grau de superaquecimento do fluído, menor que o desejado, o sensor de temperatura interno faz com que a válvula se feche, reduzindo a vazão mássica de refrigerante a ser expandido, aumentando, assim, sua temperatura na saída do evaporador. Este mecanismo permite que o grau de superaquecimento na saída do evaporador permaneça o mais estável possível, mesmo que o sistema venha operar em situações diferenciadas.

\subsubsection{Aquecedor de Ar}

Como já mencionado anteriormente, o aquecimento da cabine nos veículos convencionais se dá com a utilização do calor de rejeito do motor de combustão interna. A figura 19 mostra, como exemplo, um módulo HVAC utilizado no veículo Corsa, fabricado pela General Motors do Brasil. 


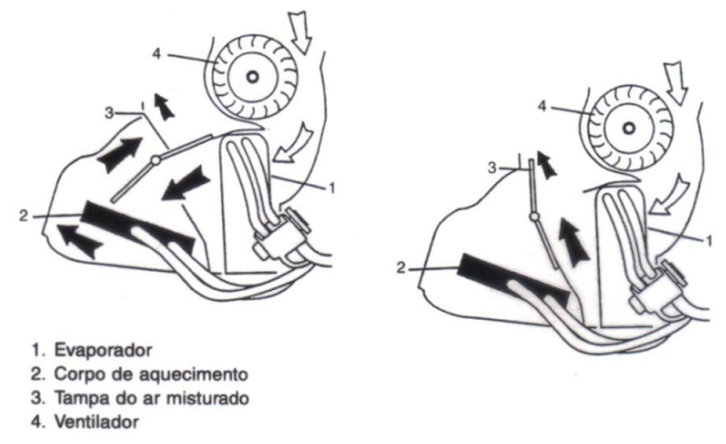

Figura 19: Módulo interno de resfriamento e aquecimento do veículo GM, Corsa (Apostila de treinamento GM, 2003).

Como mostrado na figura 18, componente (2), o trocador de calor de aquecimento, popularmente conhecido como núcleo ou corpo de aquecimento, é um trocador de calor do tipo tubos e aletas planas em alumínio, por onde se faz passar o líquido de arrefecimento do motor a uma temperatura média de $107^{\circ} \mathrm{C}$. Um trocador de calor (núcleo ou corpo de aquecimento) é mostrado na figura 20.
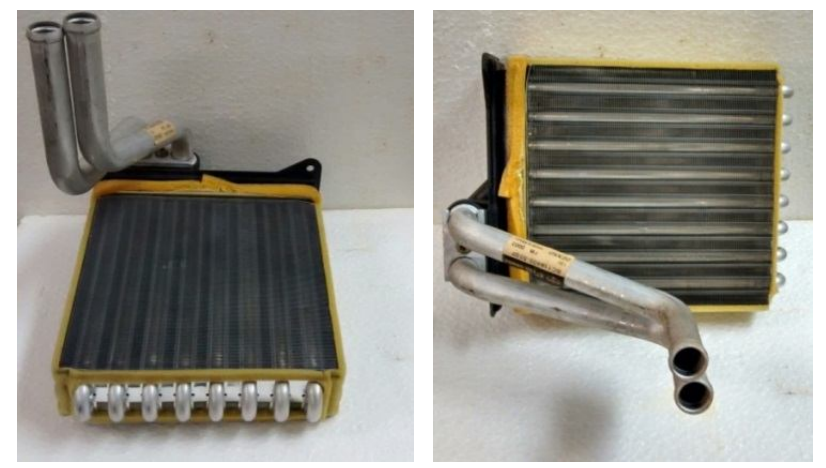

Figura 20: Vistas do trocador de calor de aquecimento da cabine utilizado nos veículos convencionais.

Nos veículos híbridos ou elétricos, que já é realidade no mundo, conforme já mencionado anteriormente, a utilização do líquido de arrefecimento do motor como fonte de calor se torna inviável. Atualmente a indústria automobilística vem utilizando sistemas de aquecedores elétricos, o que reduz a autonomia destes veículos, uma vez que o sistema propulsor utiliza a mesma energia elétrica armazenada nas baterias. 


\subsubsection{Controle da temperatura interna do veículo}

Atualmente os sistemas condicionadores de ar automotivos são integrados ao sistema eletrônico de gerenciamento do motor, permitindo um melhor desempenho do sistema como também um controle mais eficaz da emissão de gases poluentes produzidas pelos motores de combustão interna.

O acionamento e o desligamento do compressor são realizados por estas centrais eletrônicas (UCE). Entre as intervenções que a unidade de gerenciamento aplica sobre o sistema condicionador de ar, a mais oportuna é o desligamento momentâneo do compressor assim que é solicitada mais potência do motor. Quando o acelerador é acionado em mais de $70 \%$ de seu curso, nos casos de ultrapassagens, por exemplo, a UCE desliga o relé que aciona a embreagem eletromagnética do compressor pelo tempo de cinco a oito segundos disponibilizando assim algo em torno de $4 \mathrm{cv}$ a mais de potência transmitida pelo motor. Após o período de tempo mencionado, assim que a carga sobre o motor é aliviada, a UCE energiza o relé que aciona a embreagem eletromagnética do compressor restabelecendo assim as funções do sistema condicionador de ar. Essa estratégia está pressente em todos os veículos fabricados atualmente (Sistema SETE de Ensino, 2013).

\section{3}

\section{Organização do Trabalho}

O presente trabalho está organizado de tal forma que o capítulo 2 dedica-se à revisão bibliográfica, no capítulo 3 descreve-se o aparato experimental bem como a instrumentação utilizada, o capítulo 4 descreve a análise experimental, no capítulo 5 disserta-se sobre a aquisição e a redução dos dados obtidos no experimento.

No capítulo 6 são apresentados, em forma gráfica, os resultados deste trabalho. 


\section{REVISÃO BIBLIOGRAFICA}

\section{1}

\section{Resumo do Estado da Arte}

Sistemas condicionadores de ar automotivos com reversão de ciclo para operar como ar condicionado e bomba de calor, ainda são pouco estudados, conforme pode ser verificado na tabela 1 , que reúne os principais trabalhos encontrados na literatura.

\begin{tabular}{|c|c|c|c|}
\hline Autores & Título do Trabalho & Refrigerante & Trabalho \\
\hline $\begin{array}{l}\text { Antonijevic } \\
\text { D., Heckt R. } \\
(2004)\end{array}$ & $\begin{array}{l}\text { Heat pump supplemental heating for motor } \\
\text { vehicles }\end{array}$ & R134a & Experimental \\
\hline $\begin{array}{l}\text { B. Torregrosa, } \\
\text { et al. (2013) }\end{array}$ & $\begin{array}{l}\text { Design of efficient air conditioning } \\
\text { systems for electric vehicles }\end{array}$ & R134a & Simulação \\
\hline $\begin{array}{l}\text { J. Meyer et al. } \\
\text { (2004) }\end{array}$ & $\begin{array}{l}\text { R134a Heat Pump for Improved Passenger } \\
\text { Confort }\end{array}$ & R 134a & Experimental \\
\hline $\begin{array}{l}\text { L. P. Scherer } \\
\text { et al. }(2003)\end{array}$ & $\begin{array}{l}\text { On-Vehicle Performence Comparision of } \\
\text { na R-152 and R-134 }{ }^{\mathrm{a}} \text { Heat Pump System }\end{array}$ & $\begin{array}{l}\text { R-152a and R- } \\
134 \mathrm{a}\end{array}$ & Experimental \\
\hline $\begin{array}{l}\text { M. Direk et al. } \\
\text { (2011) }\end{array}$ & $\begin{array}{l}\text { Experimental performance of R134a } \\
\text { automobile heat pump system coupled to } \\
\text { the passenger compartment }\end{array}$ & R134a & Experimental \\
\hline $\begin{array}{l}\text { M.Hosoz, M. } \\
\text { Direk, (2005) }\end{array}$ & $\begin{array}{l}\text { Performance evaluation of an integrade } \\
\text { automotive air conditioning and heat pump } \\
\text { system }\end{array}$ & R134a & Experimental \\
\hline $\begin{array}{l}\text { Payá et al. } \\
\text { (2011) }\end{array}$ & $\begin{array}{l}\text { Innovative Air-Conditioning Systems for } \\
\text { Conventional and Electric Vehicles }\end{array}$ & R134a & Simulação \\
\hline $\begin{array}{l}\text { S. Shin et al. } \\
(2008)\end{array}$ & $\begin{array}{l}\text { R134a heat pump application for the buses } \\
\text { by using engine coolant as a heat source }\end{array}$ & R134a & Experimental \\
\hline $\begin{array}{l}\text { Toshihisa } \\
\text { Kondo et al. } \\
(2011)\end{array}$ & $\begin{array}{l}\text { Development of automotive air } \\
\text { conditioning systems by heat pump } \\
\text { technology }\end{array}$ & R134a & Experimental \\
\hline $\begin{array}{l}\text { Vicente } \\
\text { Pommé (2012) }\end{array}$ & $\begin{array}{l}\text { Reversible heat pump system for an } \\
\text { electrical vehicle }\end{array}$ & R134a & Experimental \\
\hline
\end{tabular}

Tabela 1: Trabalhos sobre AC e BC encontrados na literatura. 


\section{2}

\section{Estado da Arte}

Sistemas de ar condicionado veicular, para resfriamento, são extensamente estudados tanto no aspecto experimental como por meio de simulações numéricas, objetivando o aprimoramento do rendimento térmico do ciclo, bem como dos seus componentes. Estes estudos abordaram os refrigerantes $\mathrm{R} 134 \mathrm{a}$, e o $\mathrm{CO}_{2}$, e também apresentam experimentos comparativos entre os refrigerantes citados e o R152a e podem ser encontrados na literatura técnica, em grande número.

Hosoz e Direk (2006) realizaram um estudo experimental de desempenho característico de um sistema de ar condicionado veicular operando como bomba de calor utilizando o ar ambiente como fonte de calor. Neste experimento foram utilizados componentes originais de um sistema condicionador de ar automotivo. Somente um componente extra, uma válvula de reversão de fluxo, foi inserida no sistema. O sistema foi testado como ar condicionado (refrigeração) bem como bomba de calor (aquecimento) em condições variadas de operação, tais como: velocidade do compressor, temperatura do ar de entrada nos trocadores de calor interno e externo. Uma avaliação dos dados obtidos no ensaio em regime permanente foi executada, mostrando os efeitos das condições de funcionamento sobre a capacidade, o coeficiente de desempenho, a temperatura de descarga do compressor e a taxa de exergia destruída por cada componente do sistema para ambos os modos de operação. Observou-se que o funcionamento da bomba de calor fornece aquecimento adequado apenas em condições de tempo ameno e a capacidade de aquecimento decresce bruscamente com a diminuição da temperatura exterior. Porém, comparando com a operação de ar condicionado, a operação como bomba de calor, geralmente produz um maior coeficiente de desempenho (COP) e uma menor taxa de destruição de exergia por unidade de capacidade.

É também possível aumentar o desempenho do modo de aquecimento do sistema com um novo projeto do trocador de calor interno, utilizando outro refrigerante com maior taxa de rejeição no condensador e utilizando uma melhor fonte de calor como o liquido de arrefecimento do motor ou os gases da descarga.

As variações do desempenho em alguns parâmetros do sistema experimental estão mostradas nas figuras 21 a 25, para várias temperaturas do ar na entrada dos trocadores interno e externo. 

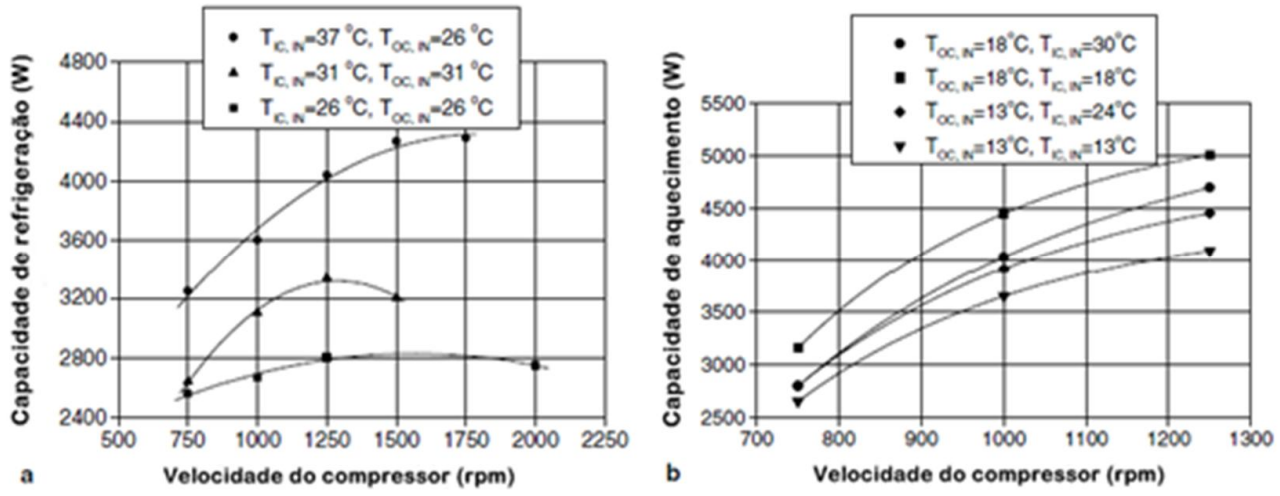

Figura 21: Variação da capacidade de refrigeração (a) e capacidade de aquecimento (b), vs. velocidade do compressor. Hosoz e Direk (2006).
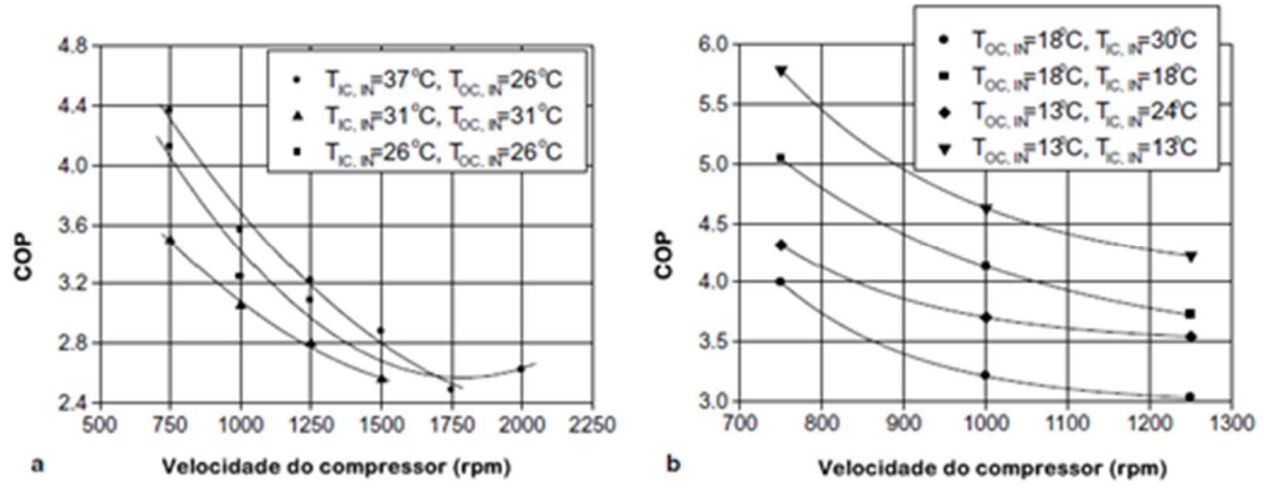

Figura 22: Variação do COP vs. velocidade do compressor, para operações em modo de refrigeração (a) e modo de aquecimento (b). Hosoz e Direk (2006).
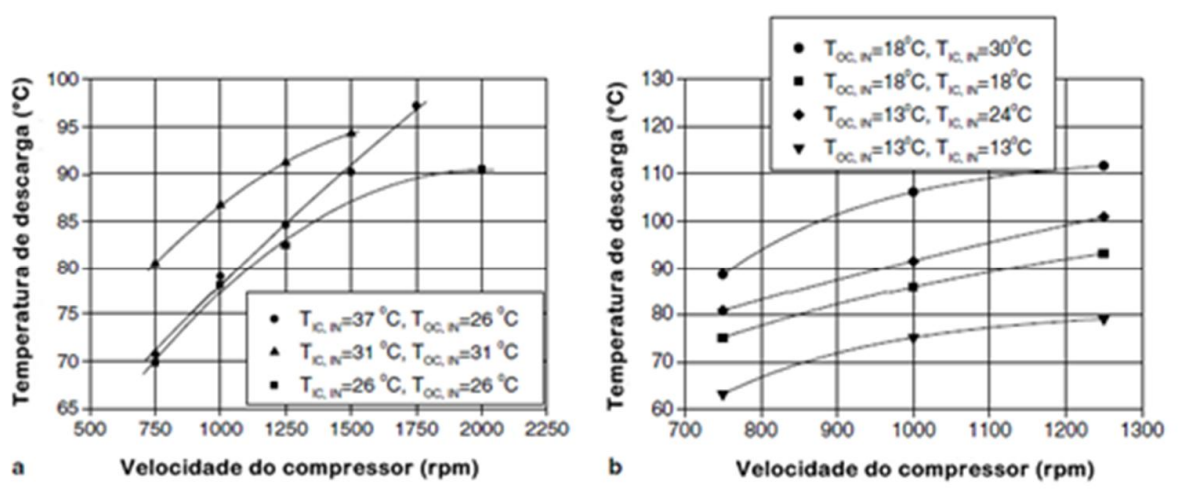

Figura 23: Variação da temperatura de descarga do compressor vs. velocidade do compressor, para operações em modo de refrigeração (a) e modo de aquecimento (b). Hosoz e Direk (2006). 

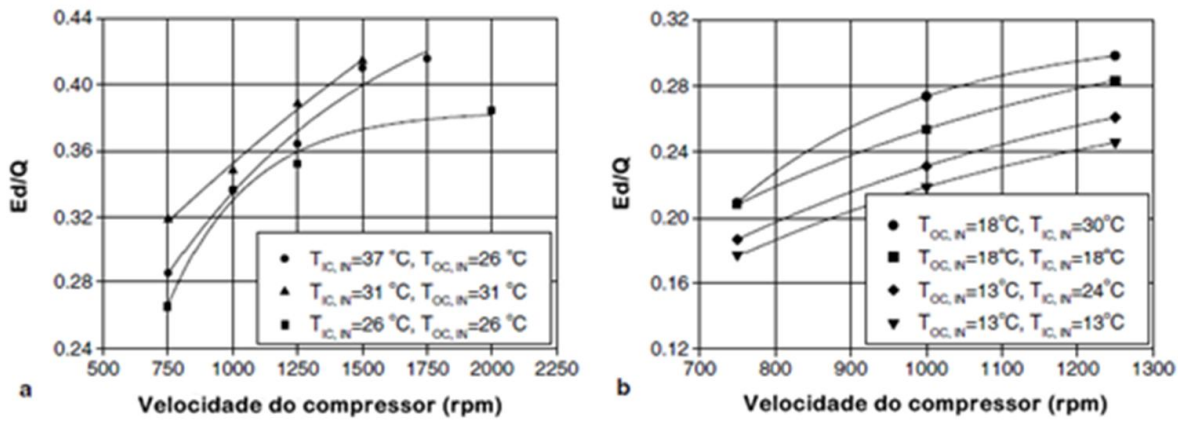

Figura 24: Taxas de destruição total de exergia por unidade de capacidade, como uma função da velocidade do compressor para os modos de refrigeração (a) e de aquecimento (b). Hosoz e Direk (2006).
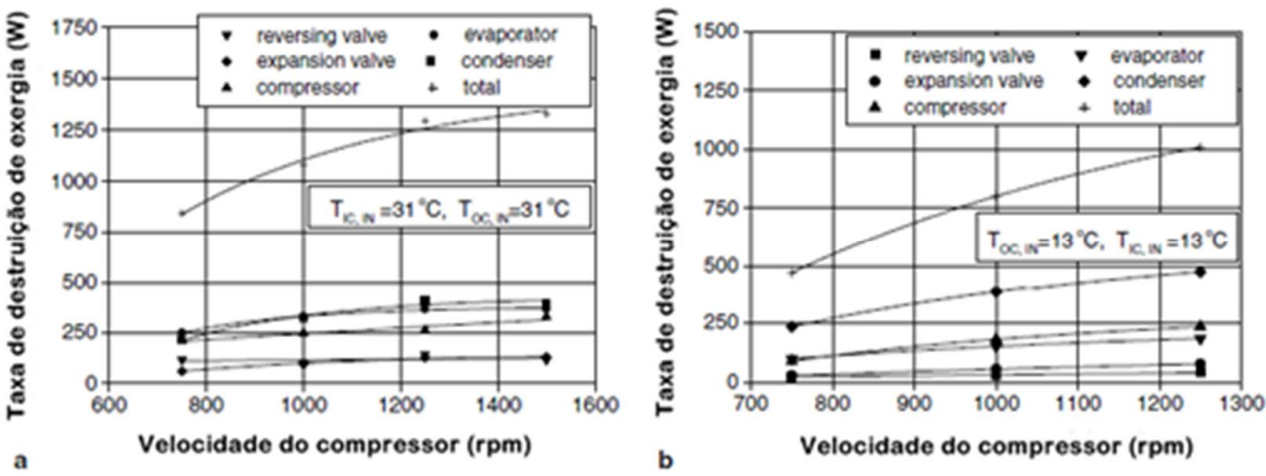

Figura 25: Taxas de exergia destruídas pelos componentes do circuito de refrigeração, como uma função da velocidade do compressor para os modos de refrigeração (a) e de aquecimento (b). Hosoz e Direk (2006).

Os efeitos da temperatura de evaporação e condensação no desempenho de alguns parâmetros são apresentados nas figuras 26 a 28. As variações das capacidades de aquecimento e resfriamento com a temperatura de evaporação é mostrada na figura 26. Os COPs, para ambos os modos de operação em função da temperatura de evaporação são apresentados na figura 27.

As mudanças da temperatura de descarga do compressor com a temperatura de evaporação são mostradas na figura 28 . 

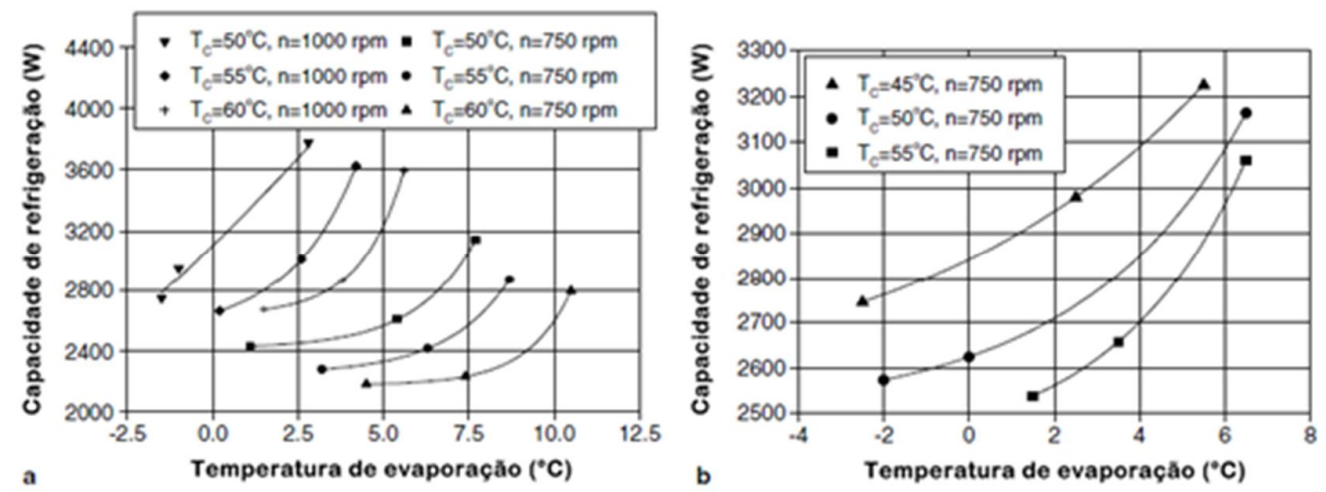

Figura 26: (a) Variação da capacidade de refrigeração; (b) Capacidade de aquecimento, vs. temperatura de evaporação. Hosoz e Direk (2006).
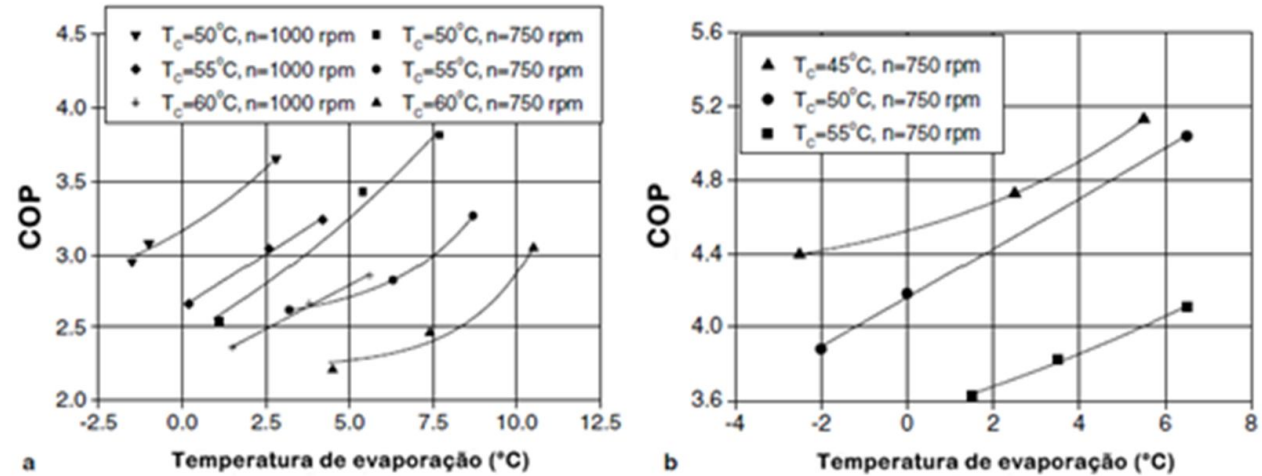

Figura 27: Variação do COP vs. temperatura de evaporação para operações em modo de refrigeração (a) e modo de aquecimento (b). Hosoz e Direk (2006).
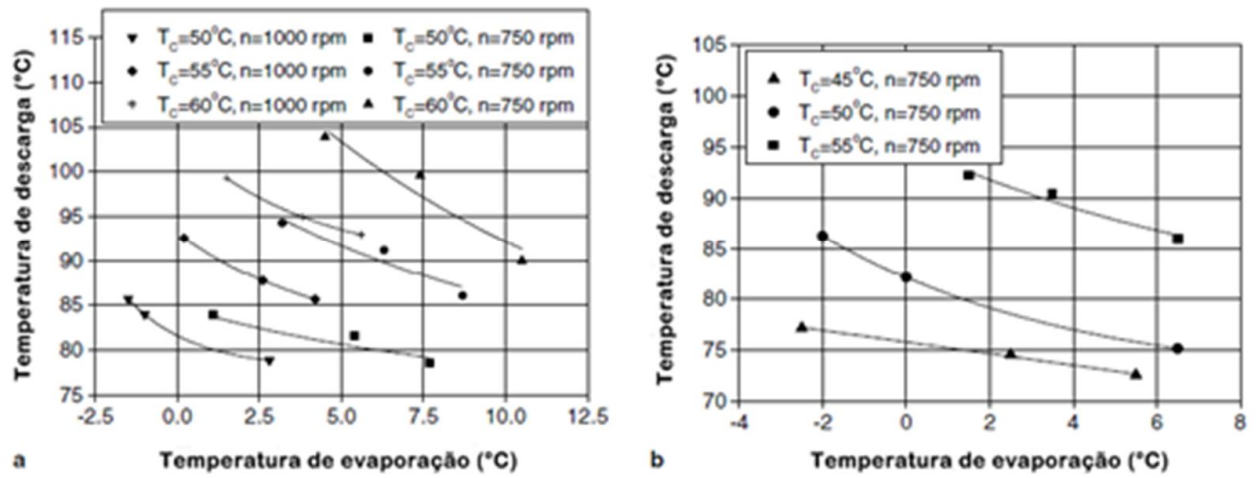

Figura 28: Variação da temperatura de descarga do compressor vs. temperatura de evaporação para operações em modo de refrigeração (a); e modo de aquecimento (b). Hosoz e Direk (2006).

O desempenho característico de um sistema integrado ar condicionado e bomba de calor automotivo usando o R134a como fluido de trabalho foi, portanto avaliado 
experimentalmente por Hosoz e Direk (2006). Com base na evidencia experimental, as conclusões finais alcançadas no referido estudo, podem ser resumido como a seguir:

- Apesar da operação bomba de calor prover uma quantidade suficiente de calor no fluxo de ar interno, em condições de clima ameno, a capacidade de aquecimento cairia em condições mais severas devido ao decréscimo de ambas temperaturas de evaporação e capacidade de ativação do sistema de controle. Portanto, a bomba de calor automotiva ar-ar, de acordo com Hosoz e Direk (2006), deve ser considerada somente como um método suplementar de aquecimento a ser utilizado em automóveis de energia eficiente, sem calor de rejeito.

- Ambas as capacidades de aquecimento e resfriamento do sistema aumentam com a velocidade do compressor, enquanto que os COPs para ambos os casos decrescem com ela. Além disso, os COPs de aquecimento superam os COPs de resfriamento, devido ao fato de o anterior levar em consideração o trabalho específico de compressão.

- Para a mesma velocidade do compressor, temperatura de evaporação/condensação, a operação de bomba de calor produz menores temperaturas de descarga do compressor.

- Em ambos os modos de operação, a proporção total de destruição de exergia no circuito a capacidade de refrigeração aumenta com a velocidade do compressor, enquanto o modo de operação de aquecimento resulta em menores proporções.

- No modo de resfriamento, ambos trocadores de calor destroem igual quantidade de exergia, considerando que no modo de aquecimento a exergia destruída pelo trocador de calor interior é o dobro da destruída pelo trocador de calor externo, significando que o evaporador não pode funcionar como condensador de forma adequada. A rejeição de calor precária neste trocador de calor também limita a quantidade de calor absorvido pelo trocador de calor exterior. Portanto, um sistema de ar condicionado e bomba de calor automotivo deve empregar, de acordo com Hosoz e Direk (2006), um trocador de calor interno com uma maior área de transferência de calor como também um fluxo de ar superior.

Direk et al. (2011) estudaram o desempenho experimental do R134a em um sistema de bomba de calor automotiva acionada por um motor diesel utilizando a capacidade de calor absorvido do ar ambiente, do líquido de arrefecimento do motor e dos gases da descarga. A bancada de testes foi desenvolvida com componentes de um sistema de ar condicionado de um veiculo compacto e foi testado com variações da rotação do 
motor, da carga do motor e temperaturas do ar na entrada do condensador e do evaporador.

O desempenho característico em regime estacionário e transiente do sistema, para cada fonte de calor foi avaliado aplicando análise de energia do sistema baseado em dados experimentais. Os resultados mostram que o sistema de bomba de calor automotivo utilizando o líquido de arrefecimento do motor promove maior capacidade de aquecimento o registro das temperaturas do ar foram tomadas nos primeiros cinco minutos dos testes. Porém, o sistema de aquecimento de referencia usualmente possui melhor desempenho que o sistema de bomba de calor automotivo, quando o regime permanente é alcançado.

O sistema de bomba de calor automotivo causa um aumento no consumo específico de combustível do motor, dentro da faixa de 4 a54\%, dependendo da carga e velocidade que o motor estiver submetido.

Os experimentos foram realizados com cinco velocidades diferentes do motor, a saber, 850, 1200, 1550, 1900 e 2250 rpm. Como a relação dos diâmetros das polias do motor e do compressor é de 1:1, logo o compressor possui a mesma velocidade do motor. Para tal foi utilizado um veiculo Fiat Doblo JTD diesel de 1900 cc.

A figura 29 mostra a comparação do quinto minuto de medida da temperatura do ar registrado na saída para o veiculo do sistema de bomba de calor automotivo e sistema de aquecimento de referência para diferentes rotações do compressor e cargas no motor.

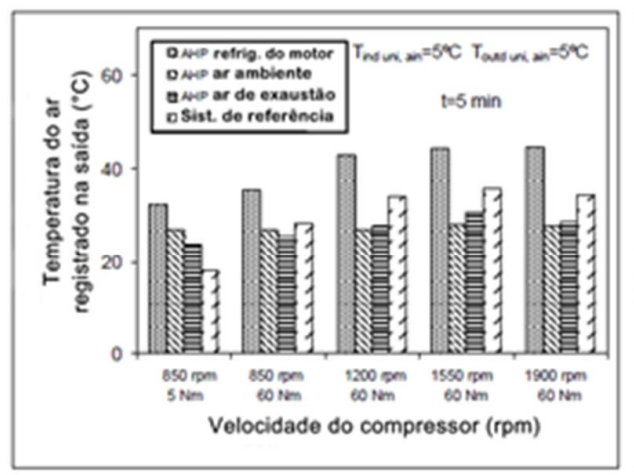

(a)

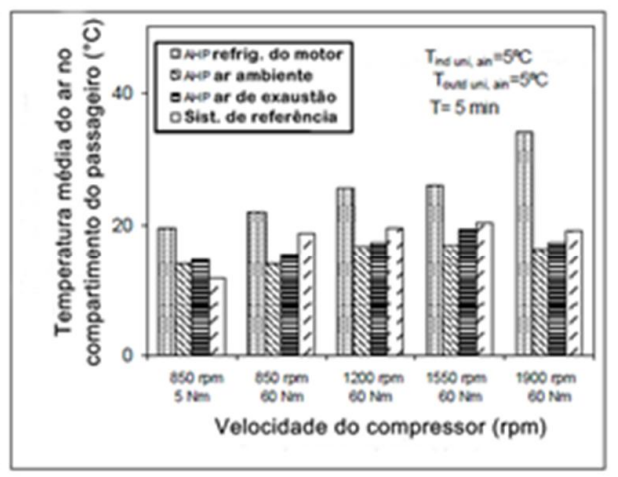

(b)

Figura 29: (a) Variação da temperatura do ar registrado na saída frontal do compartimento de passageiros; (b) Alteração da temperatura média do ar no compartimento de passageiros vs. velocidade do compressor (ambas as temperaturas foram registradas no final do período de cinco minutos de operação). Direk, et al. (2011). 
Na figura 30 são indicadas as variações no quinto minuto do teste realizado, a capacidade de aquecimento em função da rotação do compressor. A capacidade de aquecimento no final do quinto minuto do período de operação aumenta com a velocidade do compressor a uma carga no motor constante.

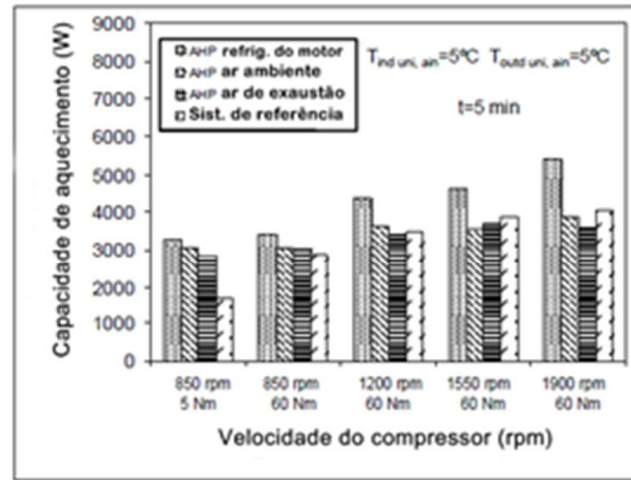

(a)

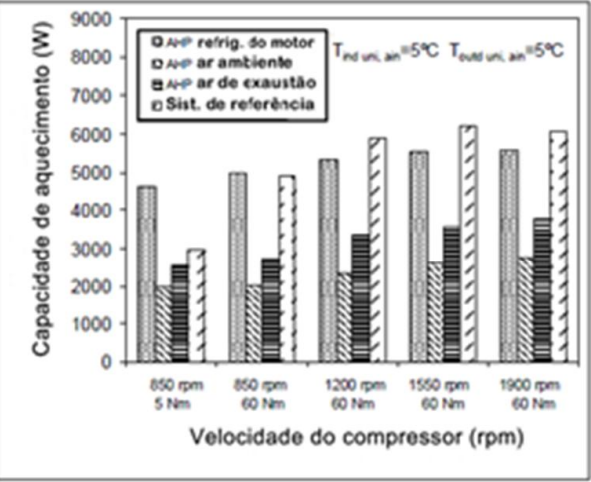

(b)

Figura 30: (a) Variação da capacidade de aquecimento no final do período de cinco minutos de operação; (b) Capacidade de aquecimento no estado de equilíbrio vs. velocidade do compressor. Direk, et al. (2011).

A figura 31 indica as variações do coeficiente de desempenho do experimento em função da rotação do compressor baseado nos dados de regime permanente. É possível ver que o COP para aquecimento decresce com o aumento da rotação do compressor.

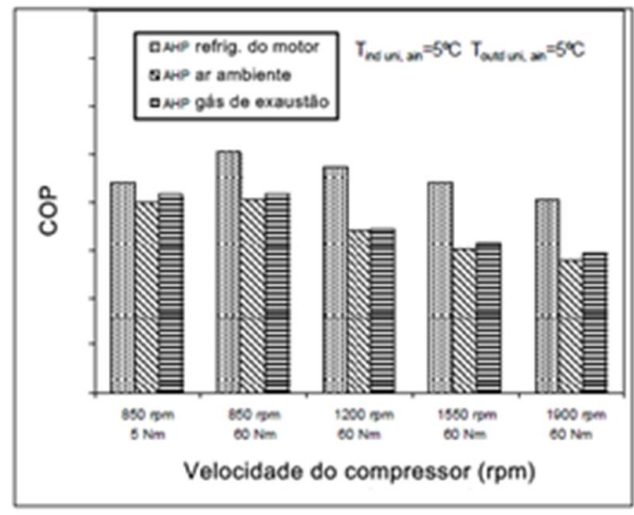

(a)

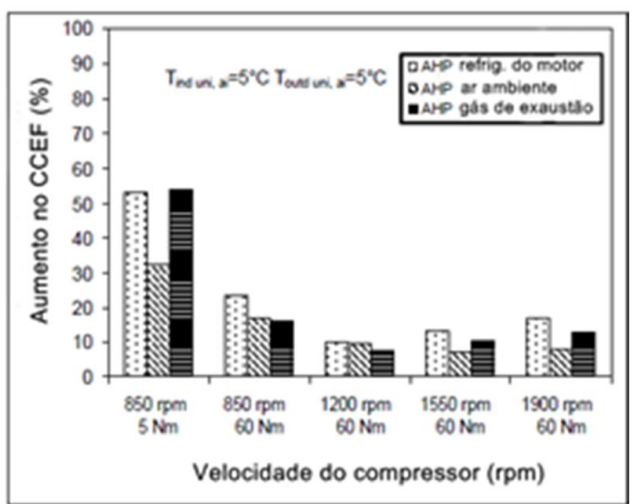

(b)

Figura 31: (a) Variação do COP; (b) Aumento no consumo de combustível específico causado pela operação do sistema AHP vs. velocidade do compressor. Direk, et al. (2011). 
Direk, et al. (2011), apresentam as seguintes conclusões:

- Quando o motor funciona em regime de marcha lenta ( $\mathrm{n}=850 \mathrm{rpm}$ e $\mathrm{T}=5 \mathrm{Nm})$ e o sistema de bomba de calor automotivo utiliza o liquido de arrefecimento como fonte de calor, as mais elevadas temperaturas do ar condicionado no estado estacionário são alcançadas e assim como as maiores capacidades de aquecimento em comparação com os sistemas de bomba de calor automotivo utilizando ar ambiente, gás de descarga e com o sistema de aquecimento de referencia.

- Com aumento do torque e velocidade do motor o sistema de aquecimento de referencia promove maior capacidades de aquecimento, depois que o regime permanente foi alcançado.

- O sistema de bomba de calor automotivo usando qualquer fonte de calor produz maiores temperaturas do ar condicionado e capacidade de aquecimento do que o sistema de aquecimento de referencia no final de um período de cinco minutos de operação, quando o motor opera em regime de marcha lenta.

- O sistema de bomba de calor automotivo usando somente o liquido de arrefecimento do motor como fonte de calor promove uma melhor capacidade de aquecimento nos cinco minutos que o sistema de aquecimento de referencia a uma velocidade do compressor de $850 \mathrm{rpm}$, quando o motor esta submetido a uma carga de $60 \mathrm{Nm}$.

- O sistema de bomba de calor automotivo, usando o líquido de arrefecimento do motor, como fonte de calor, produz os maiores COPs, enquanto que os mesmos sistemas com ar ambiente produzem os menores.

Scherer, et al. (2003) realizaram um estudo experimental comparando o desempenho do R152a, cujo GWP é de 120, com o do R134a, que possui GWP de 1300, em sistemas de bomba de calor automotivo utilizando o líquido de arrefecimento do motor como fonte auxiliar de calor.

Os experimentos foram realizados em um veiculo sedan de grande porte 2011, equipado com sistema de ar condicionado, que foi adaptado para operar como bomba de calor em ciclo reversível. Foi também utilizado um dinamômetro de rolos para a avaliação do efeito do sistema na potencia efetiva do veiculo.

No referido trabalho, foi montado um circuito de bomba de calor que utiliza o líquido de arrefecimento do motor como fonte fria. Os autores afirmam que a utilização do líquido de arrefecimento do motor como fonte de calor possui duas vantagens. Em 
primeiro lugar, tem-se uma fonte de calor de melhor qualidade que a do ar ambiente externo. Em segundo, tal solução elimina completamente a possibilidade de formação de gelo no trocador de calor externo, comumente observado nos sistemas de bomba de calor convencionais. Havendo formação de gelo no trocador de calor a ar, este perde sua capacidade de trocar calor, reduzindo assim a capacidade da bomba de calor.

O diagrama esquemático do aparato montado pode ser visualizado na figura 32 , abaixo.

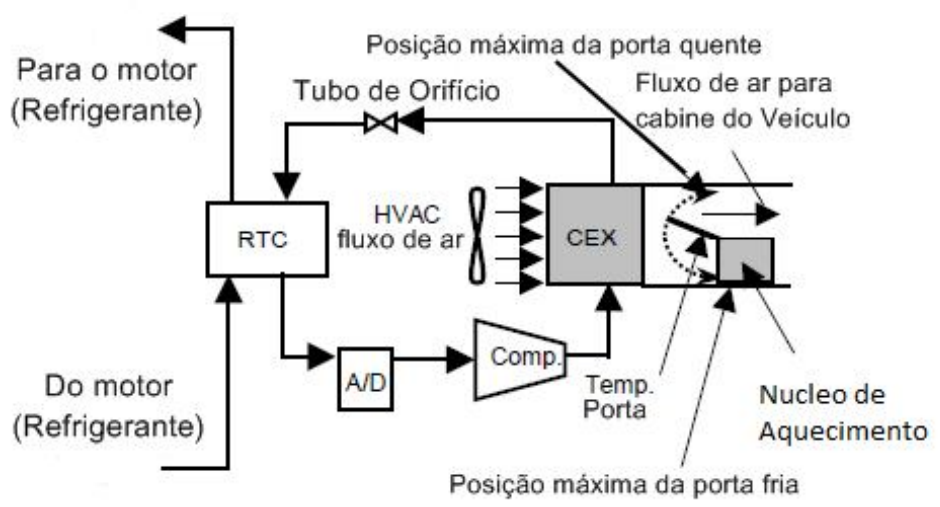

Figura 32: Diagrama do sistema de bomba de calor automotiva, Scherer, et al. (2003).

Os resultados dos testes de desempenho do sistema foram arranjados em dois grupos, a saber:

i) Regime permanente com velocidade do veiculo de $48 \mathrm{~km} / \mathrm{h}$ e $113 \mathrm{~km} / \mathrm{h}$, objetivando quantificar a capacidade de ambos os refrigerantes quando utilizados como fluidos na bomba de calor, mostrado na tabela 2 .

\begin{tabular}{|c|c|c|}
\cline { 2 - 3 } \multicolumn{1}{c|}{} & R-152a & R-134a \\
\hline Ar na saida do ventilador ( $\left.{ }^{\circ} \mathrm{C}\right)\left({ }^{\circ} \mathrm{F}\right)$ & $-10.6(13)$ & $-10(14)$ \\
\hline CEX Ar na saida ( $\left.{ }^{\circ} \mathrm{C}\right)\left({ }^{\circ} \mathrm{F}\right)$ & $47.8(118.1)$ & $43.5(110.3)$ \\
\hline 9ceX kW (Btu/min) & $9.75(555)$ & $9.05(515)$ \\
\hline Saida do Compressor kPag (psig) & $1253(181.7)$ & $1444.5(209.5)$ \\
\hline Saida RTC kPag (psig) & $752.9(109.2)$ & $1111.4(161.2)$ \\
\hline$\beta$ & $>10$ & $>10$ \\
\hline
\end{tabular}

(a) Velocidade do veículo $48 \mathrm{kph}$ (30 mph)

\begin{tabular}{|c|c|c|}
\cline { 2 - 3 } \multicolumn{1}{c|}{} & R-152a & R-134a \\
\hline Ar na saida do ventilador ( $\left.{ }^{\circ} \mathrm{C}\right)\left({ }^{\circ} \mathrm{F}\right)$ & $-12.5(9.5)$ & $-11.5(11.3)$ \\
\hline CEX Ar na saida ( $\left.{ }^{\circ} \mathrm{C}\right)\left({ }^{\circ} \mathrm{F}\right)$ & $37.7(100)$ & $42.6(108.6)$ \\
\hline 9cex kW (Btu/min) & $9.24(526)$ & $9.86(561)$ \\
\hline Saida do Compressor kPag (psig) & 1329.3 & $1472.7(213.6)$ \\
\hline Saida RTC kPag (psig) & 1024.6 & $1084.6(157.3)$ \\
\hline$B$ & $>10$ & $>10$ \\
\hline
\end{tabular}

(b) Velocidade do veículo $113 \mathrm{kph}$ (70 mph)

Tabela 2: Desempenho em regime permanente da bomba de calor a temperatura ambiente de $0^{\circ} \mathrm{F}$. (Sherer, et al. 2003) 
ii) Regime transiente do desempenho de aquecimento, cinco diferentes condições foram testadas para o regime transiente de aquecimento, a saber:

1- Somente aquecedor;

2- Aquecedor com bomba de calor com R-152a;

3- Aquecedor com bomba de calor com R-134a;

4- Somente bomba de calor com R-152a;

5- Somente bomba de calor com R-134a.

Os resultados dos testes são mostrados na tabela 3 abaixo.

\begin{tabular}{|l|c|c|c|c|c|}
\cline { 2 - 7 } \multicolumn{1}{c|}{} & Somente & \multicolumn{2}{c|}{$\begin{array}{c}\text { Aquedor \& } \\
\text { Bomba de Calor }\end{array}$} & \multicolumn{2}{c|}{$\begin{array}{c}\text { Somente } \\
\text { Bomba de Calor }\end{array}$} \\
\hline $\begin{array}{l}\text { Tempo para... } \\
32^{\circ} \mathrm{C}\left(90^{\circ} \mathrm{F}\right) \text { Vent }(\mathrm{min})\end{array}$ & 5.9 & 3.8 & 4 & 2.7 & 2.8 \\
\hline Stat. Temp. (min) & $>27$ & Nunca & Nunca & $>30$ & Nunca \\
\hline $32^{\circ} \mathrm{C}\left(90^{\circ} \mathrm{F}\right)$ CEX Saída-Ar(min) & - & 1.3 & 1.7 & 2.3 & 2.3 \\
\hline
\end{tabular}

'Tabela 3: Regime transiente de aquecimento por tempo (bomba de calor VS. sistema de base), Scherer, et al. (2003).

Nas suas conclusões Scherer et al. (2003) mostram que na busca de sistemas automotivos com baixo GWP, refrigerantes alternativos ao R134a foram pesquisados. Igualmente como os sistemas de propulsão veicular começam a serem mais eficientes, estes possuem baixo calor de rejeito para o aquecimento da cabine.

Uma alternativa para resolver este problema é operar o sistema de ar condicionado existente como bomba de calor para complementar o sistema de aquecimento da cabine dos veículos. O estudo demonstrou que tanto o R134a como o R152a como fluido da bomba de calor possuem os requisitos suplementar de aquecimento da cabine de passageiros se o líquido de arrefecimento do motor for utilizado como fonte de calor.

Considerando as informações colhidas na pesquisa alguns pontos particulares que valem a pena serem ressaltados, são:

O desempenho e capacidade de ambos os sistemas de bomba de calor operando como R134a e o R152a são praticamente iguais;

> Um sistema de bomba de calor operando com o R152a ou o R134a e o líquido de arrefecimento do motor como fonte de calor possuem níveis de desempenho para 
complementar os sistemas de aquecimento automotivo com capacidade de aquecimento do veículo inadequado bem como para reduzir consideravelmente o tempo de aquecimento da cabine.

$>$ A operação do sistema de bomba de calor a baixa carga do sistema propulsor, 48 $\mathrm{km} / \mathrm{h}$, carga de estrada, com o ventilador do HVAC ajustado para a velocidade alta, impede que o arrefecimento do motor atinja a temperatura termostática para ambos os refrigerantes;

> A capacidade do sistema de bomba de calor para ambos os refrigerantes em regime permanente com velocidade de $48 \mathrm{~km} / \mathrm{h}$, em carga de estrada são de 8,8 $\mathrm{KW}(500 \mathrm{Btu} / \mathrm{min}) \mathrm{a}-18^{\circ} \mathrm{C}\left(0^{\circ} \mathrm{F}\right)$.

De acordo com Meyer et al. (2004) os sistemas propulsores automotivos vêm se tornando cada vez mais eficientes, gerando menor calor de rejeito utilizado para o aquecimento do compartimento de passageiros dos veículos. Portanto muitos dispositivos de aquecimento complementares são atualmente comercializados, incluindo os aquecedores elétricos, aquecedores viscosos e aquecedores operados por combustíveis, cada um deles possuem deficiências associadas ao custo, à capacidade, a eficiência e/ou as preocupações ambientais,

Na tentativa de proporcionar: i) maior tempo de conforto; ii) menor custo; iii) menor peso; iv) tamanho reduzido e v) melhor eficiência, de forma ecologicamente correta, um sistema de bomba de calor operando com o R134a foi desenvolvido por Meyer et al. (2004).

Vários problemas técnicos foram superados durante o desenvolvimento deste sistema. Veículos de produção foram adaptados para incorporar o sistema de bomba de calor operando com o R134a e testado em um túnel de vento climatizado. Os resultados dos testes de aquecimento para $-18^{\circ} \mathrm{C}$ foram comparados aos valores de dados de base, que mostram melhorias significativas na média do nível de temperaturas do ar, a montante e a jusante, (Meyer et al., 2004).

Meyer et al. (2004) introduziram um novo trocador de calor no ciclo de base, denominado por eles de LTR (Liquid-to-Refrigerant), operando como evaporador para a bomba de calor. As figuras 33 (a) e (b) mostram os diagramas do aparato experimental desenvolvido. 


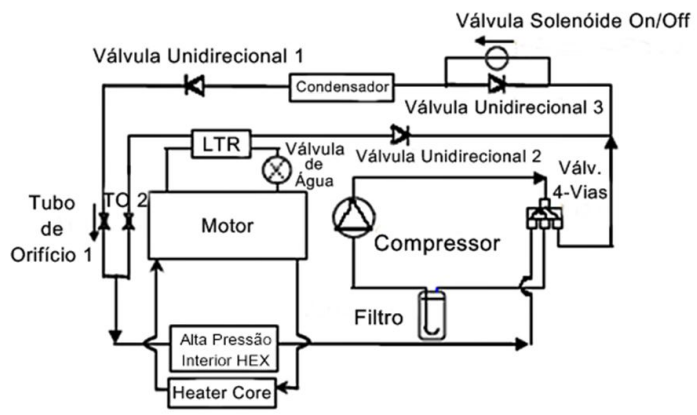

Figura 33a: Diagrama do sistema operando em modo de A/C. Meyer, et al. (2004).

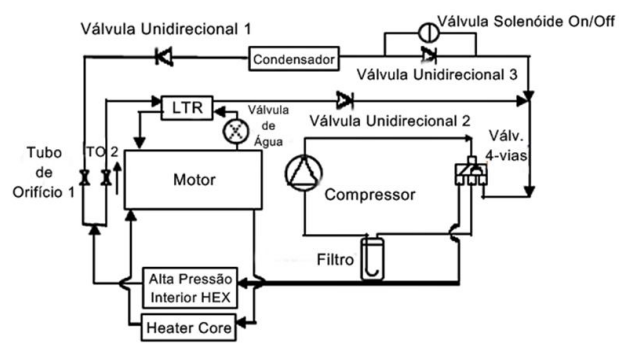

Figura 33b: Diagrama do sistema operando em modo bomba de calor. Meyer, et al. (2004).

Meyer et al. (2004) realizaram a adaptação de um veículo com sistema de bomba de calor com o R134a em um túnel de vento climatizado, tendo como objetivo avaliar o desempenho de aquecimento do compartimento de passageiros.

$\mathrm{Na}$ condição de transiente de aquecimento as seguintes condições foram utilizadas: Temperatura ambiente de $-18^{\circ} \mathrm{C}$, velocidade do veículo de $50 \mathrm{~km} / \mathrm{h}$ durante 30 minutos, em seguida de $100 \mathrm{~km} / \mathrm{h}$ por 30 minutos e finalmente regime de marcha lenta por 30 minutos. O sistema de bomba de calor foi ligado durante 20 minutos e após, este tempo, desligado. A bomba de calor foi religada e assim mantida em regime de marcha lenta por 30 minutos. Com o propósito de comparação com o sistema de aquecimento convencional que utiliza o líquido de arrefecimento do motor, foi também avaliado. Os testes foram realizados com calor máximo, com a ventilação interna direcionada para os pés, com o ventilador interno na máxima velocidade.

A tabela 4, resume os principais resultados dos testes de desempenho do sistema, realizados por Meyer, et al. (2004). 


\begin{tabular}{|c|c|c|c|}
\hline & Bomba de Calor & Linha de Base & Aumento DELTA \\
\hline Temperatura do Refrigerante & $478^{\circ} \mathrm{C}$ & $46.1^{\circ} \mathrm{C}$ & $1.7^{\circ} \mathrm{C}$ \\
\hline Temperatura do ar descarga frontal inferior & $40.4^{\circ} \mathrm{C}$ & $30.0^{\circ} \mathrm{C}$ & $10.4{ }^{\circ} \mathrm{C}$ \\
\hline Nivel de temperatura respiraçắo frontal| & $-5.5^{\circ} \mathrm{C}$ & $-73^{\circ} \mathrm{C}$ & $1.8^{\circ} \mathrm{C}$ \\
\hline \multicolumn{4}{|l|}{$10 \mathrm{Min}$ (50K PH) } \\
\hline Temperatura do Refrigerante & $68.9^{\circ} \mathrm{C}$ & $65.1{ }^{\circ} \mathrm{C}$ & $3.8^{\circ} \mathrm{C}$ \\
\hline Temperatura do ar descarga frontal inferior & $558^{\circ} \mathrm{C}$ & $47.0^{\circ} \mathrm{C}$ & $11.8^{\circ} \mathrm{C}$ \\
\hline Nivel de temperatura respiraçăo frontal & $4.7^{\circ} \mathrm{C}$ & $1.8^{\circ} \mathrm{C}$ & $2.9^{\circ} \mathrm{C}$ \\
\hline \multicolumn{4}{|l|}{$20 \mathrm{Min}(50 \mathrm{~K} P \mathrm{H})$} \\
\hline \begin{tabular}{|l|} 
Temperatura do Refrigerante \\
\end{tabular} & $885^{\circ} \mathrm{C}$ & $83.0^{\circ} \mathrm{C}$ & $5.5^{\circ} \mathrm{C}$ \\
\hline Temperotura do ar descargo frontal inferior & $77.0^{\circ} \mathrm{C}$ & $63.9^{\circ} \mathrm{C}$ & $13.1^{\circ} \mathrm{C}$ \\
\hline Nivel de temperatura respiraçăo frontal & $19.0^{\circ} \mathrm{C}$ & $15.0^{\circ} \mathrm{C}$ & $4.0^{\circ} \mathrm{C}$ \\
\hline \multicolumn{4}{|l|}{90 Min (Inativo) } \\
\hline Temperatura do Refrigerante & $69.3^{\circ} \mathrm{C}$ & $66.6^{\circ} \mathrm{C}$ & $2.7^{\circ} \mathrm{C}$ \\
\hline Temperatura do ar descargs fromtal inferior & $59.9^{\circ} \mathrm{C}$ & $43.8^{\circ} \mathrm{C}$ & $16.1^{\circ} \mathrm{C}$ \\
\hline Nivel de temperatura respiraçăo frontal & $34.3^{\circ} \mathrm{C}$ & $26.1{ }^{\circ} \mathrm{C}$ & $8.2^{\circ} \mathrm{C}$ \\
\hline
\end{tabular}

Tabela 4: Resumo dos dados de desempenho. Meyer, et al. (2004).

Concluindo, Meyer et al. (2004) afirmam que o sistema de bomba de calor desenvolvido com finalidade de aquecimento suplementar, para que seja atingido o conforto dos passageiros, é integrado como função adicional do sistema de ar condicionado existente operando com o R134a como refrigerante. Observaram que o referido sistema possui baixo custo para adaptação, é um sistema compacto de fácil montagem, se comparado com sistemas suplementares de capacidade semelhante. O sistema pode ser revertido do modo bomba de calor para ar condicionado e vice-versa.

O líquido de arrefecimento do motor utilizado como fonte de calor, no sistema de bomba de calor supera as deficiências dos sistemas que utilizam o ar como fonte de calor. O líquido do trocador de calor (evaporador LTR) é introduzido e colocado no sistema sem ser exposto à alta pressão de descarga do refrigerante. Como um controle de carga do sistema, a vazão do líquido (glicol) no LTR é modulado de modo que a pressão de descarga de refrigerante seja mantida em uma faixa desejada.

O problema do fluxo de refrigerante durante o funcionamento da bomba de calor em baixa temperatura ambiente é gerenciado de forma positiva. Para tal, válvulas de retenção (check valves) foram colocadas de forma estratégica evitando o acúmulo de refrigerante no condensador frontal (externo) e, além disso, o refrigerante pode ser transferido do condensador para o lado da sucção do compressor por um diferencial de pressão no momento da partida a frio da bomba de calor. 
Testes em regime transiente no veículo em túnel de vento climatizado mostram uma melhoria significativa na temperatura do ar à jusante e no tempo de conforto com a operação da bomba de calor. O fato de que o glicol do líquido de arrefecimento do motor não se degrada durante o funcionamento da bomba de calor indica que o calor do refrigerante fornecido à bomba de calor é mais do que compensado pelo calor adicional do motor gerado pela carga adicional para acionar o compressor.

Testes de bancada sob as mesma condições em veículos similares mostram que o sistema de bomba de calor tem um COP > 2,0 e capacidade de aquecimento (calor para o ar da cabine) pode ser maior que $6,0 \mathrm{~kW}$. Testes em túnel de vento demonstram uma significativa melhora no desempenho com a operação da bomba de calor, Meyer et al. (2004).

A recente tendência da indústria automobilística está no aumento progressivo do número de veículos elétricos produzidos e vendidos, pois estão sendo fortemente promovidos devido às questões de redução do efeito estufa, de poluição. No entanto, para alcançar um verdadeiro sucesso, faz-se necessário alcançar um nível de conforto e desempenho semelhante aos dos veículos convencionais.

Nos veículos com motor a combustão interna, o gerenciamento térmico da cabine é relativamente simples, dado o fato da existência de calor de rejeito do motor. Um núcleo de aquecimento é integrado ao sistema de refrigeração do motor que ajuda a aquecer o ar da cabine. Tais núcleos são geralmente dimensionados para fornecer de 5 a $10 \mathrm{~kW}$ de potência de aquecimento, Torregrosa et al. (2013).

No verão um sistema de refrigeração do ar, mecanicamente acionado, fornece ar frio para a cabine. A potência de refrigeração típica instalada varia de 3 a $5 \mathrm{~kW}$. O controle de temperatura é normalmente realizado por meio da mistura de ar quente e ar frio, uma vez que o sistema funciona com velocidades impostas pelo motor.

Torregrosa et al. (2013) afirmam que todos os componentes auxiliares de sistemas de ar condicionado em veículos convencionais e elétricos, apresentam um alto consumo de energia. Nos veículos totalmente elétricos, o aquecimento da cabine torna-se um desafio adicional, pois há menos calor de rejeito disponível. Por conseguinte, uma concepção cuidadosa do sistema de ar condicionado e estratégias de operação se faz necessária para se obter uma autonomia razoável nos veículos totalmente elétricos, sem comprometer o conforto térmico. 
O trabalho apresentado por Torregrosa et al. (2013) consiste em apresentar uma ferramenta para projeto, análise e otimização para um sistema de ar condicionado eficiente para um micro-ônibus elétrico.

O núcleo do sistema de uma bomba de calor reversível é água-água utilizando compressor de velocidade variável. O circuito de água interno está ligado aos trocadores de calor a ar internos da bomba de calor, enquanto o circuito externo está integrado com o sistema de rejeição de calor do circuito da eletrônica de potência utilizada. Um sistema automático de controle regula a velocidade do compressor, dos ventiladores e das bombas de circulação para alcançar o conforto térmico.

O consumo de energia tem sido analisado diante de diferentes condições de trabalho e condições de ajustes, utilizando um modelo de veículo global Torregrosa et al. (2013).

A tendência da indústria automobilística mundial é aumentar progressivamente o número de veículos elétricos, devido às questões de redução de emissões de gases efeito estufa, bem como atender as políticas de redução da poluição ambiental. No entanto para que estes veículos alcancem o real sucesso, se faz necessário que estes promovam um nível de conforto similar aos veículos convencionais, atuais.

Nos veículos convencionais movidos por motores de combustão interna, o aquecimento da cabine é realizado por meio do calor rejeitado por estes motores, o núcleo de aquecimento é integrado ao sistema de ar condicionado estes aquecedores são geralmente projetados para fornecer uma potência de aquecimento de 5 a $10 \mathrm{~kW}$.

No verão, o ar frio enviado para a cabine por meio de um ar condicionado de acionamento mecânico, os sistemas típicos utilizados possuem uma potência de resfriamento na faixa de 3 a $5 \mathrm{~kW}$ e o controle de temperatura da cabine é feito por meio de mistura de ar frio com ar quente, pois, o ar condicionado opera com rotações impostas pelo motor do veículo, Payá, et al., (2011).

No entanto, o motor dos veículos elétricos possuem características completamente diferentes e por este motivo se faz necessário reprojetar o sistema de ar condicionado, uma vez que, o motor elétrico desliga-se quando o veículo para, componentes alimentados eletricamente são utilizados para permitir uma operação contínua. Além disso, o motor elétrico produz baixo calor de rejeito, em trono de $2 \mathrm{~kW}$ a $40^{\circ} \mathrm{C}$, o que não é suficiente para aquecer a cabine no inverno. 
Portanto, o problema de controle da temperatura da cabine no inverno, o qual é inexistente para os veículos convencionais, tem que ser solucionado. Uma solução eficiente é o uso de sistemas de bomba de calor reversíveis, que opera fornecendo poder de refrigeração, bem como poder de aquecimento.

Em todo caso, os sistemas de ar condicionado são a maior carga de um veículo, possuindo uma influência significativa sobre balanço de energia global. Na verdade, este sistema pode aumentar o consumo de combustível em até $20 \%$ durante um ciclo de condução normal no verão Torregrosa et al. (2013).

Nos veículos totalmente elétricos, os sistemas de bomba de calor existentes, reduzem a autonomia destes veículos, em $8 \%$ no inverno, porém o uso das tecnologias menos eficientes como resistências elétricas pode levar a reduções da autonomia de até $24 \%$.

O impacto dos sistemas de ar condicionado pode ser minimizado selecionando-se tecnologias mais eficientes bem como controle de estratégias, para tal, se faz necessário dispor de ferramentas de simulação, incluindo modelos dinâmicos para todos os componentes do sistema, permitindo que seja avaliado o desempenho do veículo sob qualquer condição de operação Torregrosa, et al. (2013).

No trabalho apresentado por Torregrosa et al. (2013), que almeja a validação dos dados obtidos em simulação numérica utilizando o aplicativo MALTAB-SIMULINK, um sistema de bomba de calor reversível foi montado em um micro-ônibus IVECO-ALTRA, totalmente elétrico, conforme é mostrado na figura 34 , que segue.

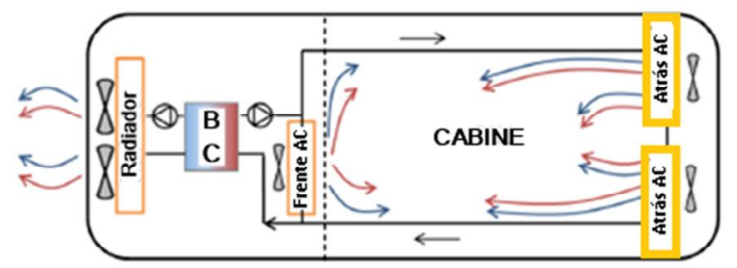

Figura 34: Layout da instalação do sistema condicionador de ar em um micro-ônibus. Torregrosa, et al. (2013).

O modelo matemático é baseado em equações diferenciais que representam balanços de massa e energia. Os mecanismos de tranferência de calor foram modelados utilizando o método de condutância incluindo inércia térmica das massas (carroceria do veículo, ar da cabine e massas internas), estes parâmetros foram calculados tomando como padrão as dimensões e características do veículo. O modelo foi validado com os 
testes de aquecimento e resfriamento, conforme mostrado na figura 35, os desvios principais a respeito das medidas foram de $2 \%$.

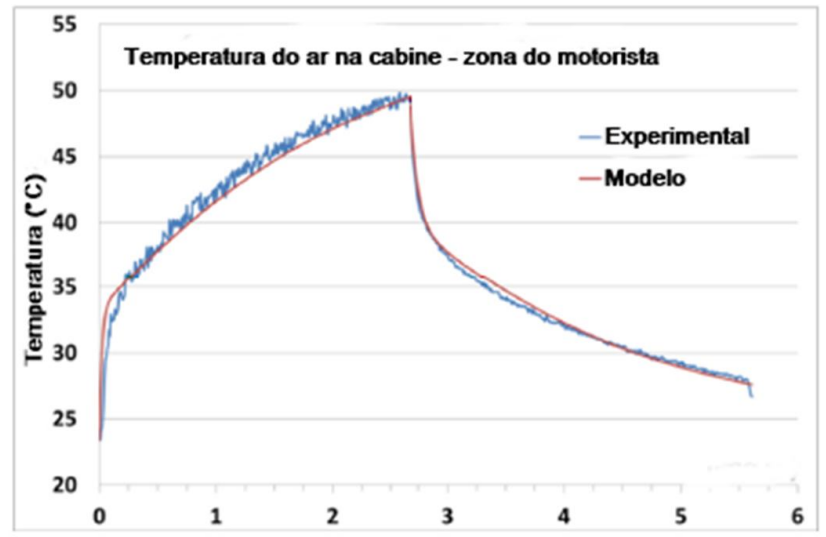

Figura 35: Validação da modelagem da cabine durante os testes de aquecimento e resfriamento. Torregrosa, et al. (2013).

A figura 36 mostra o consumo total de energia da bomba de calor comparado com os sistemas auxiliares.

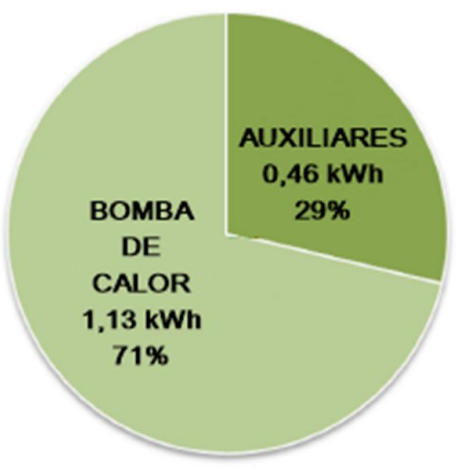

Figura 36: Consumo de energia durante uma hora de resfriamento. Torregrosa, et al. (2013).

O desempenho do modo de aquecimento é mostrado na figura 37. Uma vez que as temperaturas do lado frio são muito baixas, o desempenho do sistema é muito baixo (COP em torno de 2,5). Resultados similares são reportados na literatura por outros autores. 


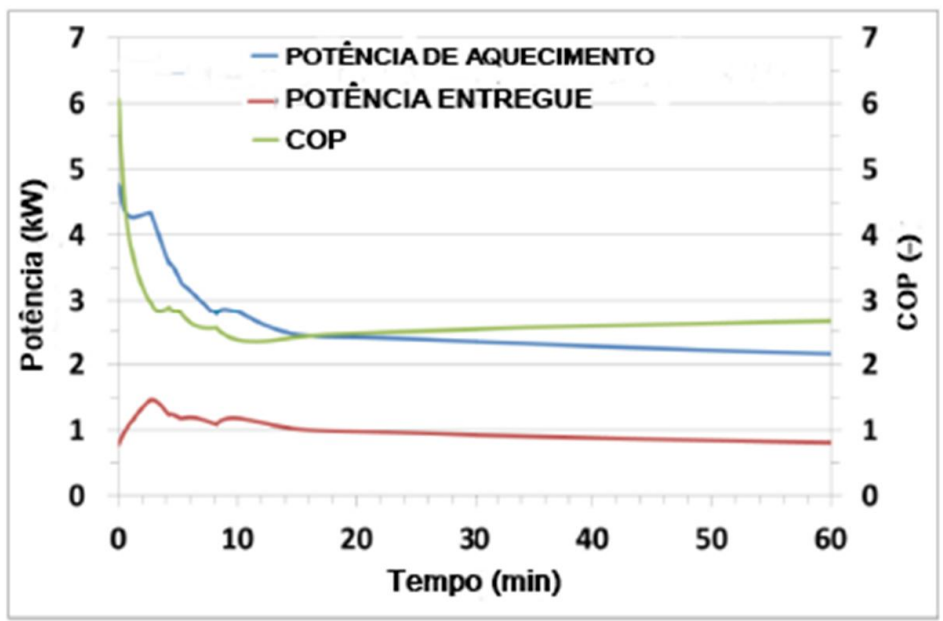

Figura 37: Desempenho da bomba de calor durante o aquecimento. Torregrosa, et al. (2013).

A figura 38 mostra o consumo total de energia da bomba de calor comparado com os sistemas auxiliares, como pode ser visto, dependendo das condições de trabalho e das configurações de controle, os sistemas auxiliares podem representar uma grande parte do consumo de energia do sistema condicionador de ar automotivo.

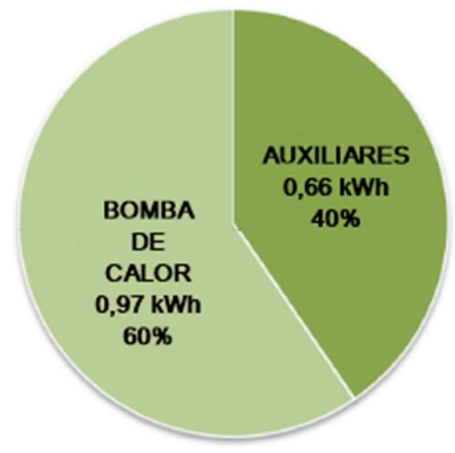

Figura 38: Energia consumida durante uma hora de aquecimento. Torregrosa, et al. (2013).

Torregrossa, et al. (2013) concluem que a modelagem de cada componente de um sistema condicionador de ar para uma "Van" totalmente elétrica foi elaborada e validada com resultados experimantais. A ferramenta pode tambem ser utilizada para outros tipos de veículos diante de simples modificações do desempenho de cada componente.

O objetivo deste modelo é auxiliar no projeto dos sistemas MAC. É uma ferramenta útil para analisar o funcionamento global, estratégias do sistema sob condições transientes, bem como para o dimensionamento e seleção de componentes e a 
otimização das definições de controle. Além disso, o impacto dos diferentes parâmetros sobre o desempenho global pode ser determinada por meio de estudos paramétricos.

A análise do sistema de ar condicionado da "Van" estudada revelou que os sistemas auxiliares elétricos, como os ventiladores consomem uma quantidade de energia significativa, variando de $29 \%$ a $40 \%$ do consumo total de enrgia. Portanto de modo geral, estratégias de controle, devem reduzir o consumo de energia. Como exemplo verificou-se que existe um ponto de temperatura ideal para a ativação do eletroventilador que melhora a relação de consumo entre a bomba de calor e os sistemas elétricos auxiliares.

Um avanço neste estudo é a utilização do calor gerado pelo sistema da eletrônica de potência, objetivando reduzir o consumo global de energia no periodo do inverno.

\section{3}

\section{Contribuição da Presente Tese}

O presente trabalho caracteriza-se por um número de ensaios cobrindo faixa de variávei muito mais ampla (temperatura do ambiente externo variando de $-5^{\circ} \mathrm{C}$ a $10^{\circ} \mathrm{C}$ para a bomba de calor e de $30^{\circ} \mathrm{C}$ a $45^{\circ} \mathrm{C}$ para ar condicionado; e velocidades do compressor variando de $900 \mathrm{rpm}$ a $3700 \mathrm{rpm}$ ) do que as encontradas em outros dos trabalhos apresentados.

Estes dados terão, dentre outras, a utilidade de servir como marco de comparação entre sistemas de capacidade equivalente e que utilizem técnicas e/ou configurações distintas.

O procedimento experimental foi apoiado por ampla instrumentação do aparato experimental para medição de temperatura e pressão, nos pontos mais importantes para a caracterização e avaliação do desempenho global do mesmo e dos seus principais componentes.

Foram motivos de estudo, no presente trabalho, as variáveis que mais influenciam o desempenho do referido sistema, por exemplo, temperaturas do ar na cabine e no ambiente externo, bem como foi iniciado o estudo específico de componentes envolvidos, como, por exemplo, efetividade e queda de pressão nos trocadores do calor. 
Diferentemente dos trabalhos aqui descritos, a presente tese utilizou câmaras climatizadas ao contrário de túneis abertos (Hozos et al.,2006) ou testes de campo (Torregrossa et al., 2013 e Toshiba et al. 2011). Acredita-se, também, que a presente tese cobriu um número total de corridas, com diferentes condições de operação, maior que os trabalhos disponíveis na literatura. Finalmente, aos componentes do ciclo foi dado tratamento individual de forma, no conhecimento do autor, ainda inédito na literatura.

Frente ao estado da arte aqui apresentado, com o presente trabalho espera-se que o volume de dados aqui apresentados contribua para um melhor entendimento dos processos de bomba de calor automotiva, por compressão de vapor. 


\section{3}

\section{APARATO EXPERIMENTAL}

\section{1}

\section{Introdução}

Para atingir o objetivo do presente trabalho, foi projetado e montado, no LRAC (Laboratório de Refrigeração, Condicionamento de Ar e Criogenia) da PUC-Rio, um aparato experimental constituído de um sistema condicionador de ar automotivo operando em três ambientes climatizados, simulando o ambiente externo, compartimento de passageiros e o compartimento do motor. A montagem do aparato experimental seguiu a norma SAE J 2765.

\section{2}

\section{Aparato Experimental e Medições}

O aparato experimental projetado e montado, no LRAC (Laboratório de Refrigeração, Condicionamento de Ar e Criogenia) da PUC-Rio, possui os seguintes componentes, a saber: i) uma câmara climatizada, simulando o compartimento de passageiros de um veículo, denominada como câmara "indoor"; ii) uma segunda câmara climatizada simulando o meio ambiente externo, denominada como câmara "outdoor" e iii) uma terceira câmara construída na bancada de testes, em placas de isopor, de alojamento do compressor simulando o compartimento do motor do veículo. Como comentado, estes sistemas operam segundo um ciclo de compressão de vapor. O sistema montado foi baseado em um sistema típico de condicionamento de ar automotivo, porém com as seguintes exceções na instalação que incluem: i) quatro válvulas do tipo esfera para a inversão do ciclo; ii) quatro válvulas unidirecionais ("Check Valve") e iii) mais um filtro secador acumulador, permitindo assim que o sistema opere como ar condicionado e como bomba de calor. O conjunto de componentes descritos em (i) compõem o que, em escala comercial corresponderia à uma válvula de reversão de 4 vias.

\subsubsection{Câmaras Climatizadas}

O aparato experimental montado no referido laboratório consta de duas câmaras climatizadas, uma simulando o compartimento de passageiro dos veículos (câmara 
"indoor") e a outra simulando o ambiente externo (câmara "outdoor"). Ambas são dotadas de sistema de refrigeração com capacidade de três toneladas de refrigeração (3TR).

As câmaras possuem as seguintes dimensões: câmara "indoor", 3,10m comp.; 3,10m larg.; 2,40m alt. e a câmara "outdoor", 3,10m comp.; 2,00m larg.; 2,40m alt., com espessura das paredes de $0,10 \mathrm{~m}$. As paredes das câmaras são fabricadas em chapa dupla de alumínio com isolamento térmico de isopor entre a chapa interna e a externa, a faixa de temperatura de operação das câmaras é de, $-20^{\circ} \mathrm{C}$ até $+50^{\circ} \mathrm{C}$. O isolamento térmico das paredes das câmaras é da ordem de $0,025 \mathrm{~W} / \mathrm{m} \mathrm{K}$.

Um diagrama ilustrativo de montagem das câmaras é mostrado na figura 39.

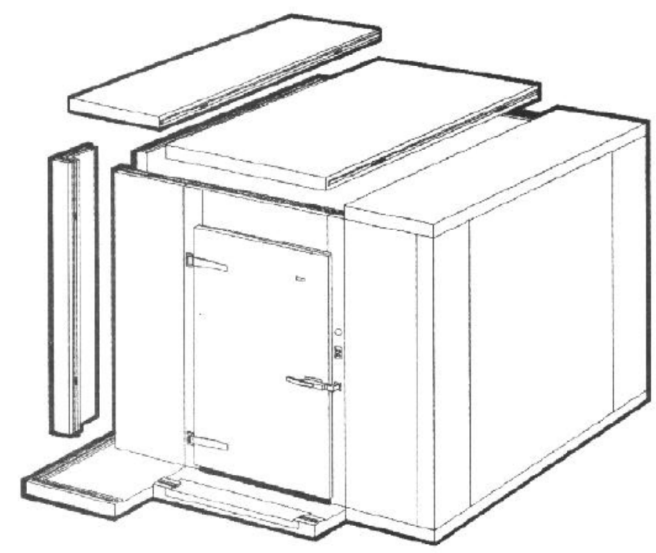

Figura 39: Diagrama ilustrativo da construção das câmaras

Para garantir a estabilidade térmica no interior das câmaras foram instaladas, em cada câmara, três resistências elétricas de $2 \mathrm{~kW}$ de potência associadas em paralelo. As resistências elétricas são controladas por controladores eletrônicos programáveis, fabricados pela Therma Instrumentos de Medição, modelo TH 91D 101-002, precisão de $+/-0,2 \%$,utilizando como sensores de temperatura, termopares do tipo $\mathrm{T}$ com incerteza de medição $0,06^{\circ} \mathrm{C}$. Um exemplo do controle PID usado pelos controladores citados é mostrado na figura 40 e a curva de calibração dos termopares encontra-se no apêndice I deste trabalho. 


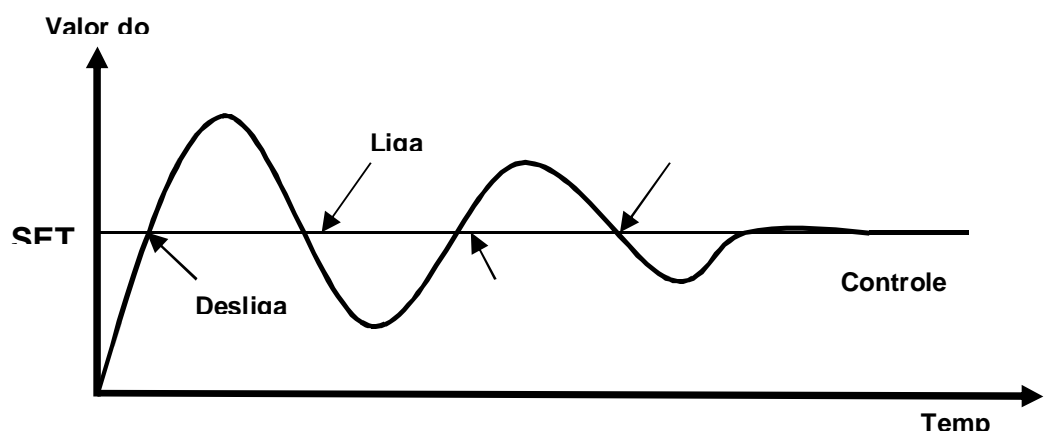

Figura 40: Auto sintonia para o controle de aquecimento.

O conjunto formado pelo sistema de refrigeração e de aquecimento do interior das câmaras permite que as condições de operação do sistema sejam variáveis, simulando um veiculo transitando em diversos tipos de clima. As câmaras são mostradas nas figuras 41 e 42. Uma visão geral da alocação no laboratório destas câmaras é mostrada na figura 43.

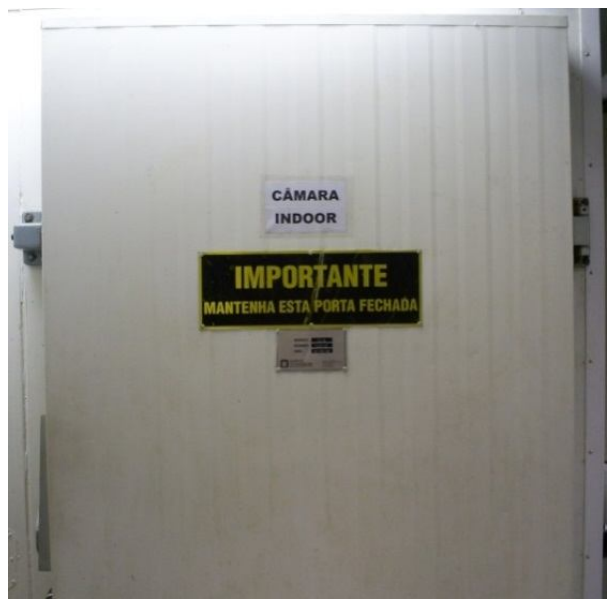

Figura 41: Câmara Indoor

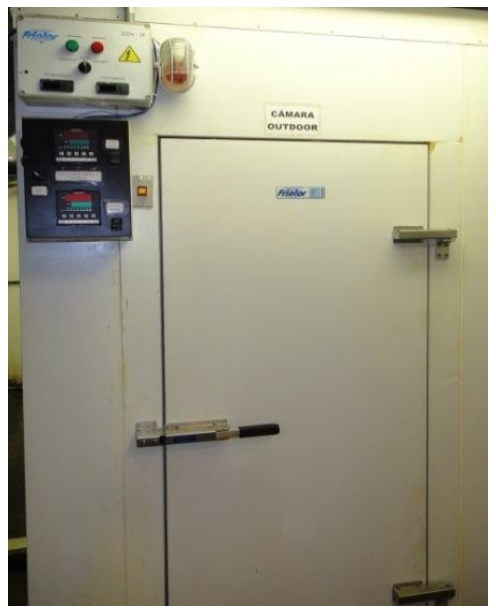

Figura 42: Câmara Outdoor 


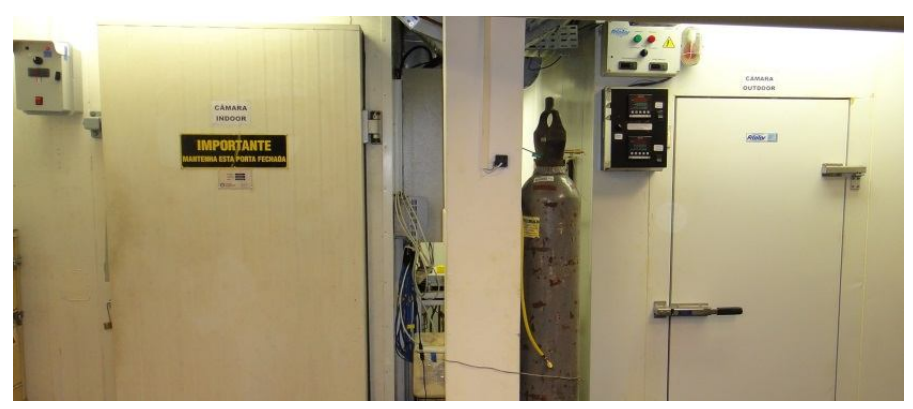

Figura 43: Visão geral da alocação das câmaras no laboratório.

O compressor está montado na terceira câmara, que representa o compartimento do motor do veículo, o qual possui temperatura na faixa de $50^{\circ} \mathrm{C}$ a $100^{\circ} \mathrm{C}$, dependendo do tipo de veículo.

Um diagrama geral, ilustrativo, da montagem do aparato experimental é mostrado na figura 44 .

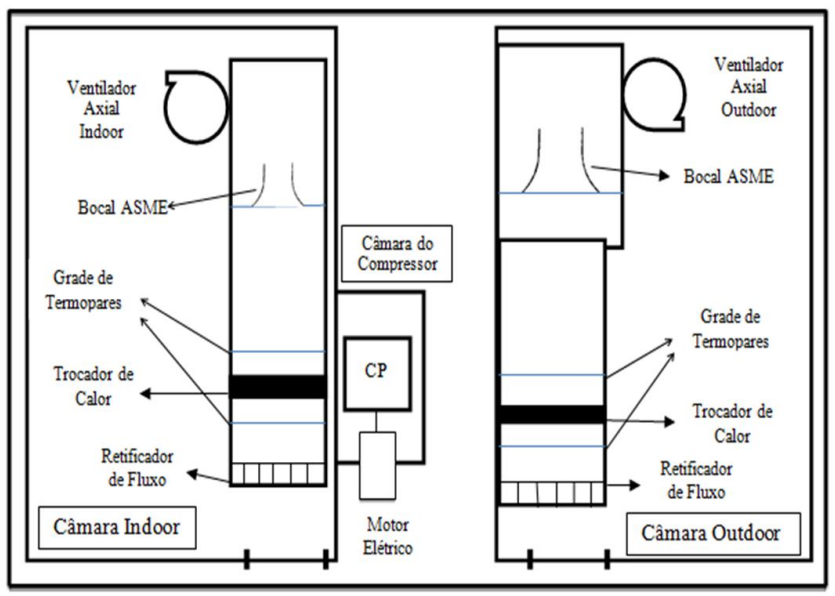

Figura 44: Diagrama llustrativo do Aparato Experimental.

\subsubsection{Túneis de Vento}

Os túneis de vento foram fabricados em chapa galvanizada com espessura de 2 $\mathrm{mm}$, possuindo na entrada um retificador de fluxo, uma grade para fixação de termopares a montante e a jusante do trocador de calor, possuindo as seguintes medidas na entrada do ar, túnel "indoor", 340 x 190 mm e o "outdoor", 500 x 300mm. 
O túnel de vento "outdoor" possui um ventilador do tipo "limit load", fabricado pela TRATAR Ltda., modelo TSL550, de rotor axial com capacidade de imprimir velocidade no ar de até $70 \mathrm{~km} / \mathrm{h}$, velocidade esta a de face do ar no condensador, a uma pressão de 90mca, permitindo a simulação de diversas condições reais de utilização de um veículo. No túnel de vento da câmara "indoor" encontra-se montado um ventilador do tipo axial ISROM, modelo VT1000.

As velocidades dos ventiladores centrífugos montados nos túneis são controladas por meio de inversores de frequência da marca WEG, modelo CFW09 VECTRUE, para o túnel "indoor” e CFW08 VECTOR para o "outdoor".

As figuras 45 (a) e (b) mostram os túneis de vento "indoor" e "outdoor" instalados nas câmaras.

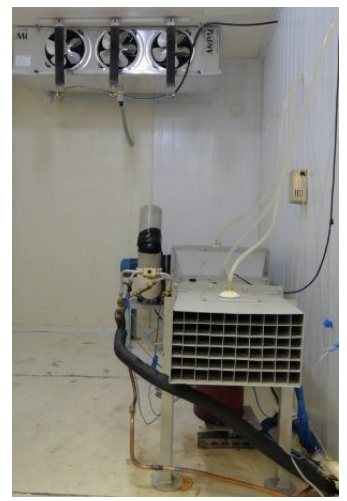

(a)

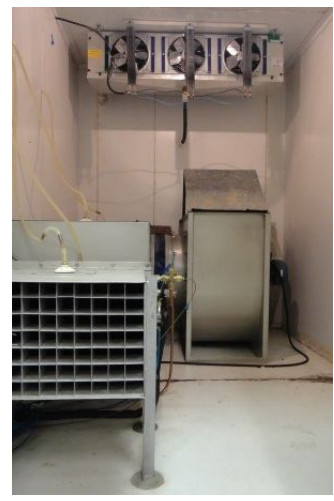

(b)

Figura 45: (a) Túnel de vento Indoor, (b) Túnel de vento Outdoor.

\subsubsection{Bancada de Componentes}

Para a montagem do compressor, motor elétrico, filtros secadores acumuladores e os transdutores de pressão uma bancada foi confeccionada em perfil de alumínio extrudado, modelo 45x45 M12, fornecido pela FAMAC Automação Industrial Ltda. A figura 46 (a) mostra a estrutura da bancada e a 46 (b) mostra a bancada com os componentes já instalados. A figura 47 (a) mostra uma vista superior da bancada e a 44 (b), mostra as válvulas do tipo esfera para inversão do ciclo. 


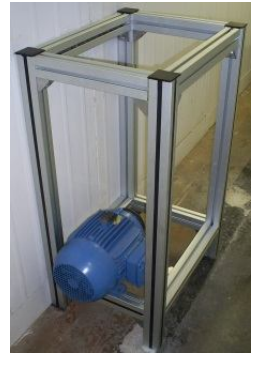

(a)

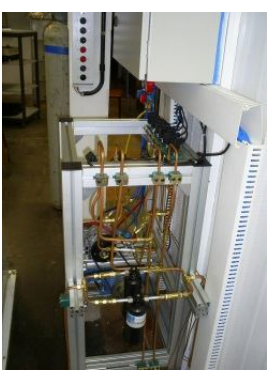

(b)

Figura 46: (a) Estrutura da bancada, (b) bancada com os componentes instalados.

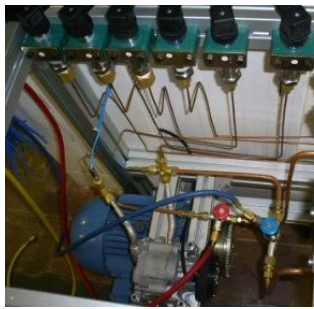

(a)

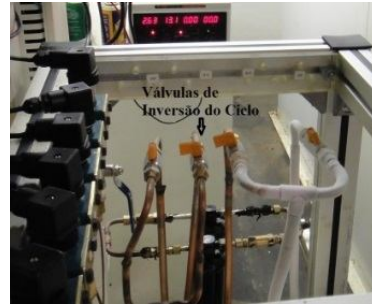

(b)

Figura 47: (a) Vista superior do sistema AC \& BC montado no laboratório, (b) Vista das válvulas de inversão do ciclo, do tipo esfera de comando manual.

Um diagrama esquemático do circuito do refrigerante montado no aparato experimental é mostrado na figura 48 , a seguir.

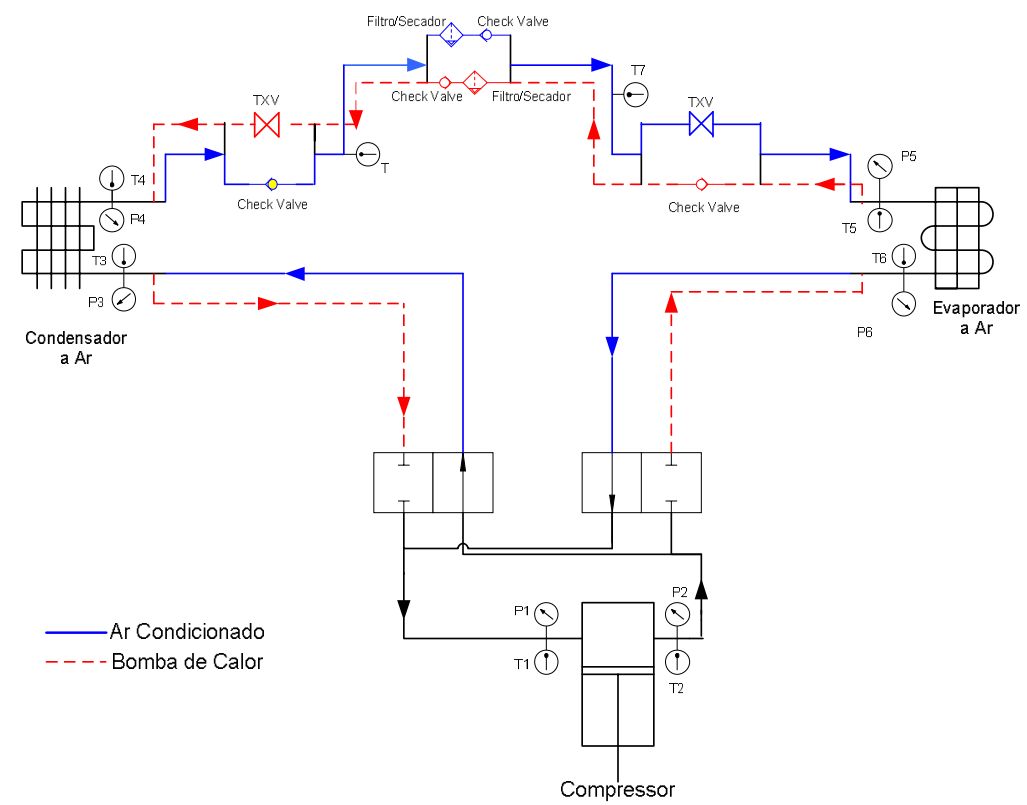

Figura 48: Diagrama do sistema ar de condicionado e bomba de calor montado no laboratório. 
O aparato experimental foi construído com componentes originais, utilizados nos sistemas condicionadores de ar automotivos dos veículos da marca Fiat, modelos, Pálio 1.0L, Sienna 1.0L e Doblô 1.3L, que serão apresentados a seguir:

\section{I) Compressor}

O compressor do tipo voluta ou "scroll", fabricado pela DENSO - Japão, com volume deslocado de $60 \mathrm{cc}$ modelo SCSB06C, mostrado na figura 5 (a), é acionado por um motor elétrico WEG, trifásico com potência de $7 \mathrm{HP}$, por meio de polias e correia multi-v que transmite o torque do motor para a polia do compressor. A velocidade do motor elétrico de acionamento do compressor é controlada por um inversor de frequência, modelo CFW09 Vectrue, fabricado pela WEG.

Os compressores automotivos são dotados de um sistema de embreagem eletromagnética que permite o acoplamento e o desacoplamento da árvore do compressor com a polia movida, mesmo quando o motor do veículo está em funcionamento. Para suprir a energia elétrica de corrente contínua necessária para o funcionamento da embreagem eletromagnética, foi utilizada uma fonte de tensão de corrente contínua estabilizada, modelo OS-5000, fabricada pela Icel Manaus, que fornece tensão de 0 a 30 Volts, DC, com corrente elétrica variando de 0 a $5 \mathrm{~A}$.

\section{II) Condensador}

O condensador utilizado é do tipo micro canal e aletas, utilizado nos veículos já citados e encontra-se montado no túnel de vento da câmara "outdoor", que são mostrados nas figuras 49 (a) e (b).

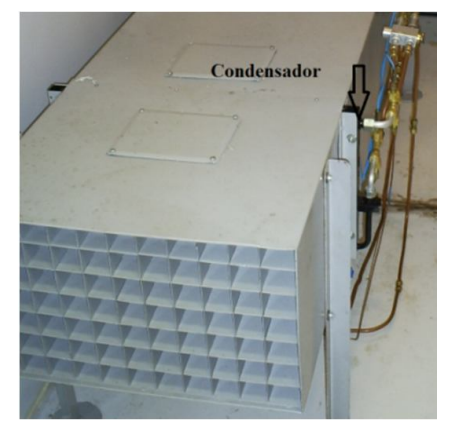

(a)

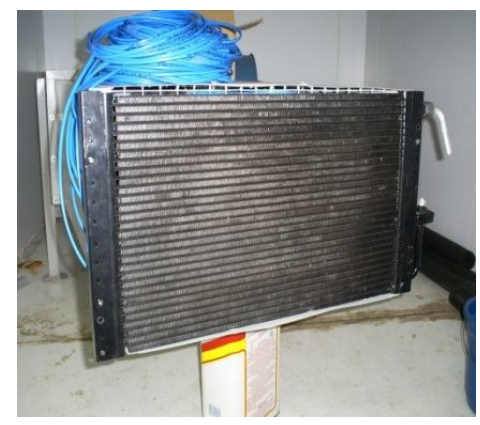

(b)

Figura 49: (a) Vista da montagem no túnel de vento outdoor e (b) Vista do condensador automotivo.

O condensador utilizado no aparato experimental possui quatro circuitos conforme é mostrado nas figuras 50 e 51. 


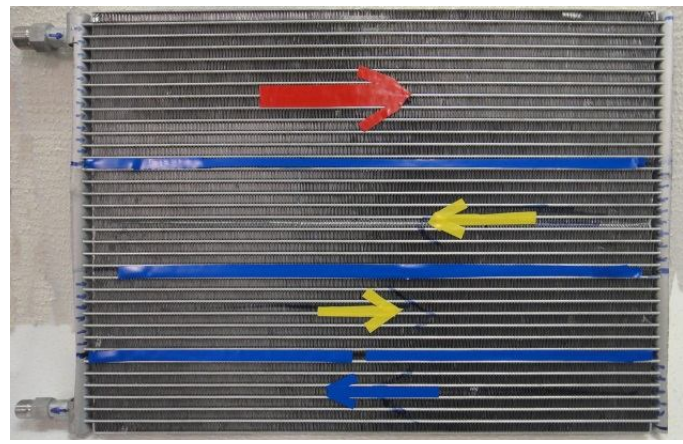

Figura 50: Circuitos do condensador utilizado.

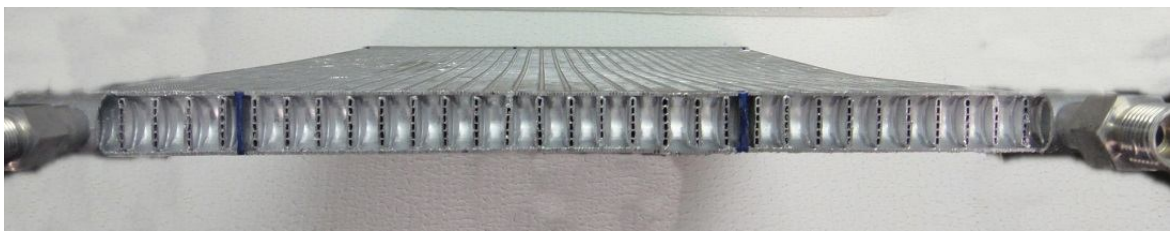

Figura 51: Vista dos tubos planos e micro canais do condensador.

\section{III) Dispositivos de Expansão}

O ciclo de compressão de vapor possui duas válvulas de expansão termostática em bloco, utilizadas nos sistemas condicionadores de ar dos veículos já citados, mostrada na figura 52, uma operando no modo de ar condicionado e a outra no modo de bomba de calor. As montagens das referidas válvulas, no ciclo, são mostradas na figura 53 (a) e (b).

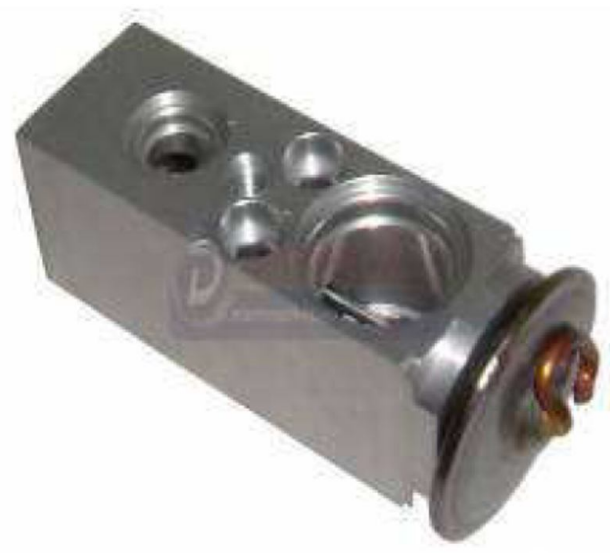

Figura 52: Válvula de expansão termostática do tipo bloco. 


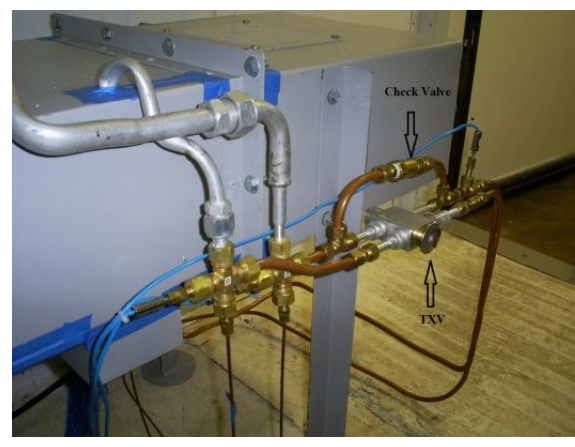

(a)

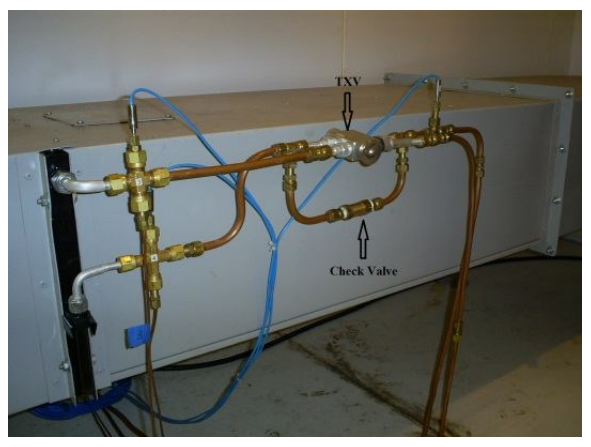

(b)

Figura 53: (a) Instalação da válvula TXV e "Check Valve" na câmara indoor e (b) Instalação da válvula TXV e "Check Valve" na câmara "outdoor".

\section{IV) Evaporador}

Um evaporador do tipo chapa brasada e aletas, original do veículo Pálio 1.0L, encontra-se montado no interior do túnel de vento "indoor", conforme mostra a figura 54. As figuras 55 (a) e (b) mostram as vistas em corte do evaporador, com ambos "manifolds" recortados, permitindo a visualização de seus circuitos internos.

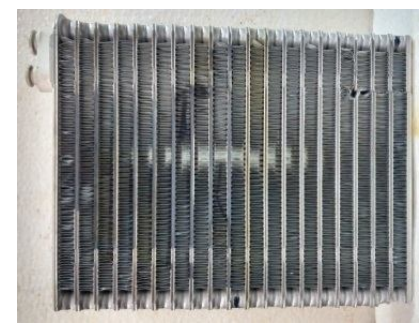

Figura 54: Vista do evaporador automotivo instalado no túnel de vento "indoor".

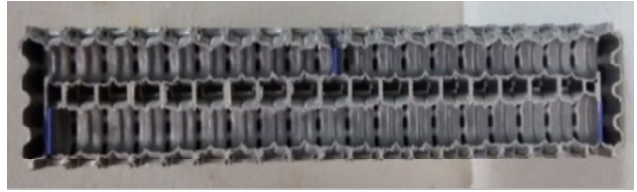

(a)

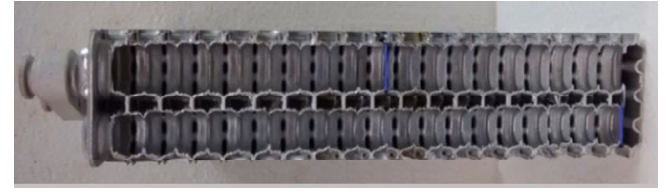

(b)

Figura 55: Vista: (a) "manifold" inferior de entrada do refrigerante, (b) "maifold" superior de saída do refrigerante.

\section{V) Filtros Acumulador Secador}

O aparato experimental, como já mencionado, possui dois filtros acumulador secador montados na linha de líquido, um para o modo de operação AC e o outro para o modo de 
operação HP, bem como duas válvulas unidirecionais, "Check Valves" que selecionam a utilização dos filtros, dependendo do modo de operação, conforme mostrado na figura 56.

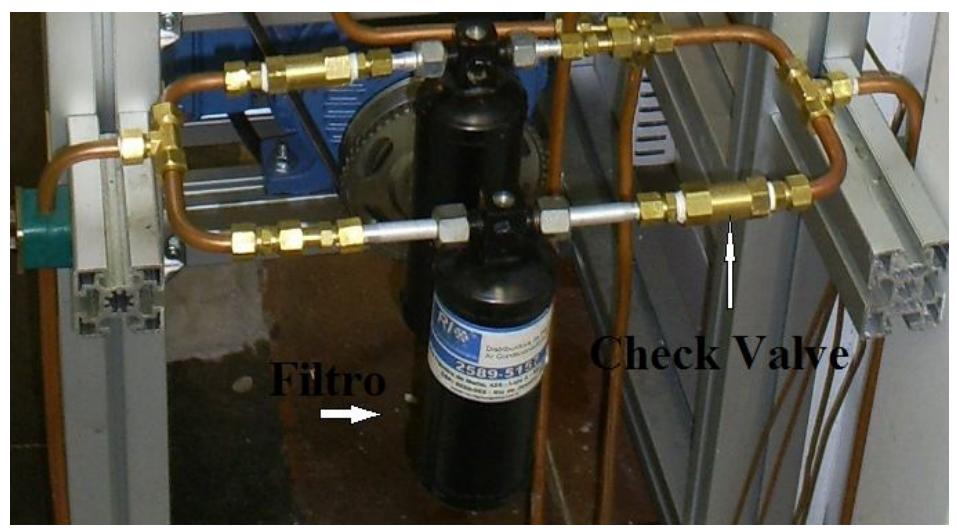

Figura 56: Vista dos filtros na linha de líquido e suas "check valves"

\section{3 \\ Instrumentação Utilizada}

Para medir as grandezas de interesse no aparato experimental foi utilizada a seguinte instrumentação.

\subsubsection{Medidas de Pressão}

Para as medidas de pressão do refrigerante em seis pontos de interesse, no ciclo, foram utilizados transdutores de pressão de sinal analógico da marca WIKA, modelo S-10 com as seguintes características: i) alimentação de $24 \mathrm{~V} \mathrm{DC}$; ii) Sinal de saída de 4 a 20 mA, 2 fios; iii) Faixa de pressão 0 a 300 Psi; iv) Precisão < 0,25\% do span e não repetitividade $<0,1 \%$ do span.

Os pontos de tomadas de pressão do refrigerante no ciclo foram nomeados por P1- pressão de sucção do compressor, P2- Pressão de descarga do compressor, P3 pressão na entrada do condensador no modo AC e saída do evaporador no modo HP, P4- Pressão na saída do condensador no modo AC e entrada do evaporador no modo HP, P5- Pressão na entrada do evaporador no modo AC e saída condensador no modo HP, P6- Pressão na saída do evaporador no modo AC e entrada do condensador no modo HP. 


\subsubsection{Medidas de Temperatura}

Para as medidas de temperaturas do refrigerante nos pontos de interesse no ciclo, foram utilizados termopares do tipo $\mathrm{T}$ com $0,06{ }^{\circ} \mathrm{C}$ de incerteza de medição, calibrados no Laboratório de Temperatura e Pressão da PUC-Rio.

Para o lado do refrigerante foram utilizados seis termopares com haste para instalação em poço, também seguindo a mesma nomenclatura e posição física adotada para os transdutores de pressão, ou seja, T1, temperatura de sucção do compressor, T2, temperatura de descarga do compressor, T3, temperatura na entrada do condensador no modo AC e saída do evaporador no modo HP, T4, temperatura na saída do condensador no modo AC e entrada do evaporador no modo HP, T5, temperatura na entrada do evaporador no modo AC e saída condensador no modo HP, T6, temperatura na saída do evaporador no modo AC e entrada do condensador no modo HP, T7, temperatura do refrigerante na entrada da TXV "indoor" no modo AC e saída da válvula unidirecional, "check valve" no modo HP, T8, temperatura do refrigerante na entrada da TXV "outdoor" no modo HP e saída da válvula unidirecional, "check valve" no modo AC.

Para o lado do ar, trinta e nove termopares foram instalados nos pontos de interesse que seguem: No túnel de vento "indoor", nove termopares foram instalados na grade de termopares a jusante e nove termopares na grade a montante do trocador de calor.

Para o túnel de vento "outdoor", nove termopares foram instalados na grade de termopares a montante e nove a jusante do trocador de calor, totalizando trinta e seis termopares para o ar no interior dos túneis de vento.

Esta configuração permite estimar as temperaturas de saída do ar a jusante nas três zonas do condensador, dessuperaquecimento, condensação e subresfriamento, bem como nas duas zonas do evaporador, evaporação e superaquecimento. $\mathrm{O}$ arranjo citado pode ser visualizado nas figuras 57 e 58 , as temperaturas das cabines, "indoor" e "outdoor", e a temperatura da câmara de alojamento do compressor são medidas por um termopar do tipo T, com as mesmas especificações dos anteriores, em cada local. 


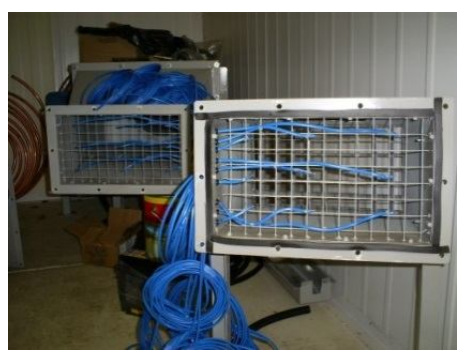

Figura 57: Grades de termopares do túnel "indoor".

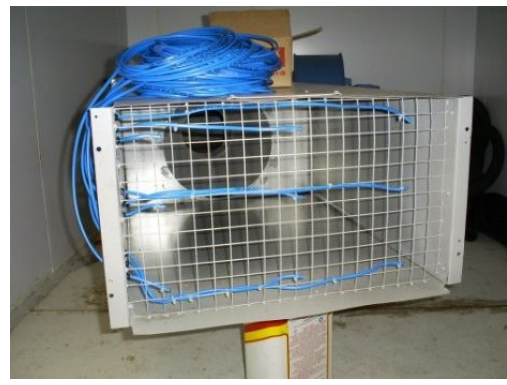

Figura 58: Grade de termopares do túnel "outdoor".

\subsubsection{Medidas dos Escoamentos de Ar}

Para as medidas de vazão de ar nos túneis de vento foram adotados os métodos de quedas de pressão do ar causadas pelos trocadores de calor e pelos bocais ASME de medição de vazão. Para tal foram utilizados quatro manômetros de coluna d'água inclinados, com faixa de medição $100 \mathrm{mmca}$, precisão de 1,0 mmca, com montagem ilustrada na figura 59 (a) e o método de medição da velocidade de face do ar na entrada dos túneis de vento. Para este método foi utilizado um termo anemômetro digital da marca Minipa, modelo MDA-11, precisão a $23^{\circ} \mathrm{C}+/-5^{\circ} \mathrm{C}, \mathrm{RH}<80 \%$, mostrado na figura 59 (b).

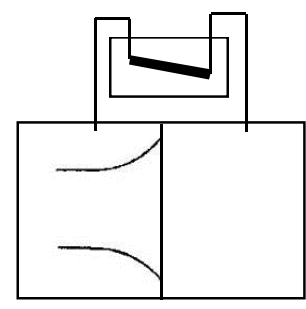

(a)

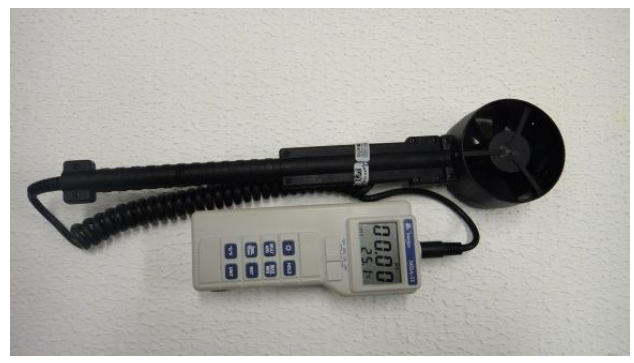

(b) 
Figura 59: (a) Diagrama de montagem dos manômetros de coluna d'água inclinado, (b) Anemômetro utilizado para medir as velocidades de face do ar na entrada dos túneis de vento.

A figura 60 mostra o manômetro de coluna d'água inclinado, utilizado no aparato experimental.

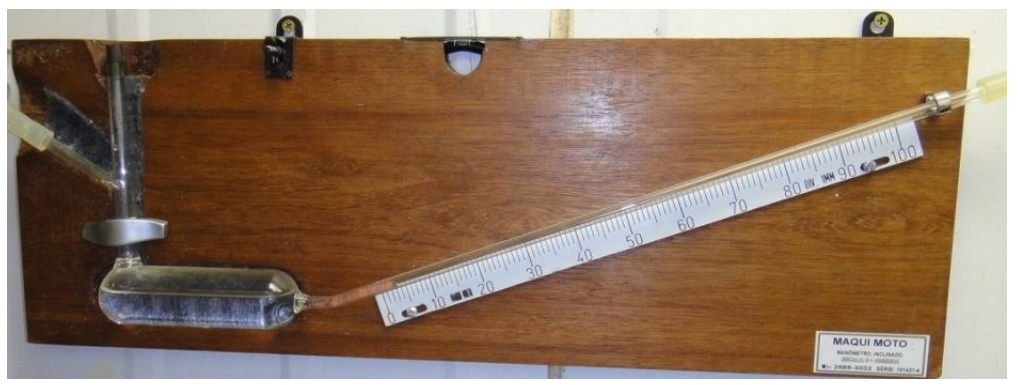

Figura 60: Manômetro de coluna d'água inclinado range de 100mm.

No interior do túnel de vento "indoor" foi instalado um bocal ASME com diâmetro de descarga de $75 \mathrm{~mm}$. Sua fabricação em fibra de vidro e montagem no interior do túnel seguiram as orientações contidas na norma SAE J2765. O referido bocal é mostrado na figura 61 .
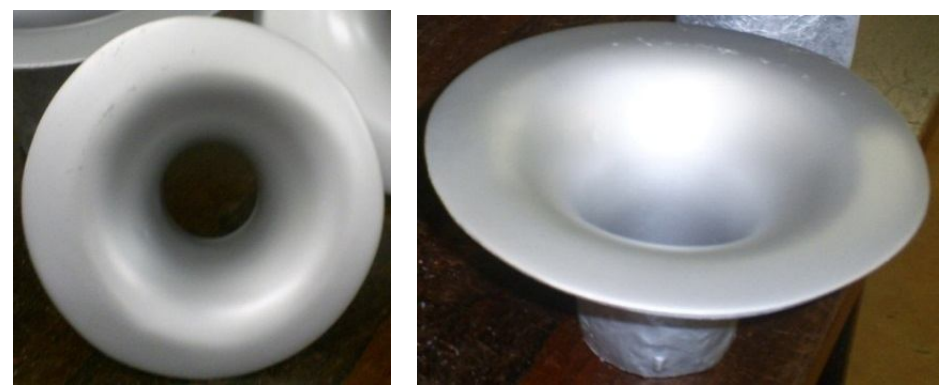

Figura 61: Vistas do bocal ASME com $75 \mathrm{~mm}$ de diâmetro de descarga, fabricado e instalado no túnel de vento "indoor".

Da mesma forma, para o túnel de vento da câmara "outdoor", foi fabricado em fibra de vidro e instalado um bocal ASME com diâmetro de descarga de $250 \mathrm{~mm}$, conforme é mostrado na figura 62 . 

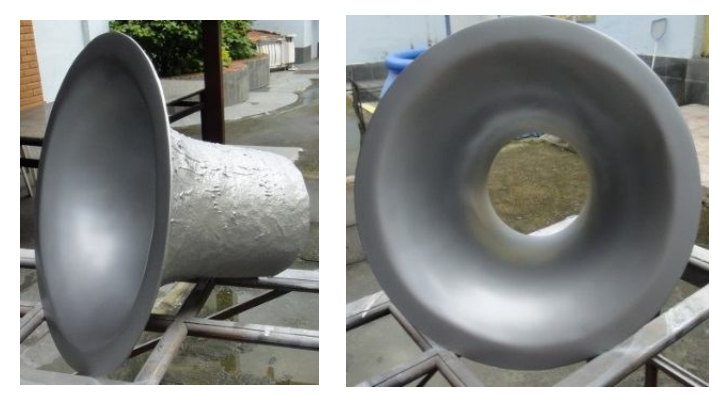

Figura 62: Vistas do bocal ASME fabricado em fibra de vidro com $250 \mathrm{~mm}$ de diâmetro de descarga, instalado no túnel "outdoor".

A localização das tomadas das pressões estáticas à montante e à jusante nos túneis de vento, "indoor" e "outdoor", tanto para os trocadores de calor como para os bocais, seguiram as orientações das normas ASME e SAE J2765.

Posteriormente, as medidas de vazão de ar no interior dos túneis de vento, "indoor" e "outdoor", realizadas por meio da queda de pressão do ar nos bocais ASME não se mostraram confiáveis devido à precisão e faixa de medição dos manômetros utilizados, como também os diâmetros de descarga dos bocais se mostraram inadequados, pois, inicialmente foram previstas velocidades de face do ar na entrada do túnel de vento “indoor" semelhantes às velocidades do ar na saída dos difusores no painel de um veículo de porte médio. Da mesma forma, foram previstas velocidades de face do ar no túnel de vento "outdoor" simulando um veículo trafegando a $70 \mathrm{~km} / \mathrm{h}$. A norma SAE J2765 prevê velocidades de face do ar no túnel de vento "indoor" superiores às medidas no veículo, produzindo um diferencial de pressão superior ao range dos manômetros utilizados.

As velocidades de face do ar no túnel de vento "outdoor", indicadas pela norma são menores que as previstas no projeto inicial, gerando um diferencial de pressão nulo, impossibilitando assim sua utilização. Foi adotado em consequência o método de medida da velocidade de face do ar na entrada dos túneis de vento, com o uso do termoanemômetro, com os quais os resultados obtidos se mostraram mais confiáveis.

\subsubsection{Peso do Condensado no Evaporador}

Para quantificar o volume da água condensada no evaporador foi construída uma balança, utilizando uma célula de carga modelo SP4M10, atuada por um "Strain Gauge" ligada em ponte de Wheatstone completa, fabricada pala HBM, GmbH, com classe de precisão C3MR, capacidade máxima de carga de $10 \mathrm{~kg}$, intervalo mínimo de $1 \mathrm{~g}$, sensibilidade (Cn) 2,0 +/- $10 \%(\mathrm{mV} / \mathrm{V})$. 
A balança foi calibrada no laboratório, utilizando para tal, massas calibradas e certificadas, fabricadas pela Fluck, pertencentes ao laboratório de Pressão e Temperatura da PUC-Rio. A calibração da balança encontra-se no apêndice I deste trabalho. A curva de calibração da balança, é mostrada pela equação 1 .

$m_{a p}=0,226664 *$ ValorLido $-0,473497$

Onde: $m_{a p}$ é a massa ajustada ou massa aparente.

\subsubsection{Umidade Relativa}

Para as medidas das umidades relativas nas câmaras "indoor", "outdoor", no interior dos túneis de vento a montante e a jusante dos trocadores de calor também foram utilizados, três termo-higrômetros, digitais sem fio, modelo, HT-7100, com resolução de $0,1 \%$, exatidão de umidade de $+/-5 \%$ de 0 a $45^{\circ} \mathrm{C}$, fabricados pela ICEL- Manaus, conforme mostrado na figura 63 e foi também utilizado dois termo-higrômetros marca TFA, com resolução de $1 \%$, exatidão de $+/-7 \%$ de 0 a $50^{\circ} \mathrm{C}$. Os termo-higrômetros utilizados foram aferidos por comparação com um termo higrômetro, TFA, calibrado pelo INMETRO, utilizado pelo Laboratório de Reologia da PUC-Rio. A figura 64 mostra o termo anemômetro da marca TFA.

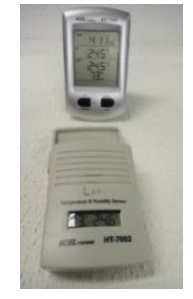

Figura 63: Termo Higrômetro ICEL.

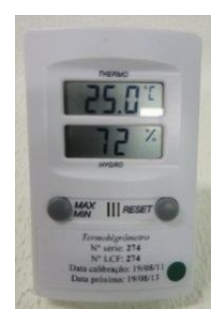

Figura 64: Termo Higrômetro TFA.

\subsection{Quadro Elétrico de Comando e Potência}

O quadro elétrico de comando e potência do aparato experimental é mostrado na figura 65, (a) e (b). Foi projetado e construído para permitir o acionamento dos motores elétricos do compressor, do ventilador do túnel de vento "outdoor", do ventilador do túnel de vento "indoor", da embreagem eletromagnética do compressor, do umidificador de ambiente e das resistências de aquecimento das câmaras. Na figura 62 (b) pode ser visualizado o sistema de aquisição de dados cDAQ 9178, fabricado pela "National Instruments", utilizado para a aquisição de dados deste trabalho. 


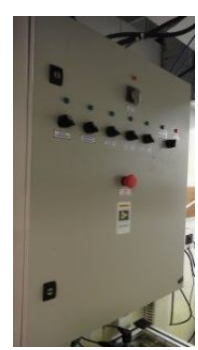

(a)

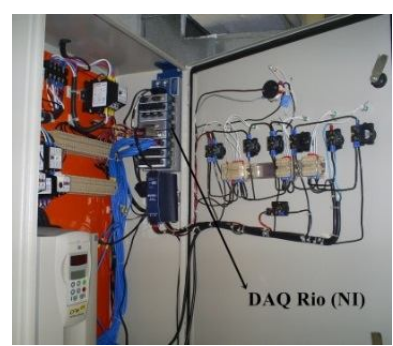

(b)

Figura 65: (a) Vista das chaves de comando; (b) Vista dos componentes no interior do painel.

Para o controle das velocidades dos motores do compressor e do ventilador da câmara "outdoor" foram utilizados inversores de frequência modelo CFW 09, fabricados pela WEG do Brasil. Para o controle de velocidade do ventilador da câmara "indoor", por se tratar de um motor elétrico de menor potência, foi utilizado um inversor de frequência modelo CFW 08, também fabricado pela WEG do Brasil, montado do lado externo do quadro elétrico. A figura 66 mostra os inversores CFW 09 montados no quadro elétrico de comando e potência.
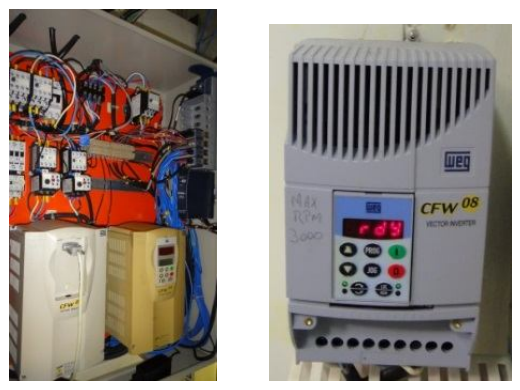

Figura 66: Inversores CFW9 no interior do quadro e o CFW8 externo ao quadro

Para o controle das temperaturas de refrigeração das câmaras, foram projetados e construídos dois quadros de comandos, utilizando controladores digitais. Para o controle de refrigeração da câmara "indoor" foi utilizado o controlador digital para refrigeração e degelo modelo TC-900Ri, fabricado pela Full Gauge Controles, com as seguintes especificações, temperatura de controle $-50{ }^{\circ} \mathrm{C}$ a $75{ }^{\circ} \mathrm{C}$, temperatura de operação 0 a 40 ${ }^{\circ} \mathrm{C}$, umidade de operação 10 a $90 \%$ sem condensação, resolução $0,1{ }^{\circ} \mathrm{C}$ entre -10 e $75{ }^{\circ} \mathrm{C}$ e $1{ }^{\circ} \mathrm{C}$ fora dessa faixa.

Para o controle de temperatura da câmara "outdoor", foi utilizado um controlador digital modelo MT-512Ri, também fabricado pela Full Gauge Controles, com as mesmas especificações técnicas que o anterior, a única diferença deste controlador é o degelo, que 
neste caso é natural, não utilizando resistências de degelo conforme utiliza o da câmara "indoor".

A figura 67 mostra o quadro de controle de temperatura da câmara "indoor"

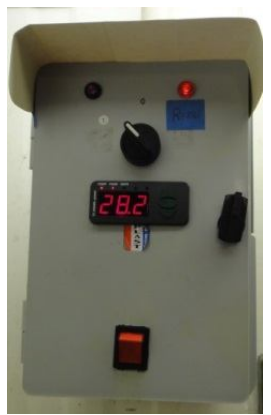

Figura 67: Quadro de controle da temperatura da câmara indoor.

Na figura 68 pode ser visualizado o quadro de controle de temperatura da câmara "outdoor"

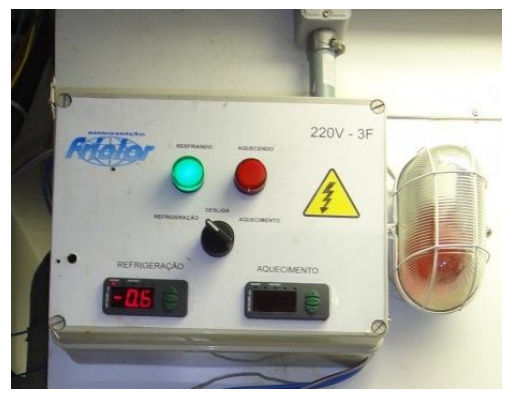

Figura 68: Quadro de controle de temperatura da câmara "outdoor" 


\section{PROCEDIMENTO EXPERIMENTAL}

Os testes, no modo ar condicionado, foram realizados em parte seguindo a norma SAE J2765, pois, o aparato construído foi projetado, segundo alguns dados experimentais obtidos em um veículo de porte médio. A faixa de velocidades de face do evaporador foram medidas pelo termo anemômetro nos ensaios citados. Para conhecer as velocidades de face no condensador, foram medidas as velocidades do eletro ventilador do veículo estacionado. Mediu-se a primeira e a segunda velocidades que serviram de parâmetros para a construção do túnel de vento, como também foi estimada a realização de testes com o veículo em movimento, chegando à velocidade de $70 \mathrm{~km} / \mathrm{h}$.

Por força de limitações na construção do aparato, não foi possível atingir algumas solicitações da referida norma, tais como:

i) O motor elétrico de acionamento do compressor, o qual possui sua velocidade controlada pelo inversor de frequência mencionado, não atinge velocidades superiores a $3500 \mathrm{rpm}$ - por esse motivo os testes da norma com velocidades de $4000 \mathrm{rpm}$ não puderam ser realizados;

ii) A umidade relativa do ar ambiente em alguns casos não atingiu os valores propostos pela norma - logo os testes foram realizados com a máxima umidade possível obtida no aparato experimental;

iii) Igualmente, a máxima velocidade de face no evaporador atingida pelo aparato é de $1,85 \mathrm{~m} / \mathrm{s}$ - os testes indicados pela norma com velocidades superiores não foram atendidos.

A tabela 5 mostra a matriz de teste indicada pela norma, onde os valores grifados em vermelho não puderam ser atingidos, conforme explicado acima, por questões construtivas do aparato.

Os testes no modo bomba de calor, pela ausência de normas específicas, foram realizados de acordo o procedimento que segue:

i) Testes em regime permanente e transiente simulando o equipamento renovando o ar do ambiente interno (OSA); 
ii) Testes em regime permanente e transiente simulando o equipamento no modo de recirculação do ar interno (REC).

A nomenclatura criada para os testes segue o critério mostrado nas tabelas número 6 para os testes com renovação do ar e número 7 para os testes com recirculação do ar.

\begin{tabular}{|c|c|c|c|c|c|c|c|c|c|}
\hline \multirow[b]{2}{*}{$\begin{array}{c}\text { Nome do } \\
\text { Teste }\end{array}$} & \multirow[b]{2}{*}{$\begin{array}{c}\text { Temp. } \\
\text { Ambiente } \\
\left({ }^{\circ} \mathrm{C}\right)\end{array}$} & \multirow[b]{2}{*}{$\begin{array}{c}\text { Veloc. } \\
\text { Compressor } \\
\text { (rpm) }\end{array}$} & \multicolumn{2}{|c|}{ Condensador } & \multicolumn{4}{|c|}{ Evaporador } & \multirow{2}{*}{$\begin{array}{l}\text { Temp. do ar } \\
\text { esperada a } \\
\text { jusante do } \\
\text { Evaporador } \\
\left({ }^{\circ} \mathrm{C}\right)\end{array}$} \\
\hline & & & $\begin{array}{l}\text { Temp. } \\
\left({ }^{\circ} \mathrm{C}\right)\end{array}$ & $\begin{array}{c}\text { Velocidade } \\
\text { de Face } \\
(\mathrm{m} / \mathrm{s})\end{array}$ & $\begin{array}{l}\text { Temp. } \\
\left({ }^{\circ} \mathrm{C}\right)\end{array}$ & $\begin{array}{l}\text { HR } \\
(\%)\end{array}$ & $\begin{array}{l}\text { Vazão } \\
\text { de Ar } \\
(\mathrm{kg} / \mathrm{s})\end{array}$ & Modo & \\
\hline 170 & 45 & 900 & 70 & 1,5 & 35 & 25 & 9,0 & REC & 3 \\
\hline 160 & 45 & 900 & 60 & 1,5 & 35 & 25 & 9,0 & REC & 3. \\
\hline 145 & 45 & 900 & 45 & 1,5 & 35 & 25 & 9,0 & REC & 3 \\
\hline L 45 & 45 & 1800 & 45 & 2,0 & 35 & 25 & 9,0 & REC & 3 \\
\hline M 45 & 45 & 2500 & 45 & 3.0 & 35 & 25 & 9,0 & REC & 3. \\
\hline $\mathrm{H} 45$ & 45 & 4000 & 45 & 4,0 & 35 & 25 & 9,0 & REC & 3. \\
\hline $150 a$ & 35 & 900 & 50 & 1,5 & 35 & 40 & 9,0 & OSA & 3. \\
\hline $135 a$ & 35 & 900 & 35 & 1,5 & 35 & 40 & 9,0 & OSA & 3 \\
\hline L 35a & 35 & 1800 & 35 & 2,0 & 35 & 40 & 9,0 & OSA & 3 \\
\hline M 35a & 35 & 2500 & 35 & 3,0 & 35 & 40 & 9,0 & OSA & 3. \\
\hline $\mathrm{H} 35 \mathrm{a}$ & 35 & 4000 & 35 & 4,0 & 35 & 40 & 9,0 & OSA & 3 \\
\hline $140 a$ & 25 & 900 & 40 & 1,5 & 25 & 80 & 6,5 & OSA & $3 / 10$ \\
\hline $125 a$ & 25 & 900 & 25 & 1,5 & 25 & 80 & 6,5 & $\mathrm{OSA}$ & $3 / 10$ \\
\hline L 25a & 25 & 1800 & 25 & 2,0 & 25 & 80 & 6,5 & OSA & $3 / 10$ \\
\hline M25a & 25 & 2500 & 25 & 3,0 & 25 & 80 & 6,5 & OSA & $3 / 10$ \\
\hline $\mathrm{H} 25 \mathrm{a}$ & 25 & 4000 & 25 & 4,0 & 25 & 80 & 6,5 & OSA & $3 / 10$ \\
\hline $140 \mathrm{c}$ & 25 & 900 & 40 & 1,5 & 25 & 50 & 6,5 & OSA & $3 / 10$ \\
\hline $125 \mathrm{c}$ & 25 & 900 & 25 & 1,5 & 25 & 50 & 6,5 & OSA & $3 / 10$ \\
\hline L 25c & 25 & 1800 & 25 & 2,0 & 25 & 50 & 6,5 & OSA & $3 / 10$ \\
\hline M 25c & 25 & 2500 & 25 & 3,0 & 25 & 50 & 6,5 & OSA & $3 / 10$ \\
\hline $\mathrm{H} 25 \mathrm{c}$ & 25 & 4000 & 25 & 4,0 & 25 & 50 & 6,5 & OSA & $3 / 10$ \\
\hline 130 & 15 & 900 & 30 & 1,5 & 15 & 80 & 6,5 & OSA & $3 / 10$ \\
\hline 115 & 15 & 900 & 15 & 1,5 & 15 & 80 & 6,5 & OSA & $3 / 10$ \\
\hline L 15 & 15 & 1800 & 15 & 2,0 & 15 & 80 & 6,5 & OSA & $3 / 10$ \\
\hline M15 & 15 & 2500 & 15 & 3,0 & 15 & 80 & 6,5 & OSA & $3 / 10$ \\
\hline H15 & 15 & 4000 & 15 & 4,0 & 15 & 80 & 6,5 & OSA & $3 / 10$ \\
\hline
\end{tabular}


Tabela 5: Matriz de testes da norma SAE J2765.

\begin{tabular}{|c|c|c|c|}
\hline TESTES & $\mathbf{C P}(\mathbf{r p m})$ & $\mathbf{T}_{\text {Indoor }}\left({ }^{\circ} \mathbf{C}\right)$ & $\mathbf{T}_{\text {Outdoor }}\left({ }^{\circ} \mathbf{C}\right)$ \\
\hline PSF 1ae & 900 & 0 & 0 \\
\hline PSF 2ae & 1800 & 5 & 5 \\
\hline PSF 3ae & 2500 & 10 & 10 \\
\hline PSF 1be & 900 & 0 & 0 \\
\hline PSF 2be & 1800 & 5 & 5 \\
\hline PSF 3be & 2500 & 10 & 10 \\
\hline
\end{tabular}

Tabela 6: Nomenclatura dos testes realizados com renovação de ar (OSA).

\begin{tabular}{|c|c|c|c|}
\hline TESTES & $\mathbf{C P}(\mathbf{r p m})$ & $\mathbf{T}_{\text {Indoor }}\left({ }^{\circ} \mathbf{C}\right)$ & $\mathbf{T}_{\text {Outdoor }}\left({ }^{\circ} \mathbf{C}\right)$ \\
\hline PSF Rec. 1a & 900 & 20 & $\mathbf{0}$ \\
\hline PSF Rec. 1b & 1800 & 20 & 5 \\
\hline PSF Rec. 1c & 2500 & 20 & 10 \\
\hline PSF Rec. 2a & 900 & 20 & 0 \\
\hline PSF Rec. 2b & 1800 & 20 & 5 \\
\hline PSF Rec. 2c & 2500 & 20 & 10 \\
\hline PSF Rec. 3a & 900 & 20 & 0 \\
\hline PSF Rec. 3b & 1800 & 20 & 5 \\
\hline PSF Rec. 3c & 2500 & 20 & 10 \\
\hline
\end{tabular}

Tabela 7: Nomenclatura dos testes realizados com recirculação de ar (REC).

\section{1}

\section{Aquisição de Dados}

Para a aquisição dos dados foi utilizado o sistema de aquisição de dados NI cDAQ 9178, fabricado pela National Instruments. O sistema consiste de um chassi com seis gavetas para a instalação de placas de leitura de dados (interfaces). No aparato experimental foram usadas duas placas para leitura de termopares, com dezesseis canais 
de entrada em cada placa, uma placa para leitura de transdutores de pressão com quatro canais de entrada, uma placa para leitura de célula de carga, com três canais de entrada.

O sistema citado é mostrado na figura 69 onde podem ser visualizadas as citadas placas instaladas.

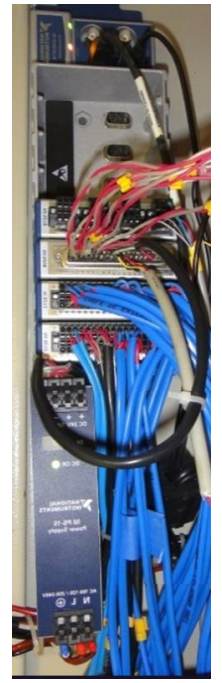

Figura 69: Sistema de aquisição de dados NI cDAQ 9178.

Para a leitura dos dados pelo sistema cDAQ, é necessário a utilização do aplicativo LabVIEW, da National Instruments. A estrutura de programação construída para a aquisição dos dados experimentais é mostrada no anexo II deste trabalho.

Uma mostra da tela de dados do aplicativo LabVIEW é mostrada na figura 70 , onde pode ser observado todas as variáveis medidas nos experimentos.

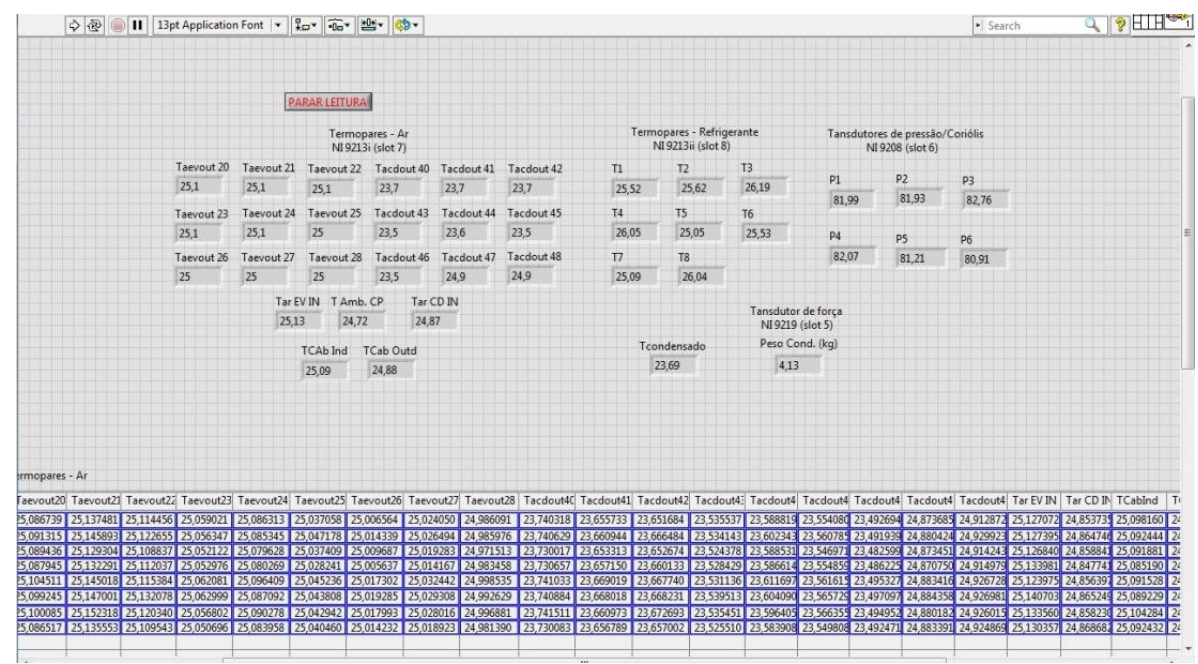

Figura 70: Tela de leitura dos dados no aplicativo labVIEW. 
Os ensaios seguiram as sequências mencionadas nas tabelas 7 a 9, por um período de tempo de trinta minutos para cada tipo de teste. Os dados adquiridos pelo sistema foram exportados para planilhas do aplicativo Excel onde foram plotados gráficos da variação dos valores das variáveis contra o tempo do ensaio. Como exemplo da metodologia utilizada para o tratamento dos dados, uma das tabelas, dos testes realizados com o sistema operando no modo ar condicionado e outra no modo bomba de calor, será mostrada a seguir pelas figuras 71 a 73 .

\begin{tabular}{|c|c|c|c|c|c|c|c|c|c|c|}
\hline CP RPM & CPI (A) & CP V(Volt) & CP Torque (N.m) & \multirow[t]{2}{*}{ Vent. Ind RPM } & \multicolumn{3}{|l|}{ Indoor Coil } & \multicolumn{2}{|c|}{$\phi$ (humid.) } & \\
\hline \multirow[t]{2}{*}{900} & 17,2 & 57 & 10,40236708 & & $\Delta \mathrm{P}-\mathrm{Hx}$ & $\triangle \mathrm{P}$-Bocal & $\Delta \mathrm{P}$-In Bocal & Montante & Jusante & $\sim \sim$ V. Face $(\mathrm{m} / \mathrm{s})$ \\
\hline & & & & 2632 & \multicolumn{2}{|l|}{1,5} & & \multicolumn{2}{|c|}{0,44} & 1,5 \\
\hline \multirow{3}{*}{$\begin{array}{r}{ }^{\Phi} \text { (humid.) Lab } \\
0,57\end{array}$} & $\operatorname{TLab}\left({ }^{\circ} \mathrm{C}\right)$ & & & \multirow{2}{*}{ Vent. Outd RPM } & Outdoor Coil & & & \multicolumn{2}{|c|}{ \$(humid.) } & \\
\hline & 26,3 & & & & $\Delta \mathrm{P}-\mathrm{Hx}$ & $\triangle$ P-Bocal & $\Delta \mathrm{P}$-In Bocal & Montante & Jusante & $\sim$ V. Face $(\mathrm{m} / \mathrm{s})$ \\
\hline & & & & 600 & 0 & & & 0,49 & 0,31 & 1,5 \\
\hline
\end{tabular}

Figura 71: Dados experimentais do ensaio de ar condicionado.

O gráfico das pressões medidas no lado do refrigerante contra o tempo total do ensaio é mostrado na figura 72. Neste experimento foram também medidos os valores do transiente de partida do sistema, as pressões P1, P2, P3, P4, P5, foram medidas nos pontos mostrados na figura 45, ou seja, P1 na sucção do compressor, P2 na descarga do compressor, P3 na entrada do condensador (AC)/saída do evaporador (BC), P4 na saída do condensador (AC)/entrada do evaporador (BC), P5 na entrada do evaporador (AC)/entrada do condensador (BC).

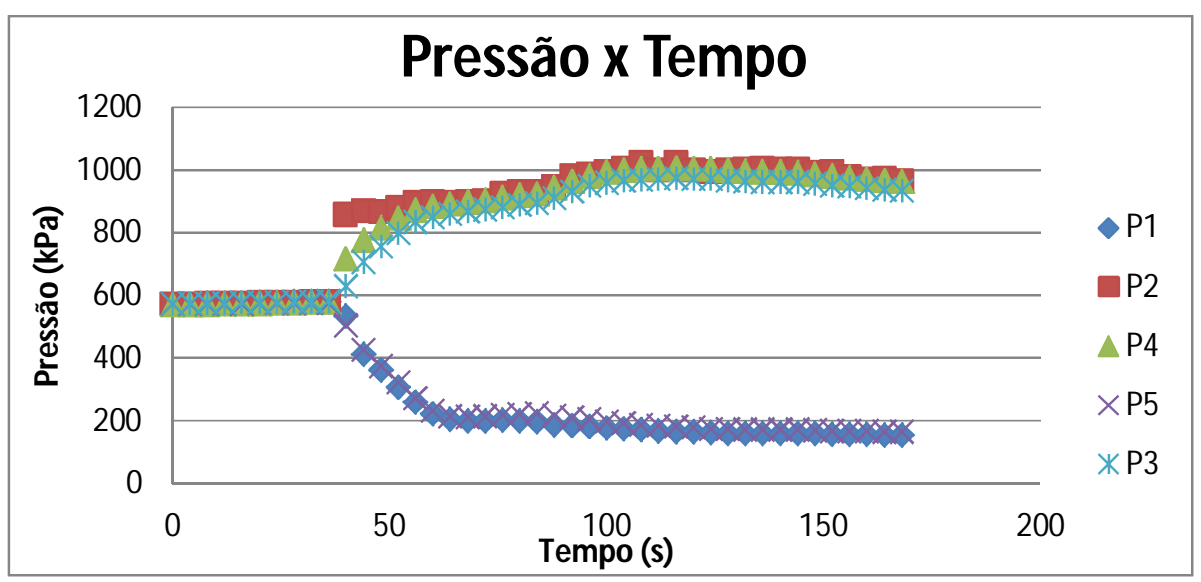

Figura 72: Pressões medidas no lado do refrigerante vs. tempo total do ensaio.

Após a construção do gráfico, era selecionado, visualmente, um período em que o sistema operou sob regime permanente, para que as médias das variáveis fossem representativas e 
utilizadas nos cálculos da redução de dados deste trabalho. A figura 73 mostra um exemplo de regime permanente utilizado no trabalho.

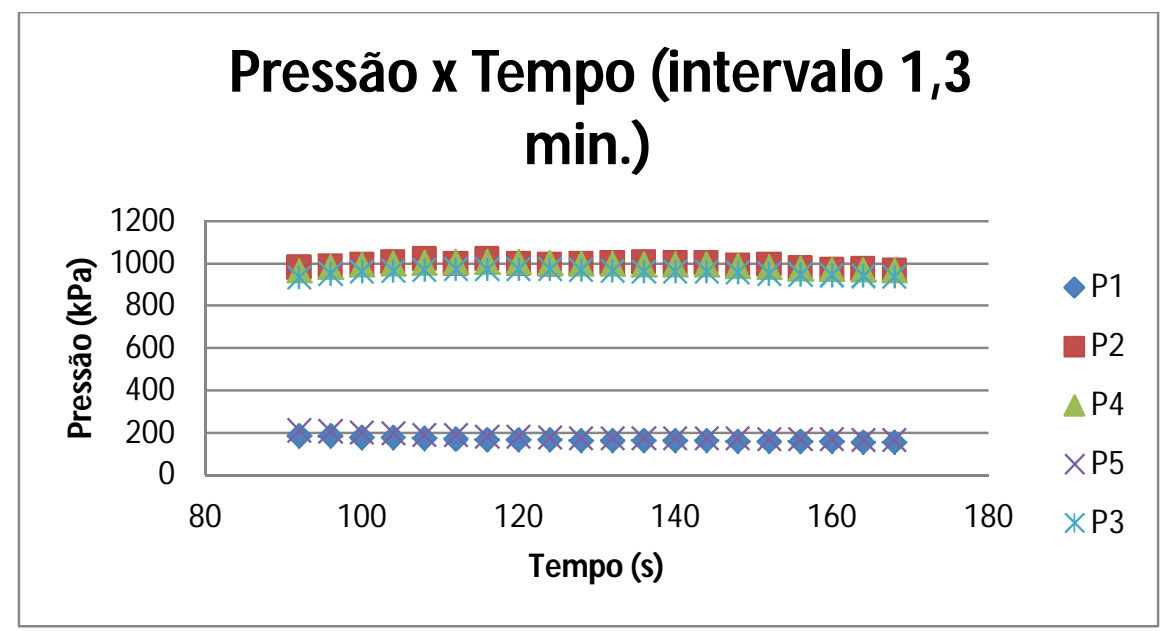

Figura 73: Pressões medidas no lado do refrigerante vs. Intervalo de tempo do ensaio em regime permanente.

As figuras 74 a 76 mostram um exemplo da metodologia utilizada quando o sistema operou como bomba de calor.

\begin{tabular}{|c|c|c|c|c|c|c|c|c|c|c|}
\hline CP RPM & CPI (A) & CP V (Volt) & CP Torque (N.m) & \multirow[t]{2}{*}{ Vent. Ind RPM } & \multicolumn{3}{|l|}{ Indoor Coil } & \multicolumn{2}{|c|}{$\phi$ (humid.) } & \\
\hline \multirow[t]{2}{*}{1800} & 14,1 & 112 & \begin{tabular}{|}
8,377916204 \\
\end{tabular} & & $\Delta \mathrm{P}-\mathrm{Hx}$ & $\triangle \mathrm{P}$-Bocal & $\Delta \mathrm{P}$-In Bocal & Montante & Jusante & ${ }^{\sim} V$. Face $(\mathrm{m} / \mathrm{s})$ \\
\hline & & & & 1500 & 1,5 & 67 & & 0,30 & 0,18 & 0,87 \\
\hline (humid.) Lab & $\operatorname{TLab}\left({ }^{\circ} \mathrm{C}\right)$ & & & Vent. Out & Outdoor Coil & & & @(hu & & \\
\hline 0,55 & 25,1 & & & & $\Delta \mathrm{P}-\mathrm{Hx}$ & $\triangle \mathrm{P}$-Bocal & $\Delta P$-In Bocal & Montante & Jusante & $\sim$ V. Face $(\mathrm{m} / \mathrm{s})$ \\
\hline
\end{tabular}

Figura 74: Dados experimentais do ensaio de bomba de calor.

A figura 75 mostra a variação das pressões do lado do refrigerante contra o tempo total do ensaio levando-se em conta o transiente de partida do sistema operando como bomba de calor.

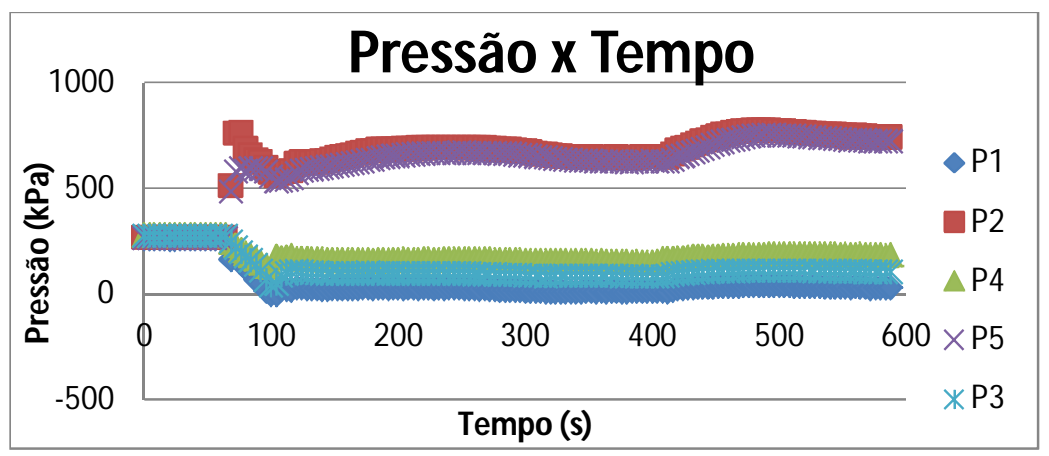

Figura 75: Pressões do lado do refrigerante vs. tempo total do ensaio com regime transiente, operando como bomba de calor. 
Como no modo de ar condicionado, um período onde o sistema trabalhou sob regime permanente foi selecionado visualmente, como mostrado pela figura 76.

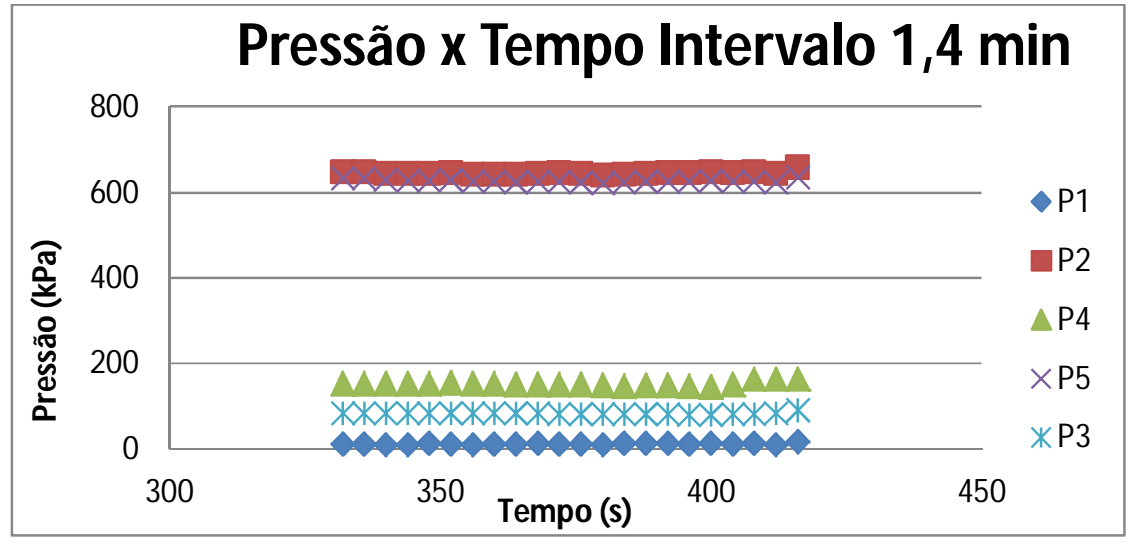

Figura 76: Pressões medidas no lado do refrigerante vs. Intervalo de tempo do ensaio em regime permanente.

\section{2 \\ Problemas Operacionais com o Aparato Experimental}

Vários foram os problemas ocorridos no aparato experimental, durante sua utilização nos testes realizados neste trabalho . Serão relatados a seguir.

a) Aproveitando a experiência adquirida no Instituto de Termodinâmica da Universidade de Braunschweig na Alemanha, foram especificadas, para a construção e montagem do aparato, conexões do tipo anilhada de dupla vedação em aço inoxidável. A tubulação que inicialmente foi especificada também em aço inoxidável se tornou inviável diante do alto custo destes produtos aqui no Brasil. Logo, como segunda opção, o aparato experimental foi construído com conexões anilhadas em latão e para a tubulação foi utilizado tubos de cobre de refrigeração doméstica e industrial.

Estes tubos possuem baixa dureza superficial, fato que causou vários problemas na vedação do sistema, pois a compressão das anilhas das conexões amassa a parede do tubo, reduzindo seu diâmetro externo e interno na região da anilha, causando vazamentos quando o sistema é pressurizado. Este problema foi solucionado com a confecção de uma ferramenta que se introduzia no interior do tubo antes da fixação da anilha. Posteriormente, esta era removida.

b) A partir do momento que o aparato entrou em funcionamento, notou-se que existia uma considerável queda de pressão do refrigerante entre a saída do evaporador e a sucção do compressor. Inicialmente, este problema foi atribuído às eletroválvulas de 
inversão do ciclo, as quais possuíam um orifício de abertura de $2 \mathrm{~mm}$ de diâmetro. Estas válvulas foram substituídas pelas válvulas do tipo esfera de acionamento manual, já mencionadas.

c) Como o sistema montado possui um número significativo de conexões, curvas e válvulas, não presentes em um sistema condicionador de ar automotivo, a carga de refrigerante não pode ser previamente estimada. Foi, então, realizado um procedimento de carga baseando-se no visor de líquido acoplado ao filtro acumulador secador. Tão logo a passagem de vapor pelo visor deixasse de ser visualizada (ausencia de bolhas), era dada como completada a carga de refrigerante, a carga de refrigerante medida foi de $1850 \mathrm{~g}$.

d) No momento em que o ciclo foi invertido para que o sistema operasse como bomba de calor, a pressão de condensação ultrapassou o valor de 300 psig, provocando o rompimento da soldagem entre as placas brasadas do originalmente "evaporador" (i.e., o trocador instalado no ambiente da cabine - "indoor") o qual, neste modo, opera como condensador, promovendo o vazamento do refrigerante. Este problema ocorreu três vezes, ou seja, durante a jornada de testes foram montados quatro evaporadores. Cabe esclarecer, novamente, que este trocador de calor é projetado para operar em baixas pressões, i.e., pressões de evaporação. No modo de operação "bomba de calor', passa a operar a altas pressões, como condensador.

e) Após a substituição do evaporador, a carga de refrigerante foi efetuada com o sistema operando no modo de bomba de calor. Porém, como o compressor já havia trabalhado sob elevada temperatura e pressão, e, provavelmente, com ingresso de líquido em alguns casos, tão logo os testes se reiniciaram ocorreu o travamento mecânico do mesmo. Novamente, o sistema necessitou ser aberto para a substituição do compressor. Este tipo de problema ocorreu durante a jornada dos ensaios por mais duas vezes, totalizando três substituições do compressor.

A causa dos problemas ocorridos com o compressor foi atribuída ao fato de que o compressor utilizado, por possuir um deslocamento reduzido, se adequando ao espaço físico de montagem, trabalhou nos ensaios com cargas térmicas superiores ao seu projeto, que é para refrigerar, e não aquecer, um veículo de pequeno porte, o Pálio, fabricado pela Fiat.

f) Durante os testes foi observada uma variação considerável na pressão de descarga do compressor, bem como nas pressões de entrada e saída do condensador, quando o sistema operava como bomba de calor. $\mathrm{O}$ fato é atribuído à modulação da válvula de expansão termostática, que também é projetada para operar antes de um 
evaporador e não de um condensador. Estes trocadores de calor possuem eficiências diferentes entre si, causando um descontrole na modulação da TXV, para garantir um grau de superaquecimento adequado, porem dependente do nível da pressão de saturação, na saída do trocador de calor.

Imagina-se que a utilização de uma válvula de expansão com controle eletrônico solucione o problema. Porém, no presente trabalho, não houve a possibilidade para a execução deste tipo de teste. 


\section{5}

\section{AQUISIÇÃO E REDUÇÃO DE DADOS}

Como já comentado nos capítulos 3 e 4 deste trabalho, a aquisição dos dados foi realizada com a utilização do sistema de aquisição de dados cDAQ fabricado pela NI.

Conforme mostrado na figura 46, os pontos de pressão medidos foram:

P1 - Pressão na sucção do compressor;

P2 - Pressão na descarga do compressor;

P3 - Pressão na entrada do condensador, modo AC e saída do evaporador, modo

$\mathrm{BC}$;

P4 - Pressão na saída do condensador, modo AC e entrada do evaporador, modo $\mathrm{BC}$;

P5 - Pressão na entrada do evaporador, modo AC e saída do condensador, modo $\mathrm{BC}$;

P6 - Pressão na saída do evaporador no modo AC e entrada do condensador, no modo BC.

Para as temperaturas do refrigerante foi seguido o mesmo critério. Os pontos do ciclo que possuem tomadas de pressão também possuem tomadas de temperaturas. Cabe informar que, para a medida de temperatura do refrigerante foram utilizados termopares do tipo $\mathrm{T}$ com haste de três milímetros de diâmetro, fabricados para tomadas em poço. Desta forma a medida de temperatura do refrigerante é realizada no próprio poço, eliminando resistências de contato na condução de calor, quando se utiliza termopares externamente aos tubos.

Para cada uma das correntes de ar, "indoor" e "outdoor", foram tomadas as seguintes medidas: velocidade de face na entrada do duto, pressão atmosférica, temperatura e umidade relativa na respectiva câmara, pressão, temperatura e umidade relativa a montante e jusante do trocador de calor. Como já explicado anteriormente, a temperatura a jusante do trocador de calor era tomada a partir da média das temperaturas em nove pontos distribuídas no mesmo plano. 
Para o compressor, tomava-se a velocidade angular, corrente e tensão no motor elétrico de acionamento, assim como a temperatura do volume de controle do compartimento do compressor.

Os dados dos ensaios aquisitados pelo sistema, perfazendo um total de 53 variáveis por corrida, eram, então, exportados para o aplicativo Excel, onde eram criadas tabelas específicas, finalmente transportadas para o aplicativo EES, com a finalidade de realizar a redução final, conforme apresentado a seguir.

\subsection{Redução dos Dados}

Para a redução dos dados medidos no aparato experimental, foi utilizado o aplicativo EES e uma nova nomenclatura própria para este fim, das grandezas medidas, foi criada.

Para tal foram utilizadas as equações fundamentais da termodinâmica e de transferência de calor, que serão mostradas a seguir.

A taxa de transferência de calor fornecida ou retirada do ambiente interno é dada pela equação que segue:

$\dot{Q}_{\text {indoor }}=\frac{\dot{m}_{a r, \text { indoor }}}{\left(1+W_{a r, \text { indoor }, I}\right)}\left[h_{\text {ar,indoor }, I I}-h_{a r, \text { indoor }, I}\right]$

onde a umidade absoluta e entalpia específica do ar úmido são determinadas a partir da pressão, temperatura e umidade relativa, com sub-rotina própria de propriedades do EES. A vazão mássica do ar é determinada a partir da massa específica do ar úmido, velocidade de face na entrada do duto e área transversal deste.

$\dot{m}_{\text {ar,indoor }}=\rho_{\text {ar,indoor }, I} V_{\text {indoor }} A_{\text {indoor }}$

Analogamente, a taxa de transferência de calor do ambiente externo é dada por:

$\dot{Q}_{\text {outdoor }}=\frac{\dot{m}_{\text {ar,outdoor }}}{\left(1+W_{\text {ar, outdoor }, I}\right)}\left[h_{\text {ar,outdoor }, I I}-h_{\text {ar,outdoor }, I}\right]$ 
A taxa de realização de trabalho do compressor, com o ciclo operando como ar condicionado ou bomba de calor, é calculada a partir da tensão e corrente medidas:

$\dot{W}_{\text {ele }}=10^{-3} I_{c p} V_{c p}$

O coeficiente de desempenho, COP, foi, neste trabalho, calculado de acordo com duas definições: baseado no consumo de energia elétrica ou aplicado ao volume de controle do refrigerante, conforme as seguintes equações:

$C O P_{\text {ele }}=\frac{\dot{Q}_{\text {indoor }}}{\dot{W}_{\text {cp ele }}}$

$C O P_{a c}=\frac{q_{e v}}{w_{c p}}=\frac{\Delta h_{e v}}{\Delta h_{c p}} \quad$ (para operação do ciclo no modo ar condicionado) (7)

$C O P_{h p}=\frac{q_{c d}}{w_{c p}}=\frac{\Delta h_{c d}}{\Delta h_{c p}} \quad$ (para operação do ciclo no modo bomba de calor)

De acordo com a definição do expoente politrópico, este é calculado a partir da pressão e volume específico do refrigerante na sucção e descarga do compressor:

$P_{1} v_{1}^{n}=P_{2} v_{2}^{n}$

A razão de pressão do compressor é calculada como:

$R_{c p}=\frac{P_{2}}{P_{1}}$ 
A eficiencia isentrópica do compressor é dada por:

$\eta_{s, c p}=\frac{h_{s, 2}-h_{1}}{h_{2}-h_{1}}$

isto é, a razão entre o trabalho isnetrópico do compressor, considerando a descarga com a memsma entropia da sucção, o trabalho adiabático com a descarga real.

A queda de pressão na linha de sucção do compressor é calculada como a diferença de pressão entre a saída do evaporador e a entrada do compressor:

$$
\begin{array}{ll}
\Delta P_{s l, a c}=P_{6}-P_{1} \quad \text { (para o modo ar condicionado) } \\
\Delta P_{s l, h p}=P_{3}-P_{1} \quad \text { (para o modo bomba de calor) }
\end{array}
$$

$\mathrm{Na}$ falta de um medidor de vazão mássica de refrigerante, esta foi calculada a partir do balanço de energia no lado do ar no condensador:

$$
\dot{m}_{r f}=\frac{\dot{Q}_{a r, c d}}{h_{3}-h_{4}}
$$

As efetividades do condensador e do evaporador foram determinadas a partir de sua definição, isto é, a razão entre a taxa real de calor trocador e a taxa máxima possível de troca de calor. Para o condensador, sem condensação da umidade do ar, tem-se:

$$
\varepsilon_{c d}=\frac{\dot{Q}_{a r, c d}}{\dot{m}_{a r, c d} c_{p, a r} \Delta T_{\text {max }, c d}}
$$

onde a diferença máxima de temperaturas é tomada entre as temperaturas de entrada do refrigerante (superaquecido) e do ar. 
Para o evaporador, levando em conta a troca de calor sensível e latente, adotou-se a seguinte definição para a entalpia:

$$
\varepsilon_{e v}=\frac{\dot{Q}_{a r, \mathrm{ev}}}{\frac{\dot{m}_{a r, \mathrm{ev}}}{\left(1+W_{a r, \mathrm{ev}, I}\right)} \Delta h_{\mathrm{max}, \mathrm{ev}}}
$$

onde a máxima diferença de entalpia é calculada entre a entalpia específica do ar úmido na entrada do trocador de calor e aquela calculada à pressão do ar a jusante do trocador de calor, temperatura igual à de entrada do refrigerante e umidade relativa igual à unidade.

\section{2}

\section{Análise das Incertezas}

\subsubsection{Introdução}

Segundo Gallas, M. R. (1998), em geral, o resultado de uma medição de uma grandeza física é apenas uma estimativa, ou aproximação do valor verdadeiro do mensurando. Como consequência desse fato, o resultado da medição somente é completo quando acompanhado do valor declarado da incerteza.

A incerteza do resultado de uma medição é composta por diversos componentes que devem ser agrupados em duas categorias, de acordo com o método utilizado para estimar seu valor numérico:

Tipo A - os que foram determinados utilizando-se a análise estatística em uma série de observações.

Tipo B - os que foram determinados por quaisquer outros meios.

\subsubsection{Avaliação da Incerteza Padrão Tipo - A}

A avaliação da incerteza padrão tipo A deve ser baseada em métodos estatísticos válidos para tratamento de dados. Por exemplo:

- Cálculo de desvio padrão da média de uma série de observações independentes;

- Utilização do método dos mínimos quadrados para ajustar uma curva aos dados a fim de estimar parâmetros da curva e seus desvios padrão; 
- Identificar e quantificar efeitos randômicos em certos tipos de medições, quando efetuando análise de variância.

\subsubsection{Avaliação da incerteza Padrão Tipo - B}

A avaliação da incerteza padrão tipo B é efetuada por outros meios que não a análise estatística de uma série de observações. É usualmente baseada em julgamentos científicos utilizando todas as informações disponíveis, que podem ser obtidas a partir de:

- Dados de medições anteriores;

- Experiência ou conhecimento geral do comportamento dos instrumentos;

- Especificações do fabricante;

- Dados provenientes de calibrações e de outros certificados;

- Incertezas atribuídas a dados de referência provenientes de manuais ou publicações;

- O equipamento que está sendo calibrado ou medido, por exemplo, sua resolução e qualquer instabilidade durante a calibração;

- Procedimentos operacionais;

- Os efeitos das condições ambientais nas informações citadas acima.

\subsubsection{Determinação da Incerteza de Medição}

De acordo com o GUM (Guia para determinação da incerteza em medição) o cálculo da incerteza em uma medição deve ser realizado empregando-se o seguinte procedimento:

a) Se possível, determine a relação matemática entre o valor estimado das grandezas de entrada e o valor estimado da grandeza de saída.

$$
y=f\left(x_{1}, x_{2}, \ldots \ldots, x_{n}\right)
$$

b) Identificar todas as correções que devem ser aplicadas aos resultados de medição de uma grandeza (mensurando) para as correções das medições. Incluído entre as grandezas de entrada xi estão além das correções ou fatores de correções, fatores que possibilitam que sejam considerados outras fontes de variabilidade tais como diferentes observadores, instrumentos, amostras, laboratórios e tempos em que as observações são feitas, por exemplo, dias diferentes. Assim, a função $(f)$ da equação acima não deve expressar uma simples lei física, mas o processo de medição e, 
em particular, ela deve contemplar todos os fatores que contribuem de forma significativa para a incerteza do resultado.

c) Listar os componentes sistemáticos de incerteza associados a erros sistemáticos corrigidos ou não, tratados como incertezas.

d) Determinar o valor da incerteza padrão para cada componente obtida da avaliação do tipo B, conforme estabelecido abaixo:

Para distribuição retangular:

$u\left(x_{i}\right)=\frac{a_{i}}{\sqrt{3}}$

Para distribuição normal:

$$
u\left(x_{i}\right)=\frac{\text { incerteza expandida }}{K}
$$

Ou refira-se a outras referencias caso as distribuições de probabilidade assumidas forem diferentes, como exemplo a Triangular.

e) Se uma incerteza de componente aleatória é significativa, faça medições repetidas para obter a média de equação:

$$
\bar{x}=\frac{1}{n} \sum_{k=1}^{n} x_{k}
$$

f) Calcule o desvio-padrão da média $[s(\bar{x})]$ :

$$
s(x)=\sqrt{\frac{\sum_{k=1}^{N}\left(x_{i}-\bar{x}\right)^{2}}{(N-1)}} \Rightarrow s(\bar{x})=\frac{s\left(x_{k}\right)}{\sqrt{N}}
$$

Ou refira-se a medições de repetitividades prévias para uma boa estimativa e $\left(x_{k}\right)$, baseado em um grande número de leituras.

g) Mesmo quando a incerteza de componente aleatória não for significativa, procure verificar a indicação do instrumento pelo menos uma vez para minimizar erros de anotação do operador.

h) Calcule a incerteza padrão para as avaliações Tipo A acima tomando como base a seguinte equação:

$$
u(x i)=s(\bar{x})
$$


i) Calcule a Incerteza Padrão Combinada para as grandezas de entrada nãocorrelatas, utilizando a equação abaixo, no caso de se utilizar valores absolutos.

$u_{c}(y)=\sqrt{\sum_{i=1}^{N} c_{i}^{2} u^{2}(x i)} \equiv \sqrt{\sum_{i=1}^{N} u_{i}^{2}(y)}$

Onde $c_{i}=\partial f / \partial x i$ ou um coeficiente conhecido

j) Sendo constatada a existência de correlação entre grandezas, deve ser utilizada a seguinte expressão:

$u_{c}(y)=\sqrt{\sum_{i=1}^{N}\left(\frac{\partial f}{\partial x i}\right)^{2} u^{2}(x i)+2 \sum_{i=1}^{N-1} \sum_{j=i+1}^{N} \frac{\partial f}{\partial x i} \frac{\partial f}{\partial x j} u(x i, x j)}$

\subsubsection{Possíveis fontes de Incerteza em calibrações de instrumentos elétricos}

- Certificado de calibração do instrumento.

- Estabilidade do instrumento.

- Condições ambientais.

- Efeitos elétricos operacionais (potência dissipada, distorção harmônica, níveis de tensão aplicados diferentes quando da calibração da referência, aquecimento, variações da rede de alimentação).

- Interpolação dos dados de Calibração.

- Resolução do instrumento.

- Configuração (lay-out) dos equipamentos (fugas para terra, loops de terra, fuga de campos eletromagnéticos).

- Força termo-eletromotriz.

- Impedância de cargas e cabos.

\subsubsection{Análise de Incertezas utilizada}

Para o cálculo das incertezas, das grandezas medidas e calculadas, neste trabalho foi utilizada a análise de incerteza baseada na expansão de Taylor com fator de confiabilidade $\mathrm{K}=2$.

As grandezas medidas foram: Temperatura $(\mathrm{T}),\left({ }^{\circ} \mathrm{C}\right)$; Pressão $(\mathrm{P}),(\mathrm{kPa})$; Velocidade de escoamento do ar nos túneis de vento $\left(\mathrm{V}_{\mathrm{f}}\right),(\mathrm{m} / \mathrm{s})$; Umidade relativa 
do ar (Hr), (\%); Tensão de alimentação do motor elétrico de acionamento do compressor (V), (Volt); Corrente elétrica consumida pelo motor elétrico (I), (A).

As grandezas calculadas foram: COP de aquecimento e refrigeração; Efetividade dos trocadores de calor; Taxa de calor fornecida e retirada do compartimento de passageiros (indoor); Taxa de calor fornecida e retirada do ambiente externo (outdoor); Trabalho do compressor; Vazão mássica de refrigerante; Expoente politrópico do compressor; Razão de compressão.

Para o cálculo das incertezas das grandezas mencionadas, na utilização da expansão de Taylor consideramos os valores das incertezas dos instrumentos, do sistema de aquisição de dados e das medições, conforme mostrado pela equação (25).

$u^{2}=u_{\text {inst. }}^{2}+u_{\text {aq. }}^{2}+u_{\text {med } .}^{2}$

As medidas de pressão e temperatura fora realizadas por meio do sistema de aquisição de dados durante 15 minutos de ensaio, conforme comentado anteriormente, logo, foi possível obter uma amostra com um número de dados considerável. Para as medidas de tensão e corrente elétrica, velocidade do ar na entrada dos túneis de vento, umidade relativa do ar, foram considerados valores médios da variação das mesmas, diante deste fato, o número de amostra por ensaio é unitário.

Deste modo o cálculo das incertezas de medição, da aquisição e da instrumentação foi dividido em duas etapas, a primeira das grandezas temperatura e pressão e a segunda das grandezas restantes.

Para o cálculo da incerteza da grandeza temperatura utilizou-se a equação (26).

$u_{T c}^{2}=\left(\frac{U_{T c}}{K}\right)^{2}+\left(\frac{U}{\sqrt{3}}\right)^{2}+\left(\frac{S}{\sqrt{N}}\right)^{2}$

Onde: $\mathrm{U}_{\mathrm{Tc}}$ é a incerteza do termopar, $\mathrm{K}$ é o coeficiente de confiabilidade, $\mathrm{U}$ é a precisão da placa de aquisição de dados, S é o desvio padrão dos dados obtidos no ensaio e $\mathrm{N}$ é o número de amostras do ensaio.

Para o cálculo da incerteza da grandeza pressão, utilizou-se a equação (27), onde $\mathrm{o}$ índice $\mathrm{T}_{\mathrm{p}}$ refere-se aos transdutores de pressão utilizados na instrumentação do aparato.

$u_{T p}^{2}=\left(\frac{U_{T p}}{K}\right)^{2}+\left(\frac{U_{p l a c a}}{\sqrt{3}}\right)^{2}+\left(\frac{S_{\text {med. }}}{\sqrt{N}}\right)^{2}$ 
Para o cálculo da incerteza das demais grandezas instrumentadas, foi utilizada a equação (28), que segue:

$u_{g}=\frac{U_{\text {Inst. }}}{\sqrt{3}}$

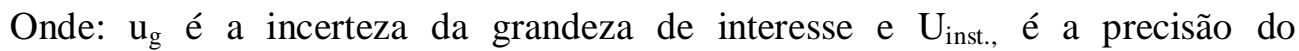
instrumento utilizado.

O cálculo das incertezas neste trabalho foi realizado com a utilização dos valores obtidos com as equações acima, juntamente com o uso do aplicativo EES, logo para as temperaturas medidas as respectivas incertezas são mostradas a seguir.

$$
\begin{aligned}
& u_{T c}=\frac{0,05}{2}=0,01^{\circ} \mathrm{C} \\
& u_{\text {placaTc }}=\frac{0,02}{\sqrt{3}}=0,011547^{\circ} \mathrm{C} \\
& u_{\text {medição }}=\frac{S}{\sqrt{N}} \square\left\{\begin{array}{l}
u_{\text {nress } \tilde{a} \Omega}=11,2741 \mathrm{kPa} \\
u_{\text {temn }}=0,2827^{\circ} \mathrm{C}
\end{array}\right.
\end{aligned}
$$

Para o cálculo de incerteza de medição das grandezas; tensão elétrica, corrente elétrica e velocidade de face do ar na entrada dos túneis de vento, a equação (28) foi utilizada, pois, os valores foram obtidos por meio de uma única medida $(\mathrm{N}=1)$.

Incerteza da tensão elétrica medida: $\quad u_{V}=\frac{1(V)}{\sqrt{3}} \quad \operatorname{logo} u_{V}=0,57735 \mathrm{~V}$

Incerteza da corrente elétrica medida: $\quad u_{I}=\frac{0,1(A)}{\sqrt{3}} \operatorname{logo} u_{I}=0,057735 A$

Incerteza da velocidade de face do ar na entrada dos túneis:

$$
u_{V f}=\frac{0,01(\mathrm{~m} / \mathrm{s})}{\sqrt{3}} \operatorname{logo} u_{V f}=0,0057735 \mathrm{~m} / \mathrm{s}
$$




\section{6 \\ RESULTADOS}

Neste capítulo serão apresentados os resultados, em forma gráfica, obtidos das equações apresentadas no capítulo anterior, Redução de Dados. Para tal foram plotados gráficos dos valores obtidos a partir dos dados experimentais medidos nos ensaios do aparato, operando nos modos ar condicionado e bomba de calor, totalizando 83 ensaios.

Inicialmente, dedicar-se-á à análise dos dados de operação no modo bomba de calor, isto é, baixas temperaturas externas e ciclo de compressão de vapor aquecendo o ar recirculante da cabine. A figura 77 mostra a variação da taxa de calor cedida pelo sistema ao ambiente interno, ou seja, à cabine de passageiros de um veículo vs. a rotação do compressor.

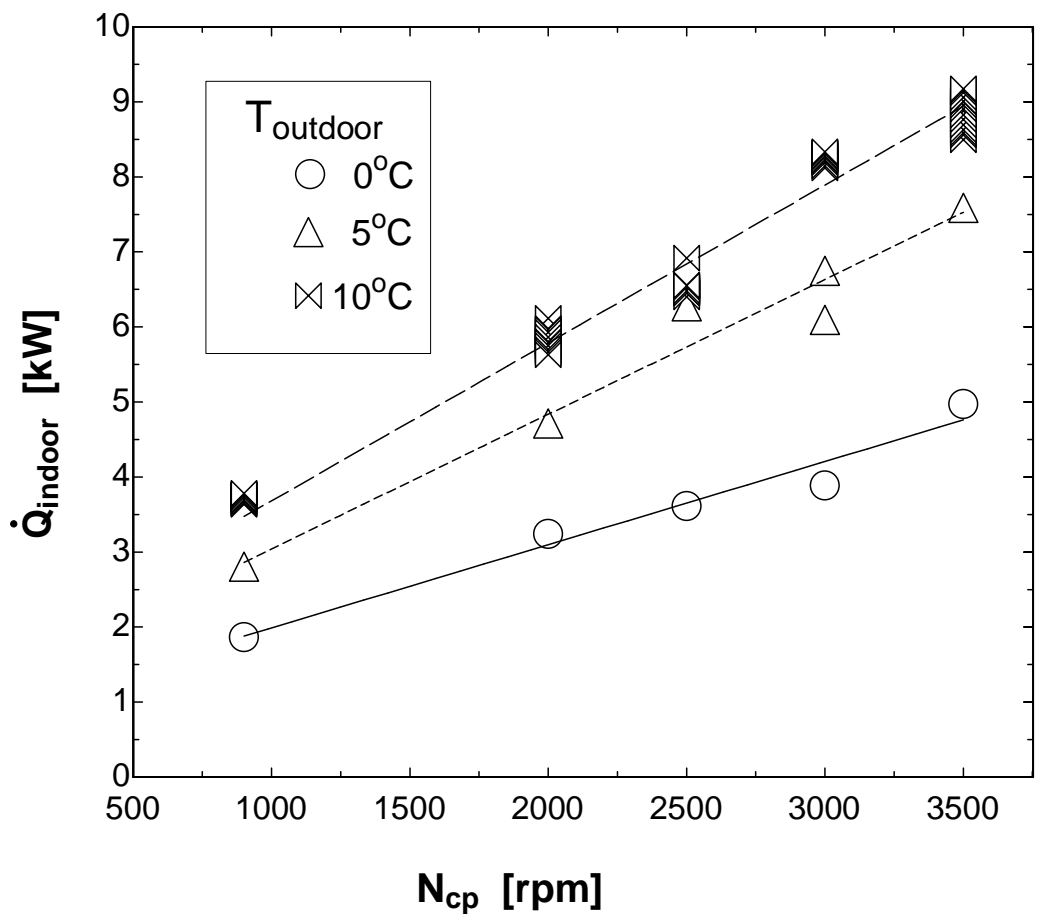

Figura 77: Variação da taxa de transferência de calor interna vs. a variação da rotação do compressor e temperatura do ambiente externo.

Observa-se que o sistema montado foi capaz de operar no modo bomba de calor, para temperaturas externas entre 10 e $0^{\circ} \mathrm{C}$, com a temperatura de cabine de $20^{\circ} \mathrm{C}$. Como em qualquer bomba de calor utilizando o ciclo de compressão de vapor, maior capacidade foi encontrada para maior rotação do compressor e menor temperatura da fonte fria. Este 
último aspecto destaca um fator limitante para o uso de bombas de calor ar-ar: sua capacidade diminui quanto mais se precisa dela, isto é, a baixas temperaturas externas.

$\mathrm{Na}$ figura 78 pode ser observada a variação do COP elétrico, calculado a partir do consumo de potência do motor elétrico de acionamento do compressor, contra a variação da rotação do compressor.

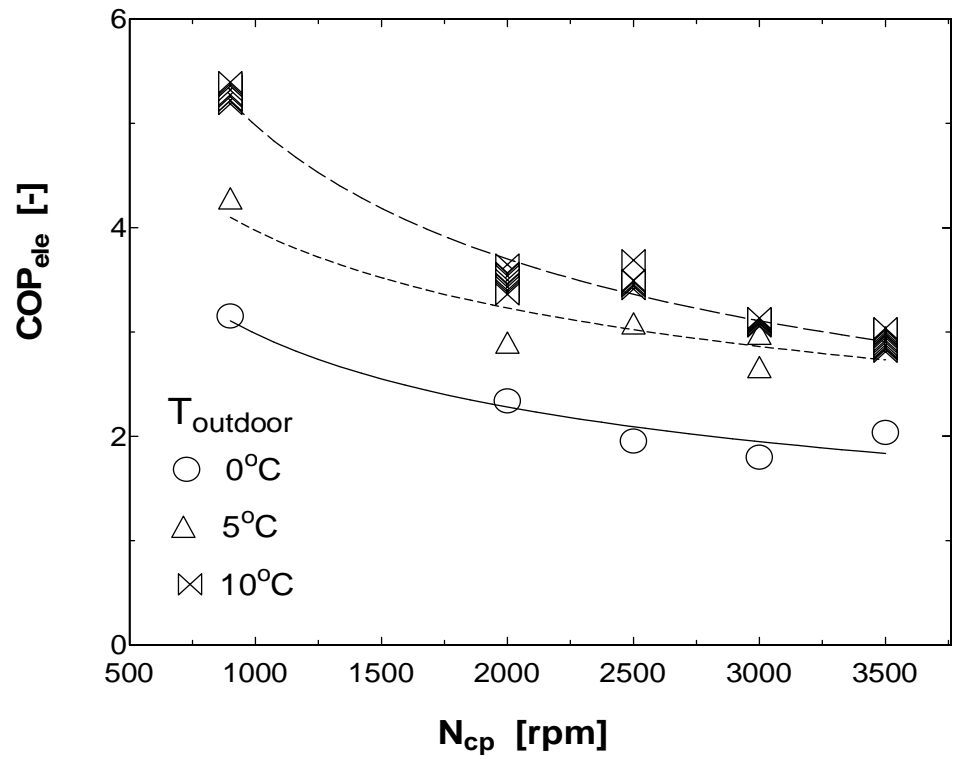

Figura 78: Variação do COP elet. vs. rotação do compressor e temperatura do ambiente externo.

De qualquer forma, a figura 78 mostra que o $\mathrm{COP}_{\text {ele }}$ é sempre superior à unidade, mostrando que mais energia térmica é fornecida para o aquecimento da cabine do que a energia elétrica é consumida. A alternativa para o aquecimento da cabine de um veículo elétrico, esgotada a recuperação do calor de rejeito do circuito da eletrônica de potência, seria um aquecedor elétrico convencional, com COP não maior do que 1. A tendência encontrada é semelhante aos resultados geralmente encontrados na literatura, por exemplo, Hozos e Direk (2006).

A figura 79 mostra a temperatura do ar de insuflamento, isto é, do ar aquecido fornecido à cabine, em função da temperatura externa e da rotação do compressor. Os valores de temperatura encontrados, entre $25^{\circ} \mathrm{C}$ e $45^{\circ} \mathrm{C}$, aproximadamente, mostram-se adequados para o aqueciemnto de um ambiente a $20^{\circ} \mathrm{C}$.

Observando-se as figuras 77 e 79 podemos notar que a capacidade da bomba de calor estudada aumenta com a rotação do compressor. Este não necessariamente necessita 
ser acionado por acoplamento ao motor de tração veicular. Assim, a rotação do compressor torna-se uma efetiva variável de controle da capacidade do sistema, ao contrário dos compressores dos veículos convencionais, que dependem da rotação do motor de combustão interna.

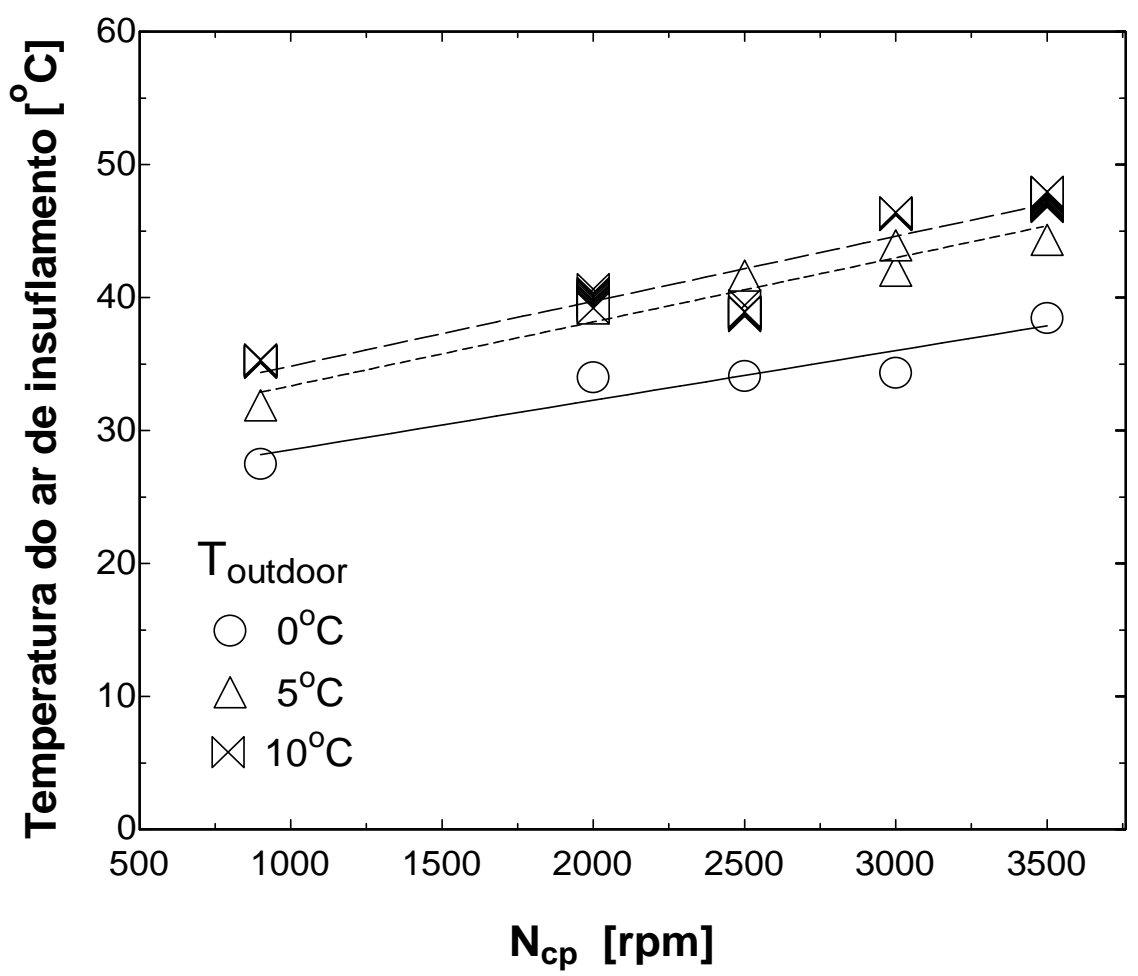

Figura 79: Variação da temperatura de insuflamento vs. rotação do compressor e temperatura do ambiente externo.

Observa-se que tendência dos pontos deste gráfico, fiura 78, é igual à tendência encontrada por Torregrossa et al. (2013).

Outra evidência de que a bomba de calor operou satisfatoriamente pode ser observado na figura 80, onde é mostrado que a temperatura do ar de saída do evaporador se mantem abaixo da temperatura do ambiente externo. O COP maior do que 1 é resultado do fato de a bomba de calor ter capacidade de remover calor da fonte fria, isto é do meio ambiente externo.

A figura 81 mostra claramente que o trabalho do compressor é pouco sensível à variação da temperatura do ambiente externo, variando mais expressivamente com sua rotação. 


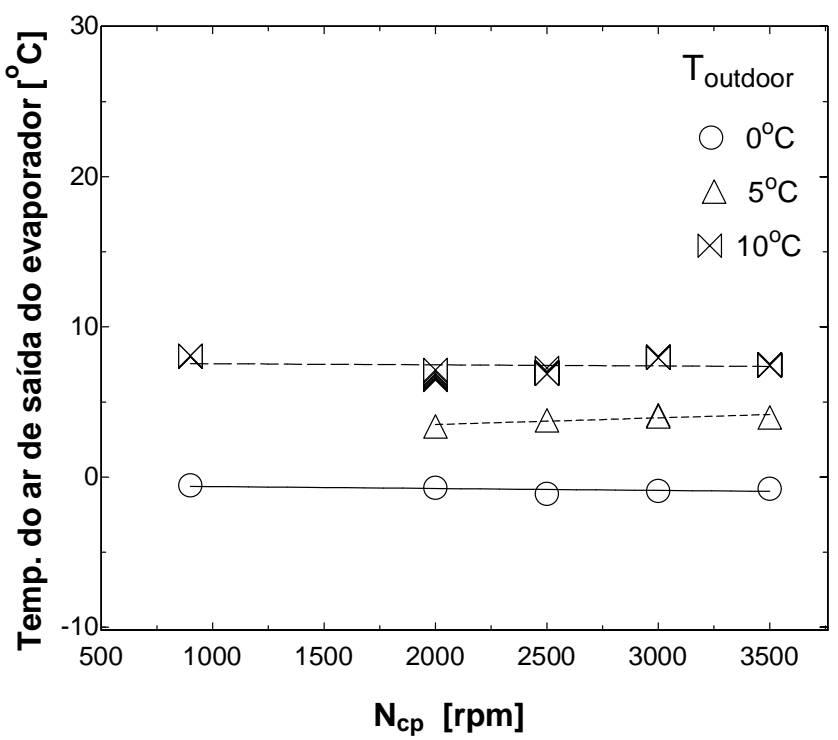

Figura 80: Variação da temperatura do ar na saída do evaporador vs. rotação do compressor e temperatura do ambiente externo.

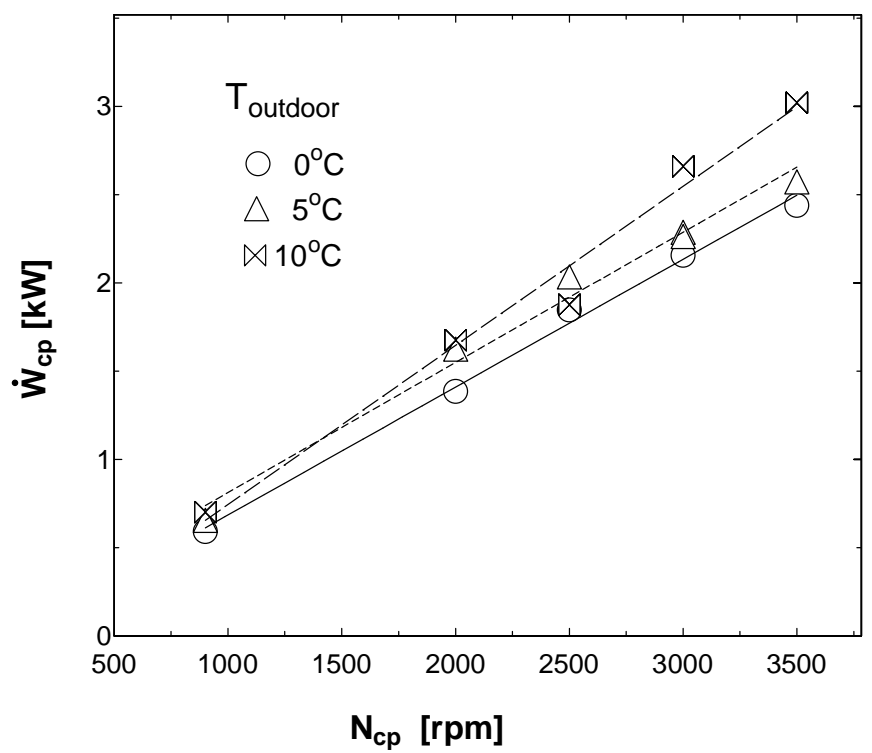

Figura 81: Variação do trabalho do compressor vs. rotação do compressor e temperatura do ambiente externo.

Na figura 82 pode ser visualizada a variação da taxa de transferência de calor no evaporador da bomba de calor. É possível notar que esta taxa é função, não somente da rotação do compressor, como também da temperatura do ambiente externo.

Mais uma vez é possível verificar que, quanto menor for a temperatura ambiente menor é a troca de calor, para baixas temperaturas ambiente a bomba de calor estudada produziu, como esperado, menor quantidade de calor. Entretanto, ocorre uma inversão 
para as temperaturas do ambiente externo de $10^{\circ} \mathrm{C}$ e $5{ }^{\circ} \mathrm{C}$, para maiores rotações do compressor. Outros fatores podem ter sido determinantes para este efeito, podendo-se citar: queda de pressão no evaporador ou coeficiente de troca de calor no lado do refrigerante, entre outros.

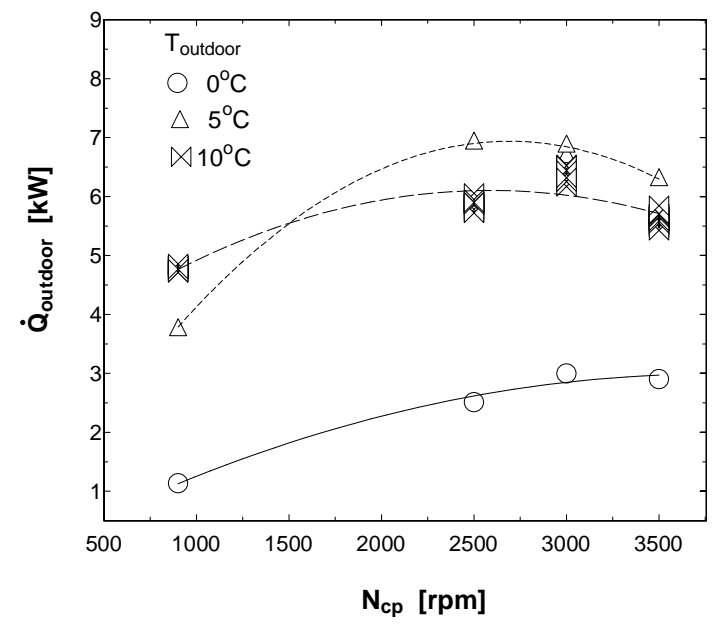

Figura 82: Variação da taxa de transferência de calor no evaporador vs. rotação do compressor e temperatura do ambiente externo.

Na figura 83 pode ser observado que o COP acompanha a tendência esperada para os sistemas de bomba de calor operando com ciclo de compressão de vapor. Quanto maior for a diferença de temperatura entre o ambiente interno e o externo, refletida na diferença entre temperaturas de condensação e de evaporação, menor será o valor do COP. Porém, cabe destacar que, em momento algum, este valor se mostrou inferior à unidade.

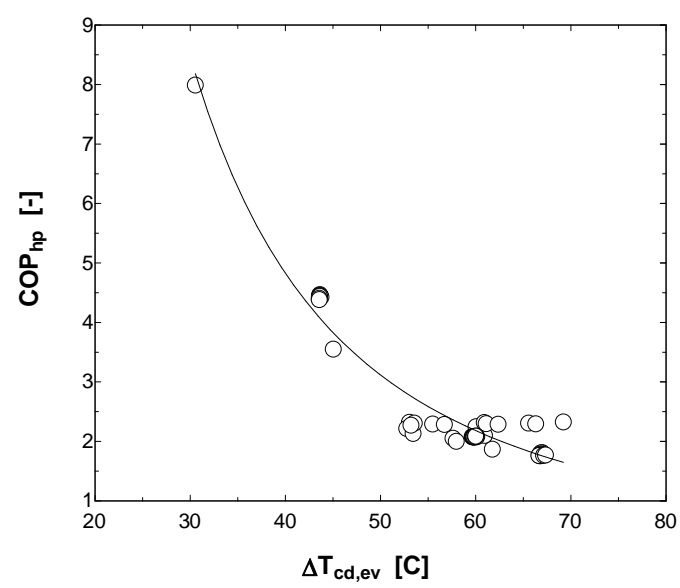

Figura 83: Variação do COP da bomba de calor vs. rotação do compressor e temperatura do ambiente externo. 
Resultados dos ensaios do aparato operando como ar condicionado, realizados neste experimento, serão a partir de agora apresentados.

A taxa de transferência de calor, no lado do evaporador, ambiente agora interno, apresentou pouca variação, indicando uma independência com a rotação do compressor bem como da temperatura do ambiente externo. A figura 84 mostra a variação da taxa de calor retirado no ambiente interno contra a rotação do compressor e temperatura do ambiente externo, encontrada nos experimentos.

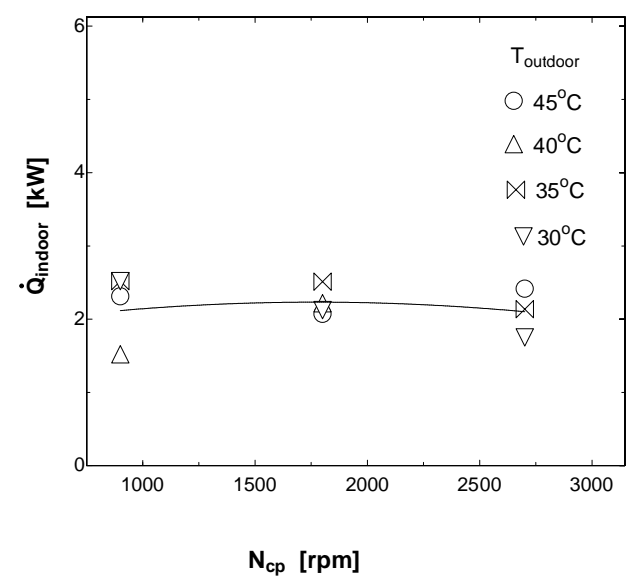

Figura 84: Variação da taxa de transferência de calor no ambiente interno vs. rotação do compressor e temperatura do ambiente externo.

Já a taxa de transferência de calor do lado do condensador, agora no ambiente externo à cabine, apresentou variações significativas, tão somente com a rotação do compressor, mostrando ser pouco sensível à variação da temperatura externa, figura 85 .

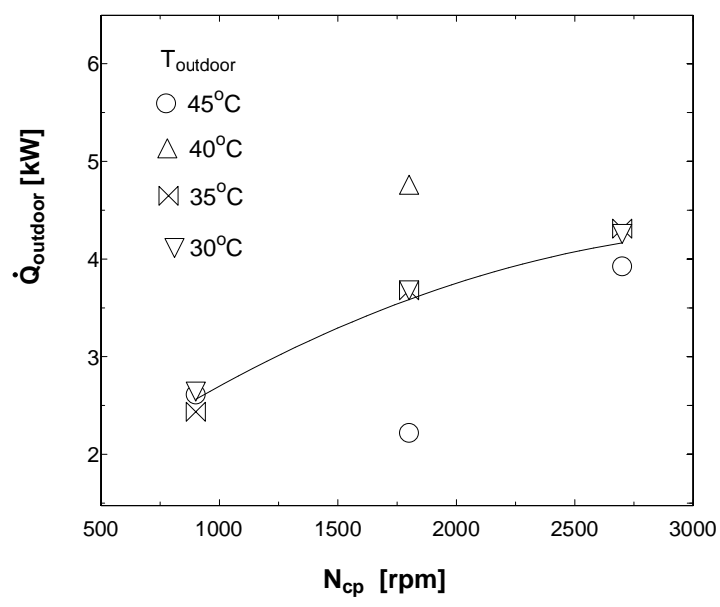

Figura 85: Variação da taxa de transferência de calor do condensador vs. rotação do compressor e temperatura ambiente. 
A figura 86 mostra que, também para o sistema operando como ar condicionado, o COP segue a tendência esperada, da mesma forma quando o sistema trabalhou no modo bomba de calor.

De modo análogo à bomba de calor, quando a diferença de temperatura entre o ambiente externo e o interno aumenta o desempenho do sistema decresce. Porém, mais uma vez lembramos que o COP permaneceu acima da unidade em todos os experimentos, indicando que o sistema funcionou como esperado.

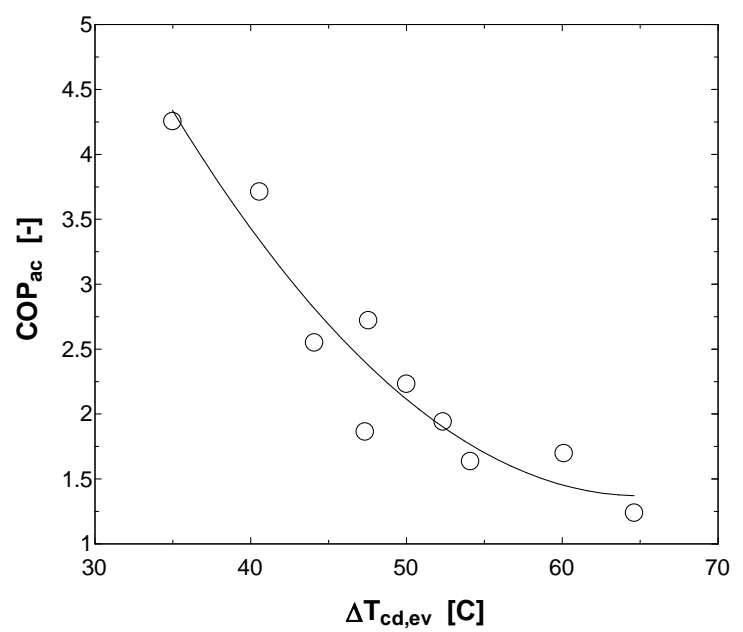

Figura 86: Variação do COP vs. diferença de temperatura entre o condensador e o evaporador.

A figuras 87 e 88 mostram a variação da diferença de temperatura do ar através do trocador de calor, neste caso o evaporador, e a taxa de transferência de calor no condensador.

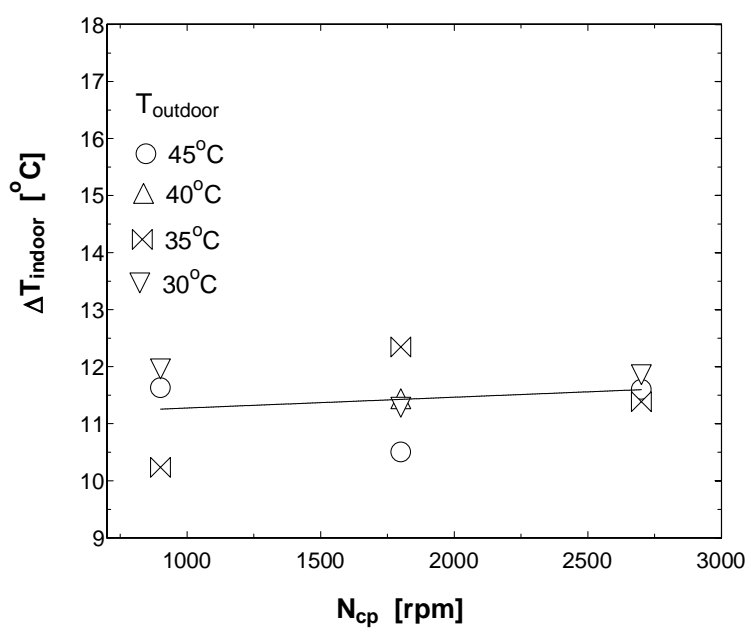

Figura 87: Variação da temperatura do ar através do evaporador vs. rotação do compressor e temperatura do ar do ambiente externo. 


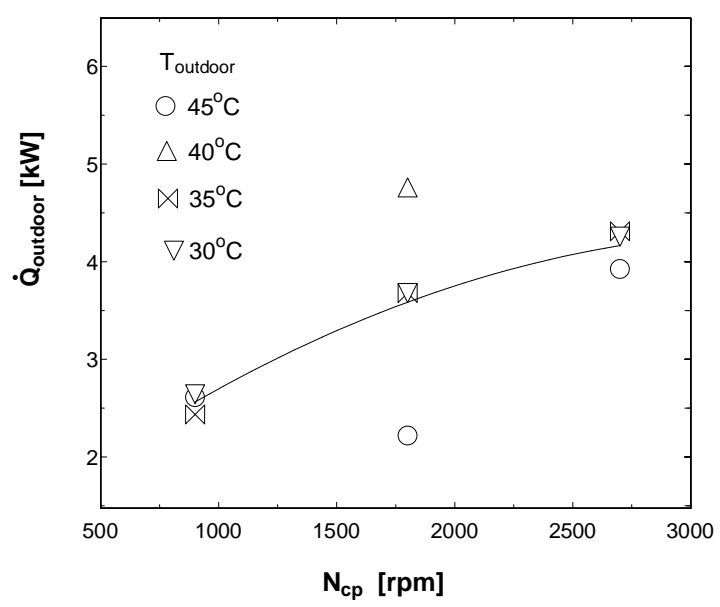

Figura 88: Taxa de transferência de calor para o ar do condensador, vs. rotação do compressor e temperatura do ar do ambiente externo.

Neste caso podemos observar que o sistema, mais uma vez se comportou como esperado, pois com o aumento da rotação do compressor a taxa de troca de calor aumenta com o aumento da rotação do compressor e ainda mostra que a variação da taxa de transferência de calor é pouco sensível as variações da temperatura do ambiente externo.

A figura 89 mostra a variação da taxa de trabalho do compressor com sua rotação e com a temperatura do ambiente externo, quando o sistema opera como ar condicionado. Mais uma vez, podemos notar que o sistema funcionou como esperado pois o trabalho aumenta com o aumento da rotação e temperatura do ambiente externo.

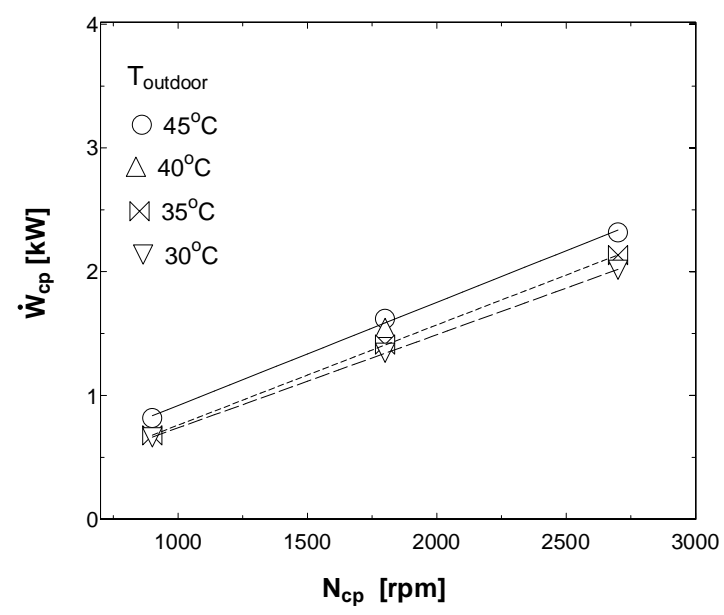

Figura 89: Trabalho do compressor, vs. rotação e temperatura do ambiente externo.

Neste trabalho, os componentes do sistema também foram analisados individualmente. A seguir serão mostrados os estudos realizados sobre comportamento do compressor. 
A figura 90 mostra que o comportamento do compressor tanto para as operações como bomba de calor quanto para ar condicionado permaneceu praticamente inalterado, nos permitindo afirmar que o compressor não é sensível ao modo de operação do sistema, ou seja, não "reconhece" quando o sistema opera no modo bomba de calor ou ar condicionado.

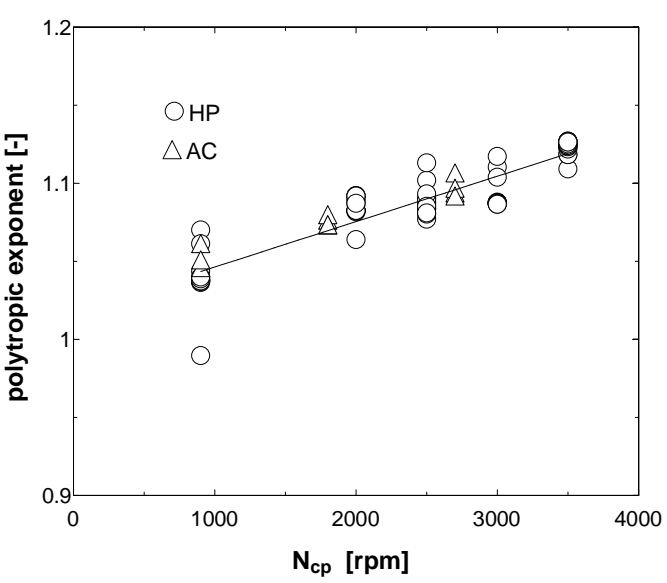

Figura 90: Variação do expoente politrópico do compressor vs. rotação do compressor e temperatura do ambiente externo.

O mesmo comportamento do compressor é verificado na figura 91, que mostra a variação do expoente politrópico do compressor contra a variação da razão de compressão. Igualmente à figura 89 o compressor não é sensibilizado pelo tipo de operação do ciclo, ou seja, bomba de calor ou ar condicionado.

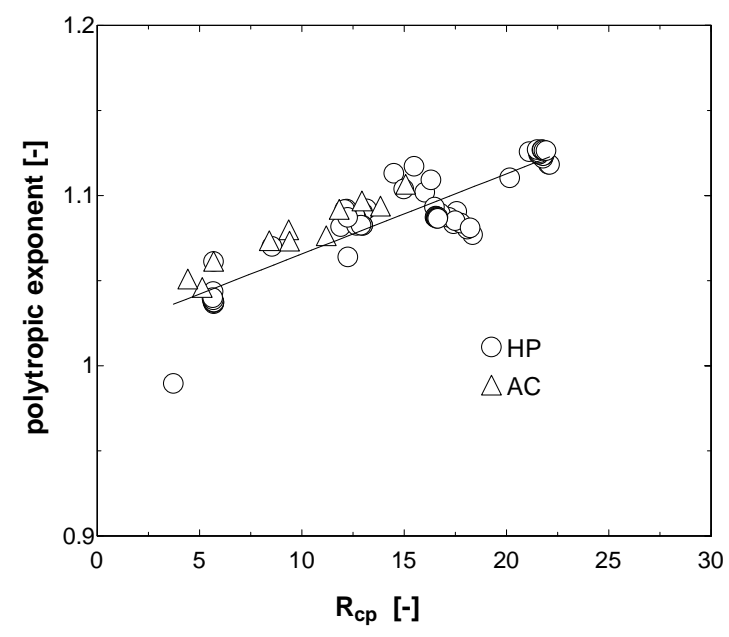

Figura 91: variação do expoente politrópico do compressor vs. razão de compressão do compressor e temperatura do ambiente externo.

A figura 92 mostra a variação da eficiência isentrópica do compressor contra a razão de compressão, com o sistema operando como bomba de calor e ar condicionado. 
Os testes foram realizados com o sistema operando sob variadas temperaturas do ambiente externo.

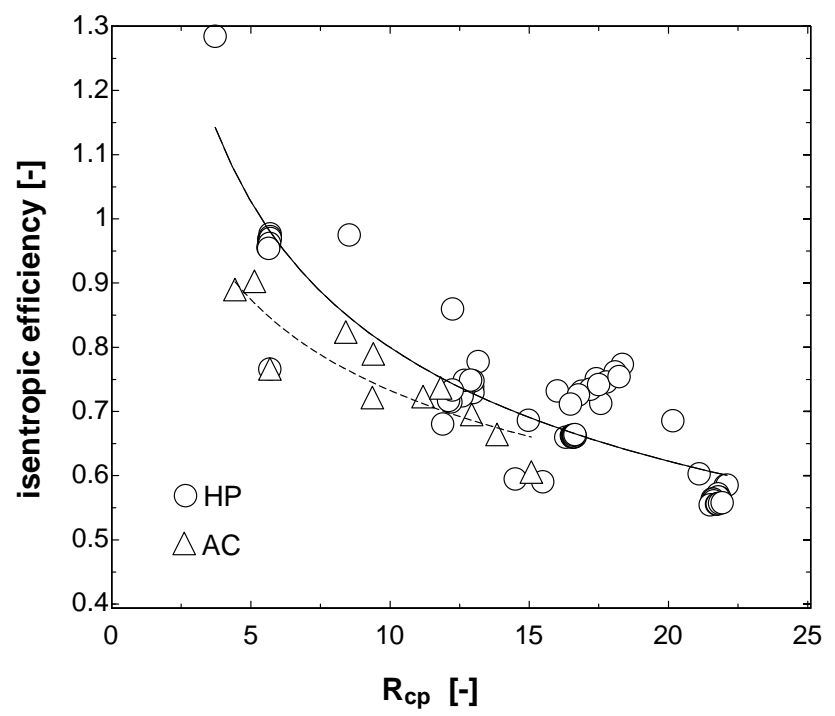

Figura 92: Variação da eficiência isentrópica do compressor vs. razão de compressão e temperatura do ambiente externo.

$\mathrm{Na}$ figura 92 pode ser visualizado um ponto com eficiência isentrópica superior à unidade. Este fato pode ser atribuído a uma situação onde a compressão tenha ocorrido com grande perda de calor, promovendo uma entalpia de descarga inferior à isentrópica.

A figura 93 mostra a variação da queda de pressão na linha de sucção do ciclo contra a rotação do compressor e temperatura do ambiente externo.

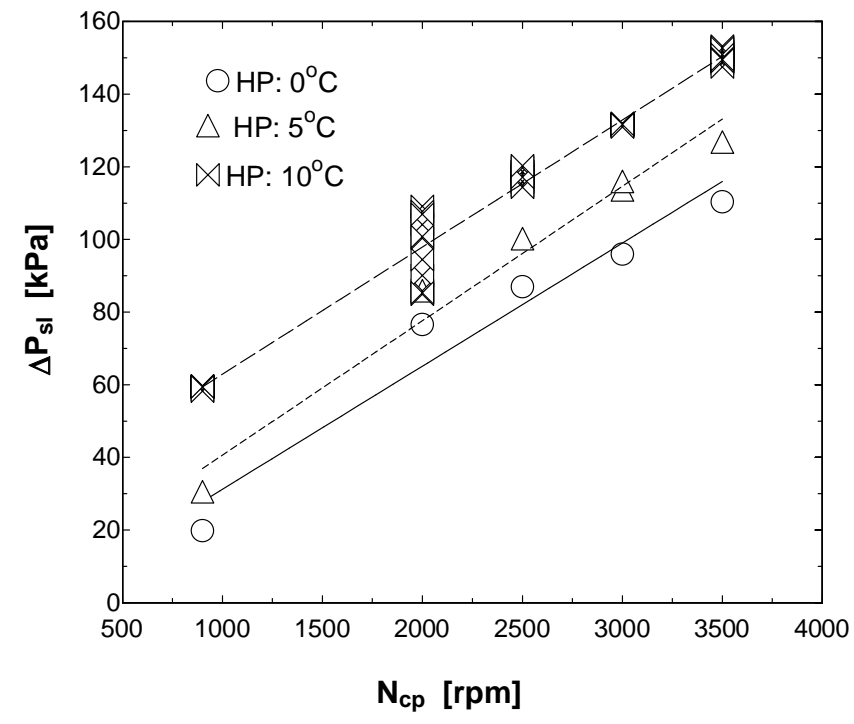

Figura 93: Variação da queda de pressão na linha de sucção vs. rotação do compressor e temperatura do ambiente externo. 
Como esperado, a queda de pressão na linha de sucção aumenta com a rotação do compressor e temperatura do ambiente externo, quando o sistema opera como bomba de calor. Cabe aqui lembrar que o ciclo estudado possui quatro válvulas unidirecionais ("check valve"), que causam restrições ao fluxo do refrigerante. O possível motivo de se observar elevadas quedas de pressões é a restrição causada por tais válvulas, que se encontram montadas na citada linha.

Igualmente mostrado na figura 94, quando o sistema opera como ar condicionado, nos deparamos com altas quedas de pressão na linha de suç̧ão quando a rotação do compressor aumenta. Porém, quando o sistema opera como ar condicionado a temperatura do ambiente externo não interfere na variação da queda de pressão.

Da mesma forma que no caso anterior, o possível fator que eleva a queda de pressão pode ser atribuído às válvulas unidirecionais ("check valve") que se encontram montadas nesta linha.

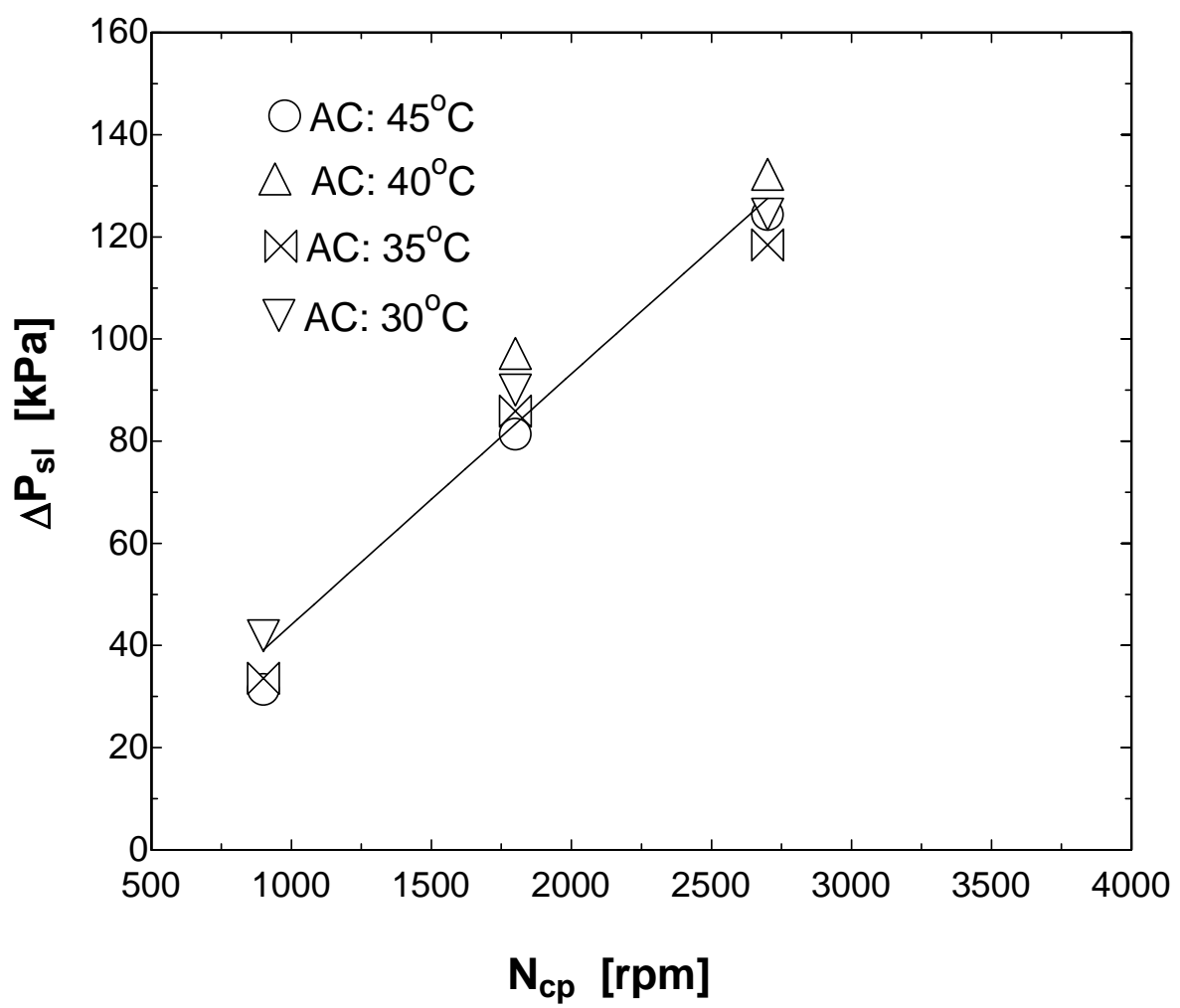

Figura 94: Variação da queda de pressão na linha de sucção vs. rotação do compressor e temperatura do ambiente externo. 
A efetividade dos trocadores de calor, do aparato experimental, foi estudada, com o ciclo operando como bomba de calor e como ar condicionado. Os resultados da variação da efetividade contra rotação do compressor e temperatura do ambiente externo são mostrados nas figuras 95 e 96, a seguir.

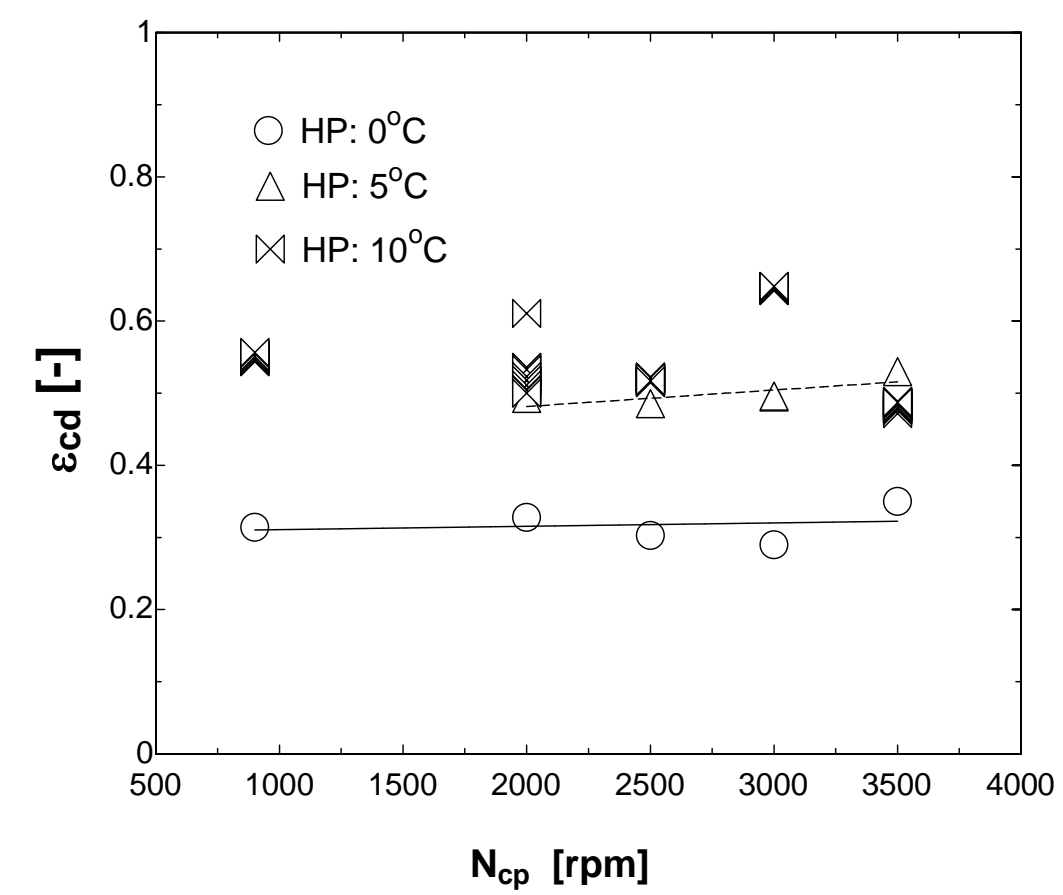

Figura 95: Variação da efetividade do trocador indoor vs. rotação do compressor e temperatura do ambiente externo.

Analisando-se a figura 96 podemos verificar que o comportamento da efetividade do trocador de calor "outdoor", quando o sistema opera como bomba de calor, permanece praticamente constante em relação à rotação do compressor, com exceção dos testes realizados com temperatura do ambiente externo de $10^{\circ} \mathrm{C}$, quando o sistema mostrou maior sensibilidade à variação da temperatura do ambiente externo. 


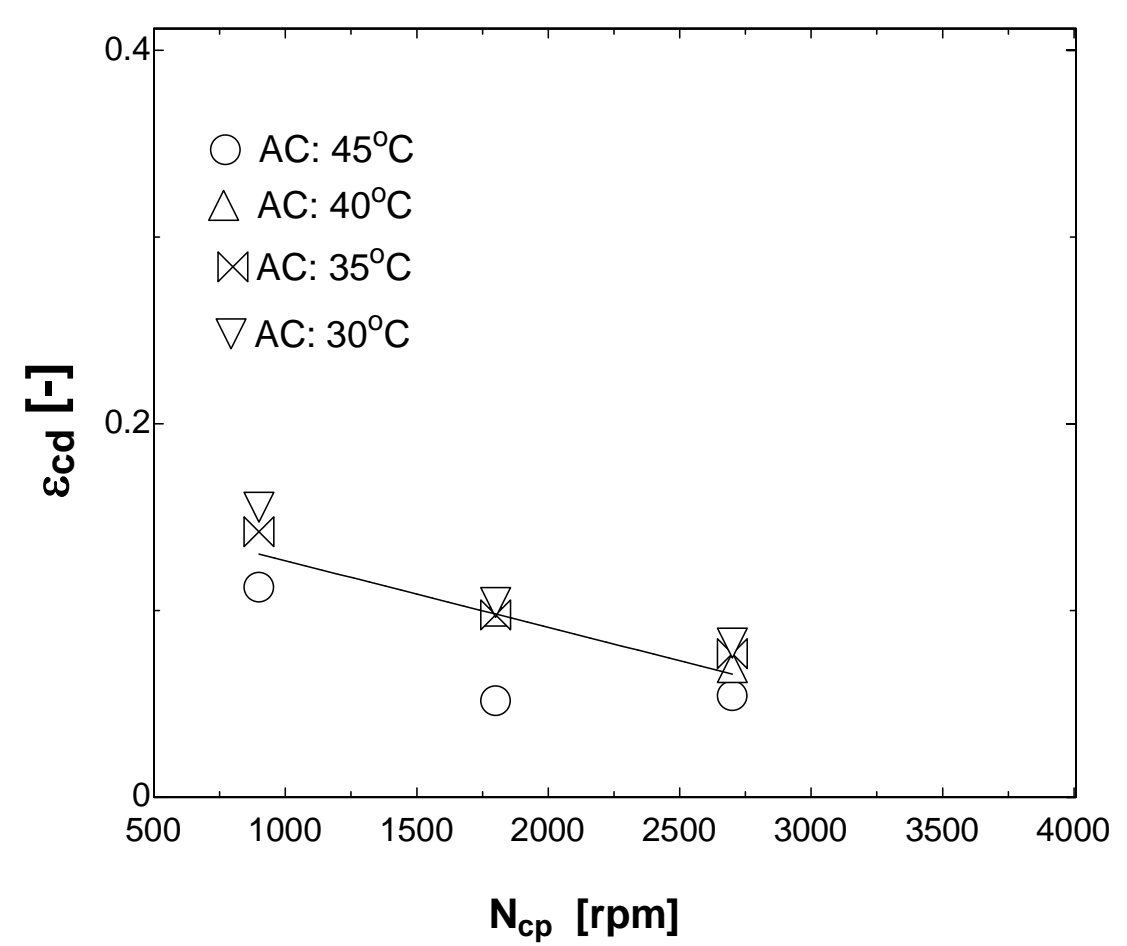

Figura 96: Variação da efetividade do trocador outdoor vs. rotação do compressor e temperatura do ambiente externo.

Porém, quando o sistema operou como ar condicionado foi notada uma variação na efetividade deste trocador de calor, decrescendo com a rotação do compressor, e sofrendo uma influência quase nula com o efeito da temperatura do ambiente externo.

Este fato pode ser atribuído à queda de pressão, do lado do refrigerante, ocorridas durante os testes, bem como ao efeito da modulação de abertura da válvula de expansão termostática, conforme pode ser visualizado nas figuras 95, quando o sistema trabalhou como bomba de calor e 96 , com o sistema operando no modo ar condicionado.

Nas figuras 97 e 98, pode ser observado que a queda de pressão no trocador de calor é sensível à rotação do compressor, bem como à variação da temperatura do ambiente externo, atingindo valores superiores a $100 \mathrm{kPa}$, fato este que influencia diretamente as variações da efetividade deste trocador de calor, como mostradas nas figuras 95 e 96. 


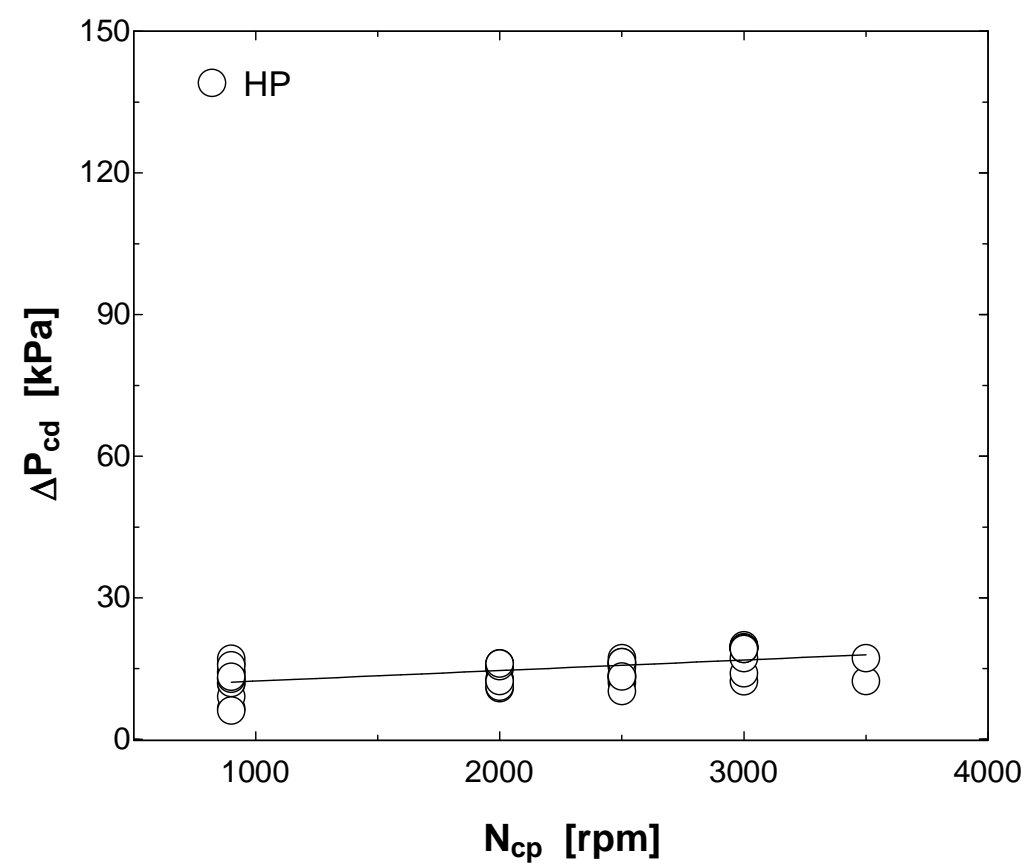

Figura 97: Variação da queda de pressão no condensador vs. rotação do compressor e temperatura do ambiente externo, sistema operando como bomba de calor.

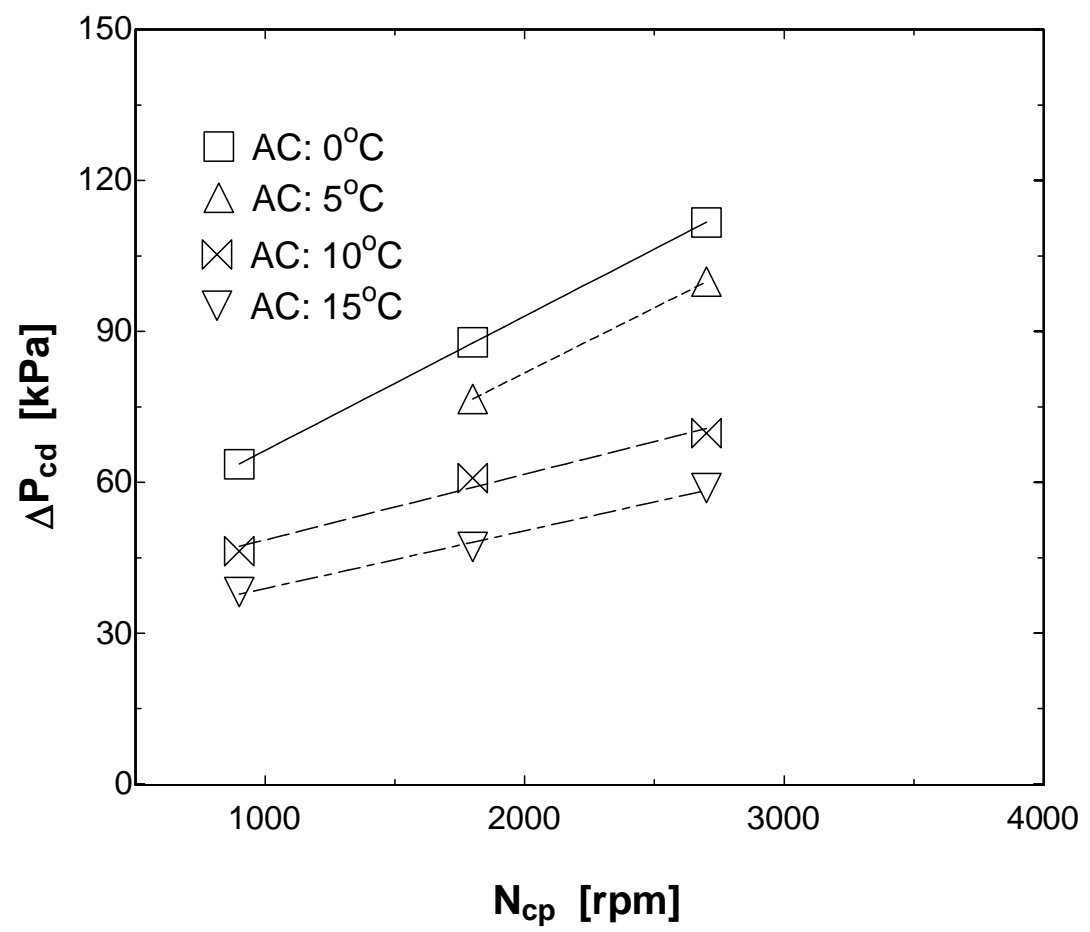

Figura 98: Variação da queda de pressão no condensador vs. rotação do compressor e temperatura do ambiente externo, sistema operando como ar condicionado. 
No evaporador, as variações da efetividade contra a rotação do compressor e temperatura do ambiente externo, com o sistema operando no modo bomba de calor e no modo de ar condicionado são mostradas pelas figuras 99 e 100, respectivamente.

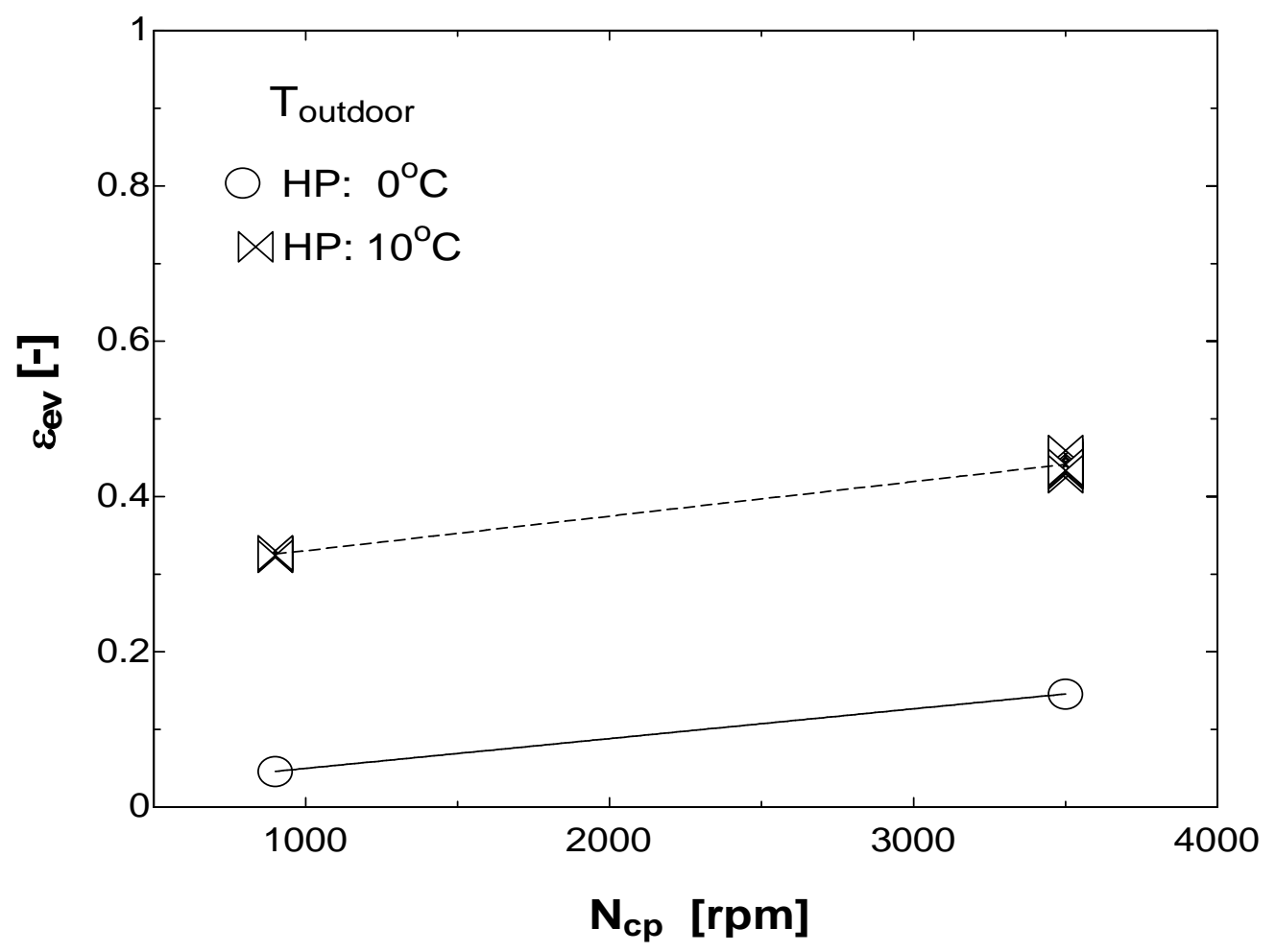

Figura 99: Variação da efetividade do evaporador no modo bomba de calor vs. rotação do compressor e temperatura do ambiente externo.

No modo bomba de calor, a efetividade do evaporador seguiu uma tendência esperada, mostrando que o sistema funcionou satisfatoriamente, ou seja, rejeitou o calor retirado do ambiente externo a baixa temperatura transferindo-o para o ar do ambiente interno. Nota-se que a efetividade é função da temperatura do ambiente externo: quanto mais baixa for esta temperatura, menor é a efetividade do trocador de calor.

O fato dos baixos valores das efetividades encontradas pode ser atribuído à questão já abordada, pois o trocador utilizado como evaporador é projetado para atuar como condensador. 
Quando o sistema opera como ar condicionado, a efetividade do trocador de calor se mostrou mais elevada, pois mais uma vez pode ser afirmado que o trocador de calor utilizado para este modo de operação, é realmente um evaporador.

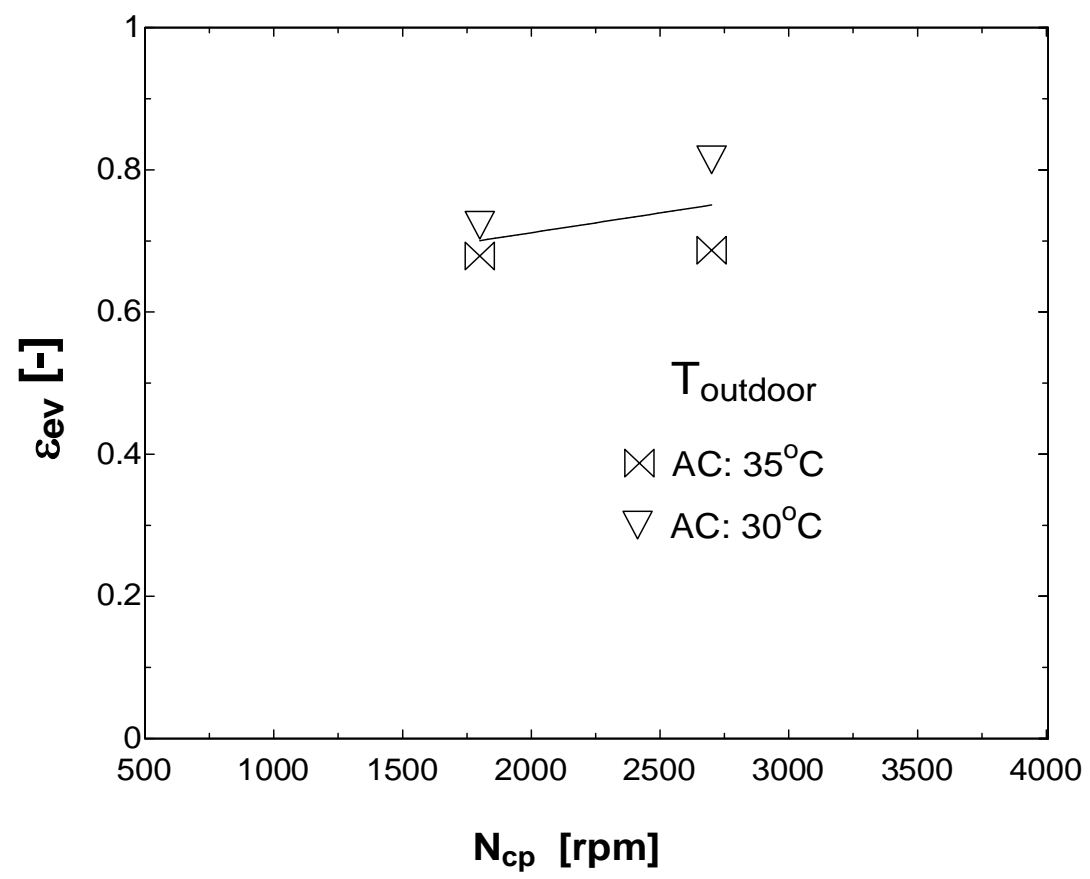

Figura 100: Variação da efetividade do evaporador no modo ar condicionado vs. rotação do compressor e temperatura do ambiente externo.

As variações da queda de pressão no evaporador, quando o sistema operou como bomba de calor e ar condicionado, avaliadas neste trabalho, são mostradas nas figuras 101 e 102, que seguem. 


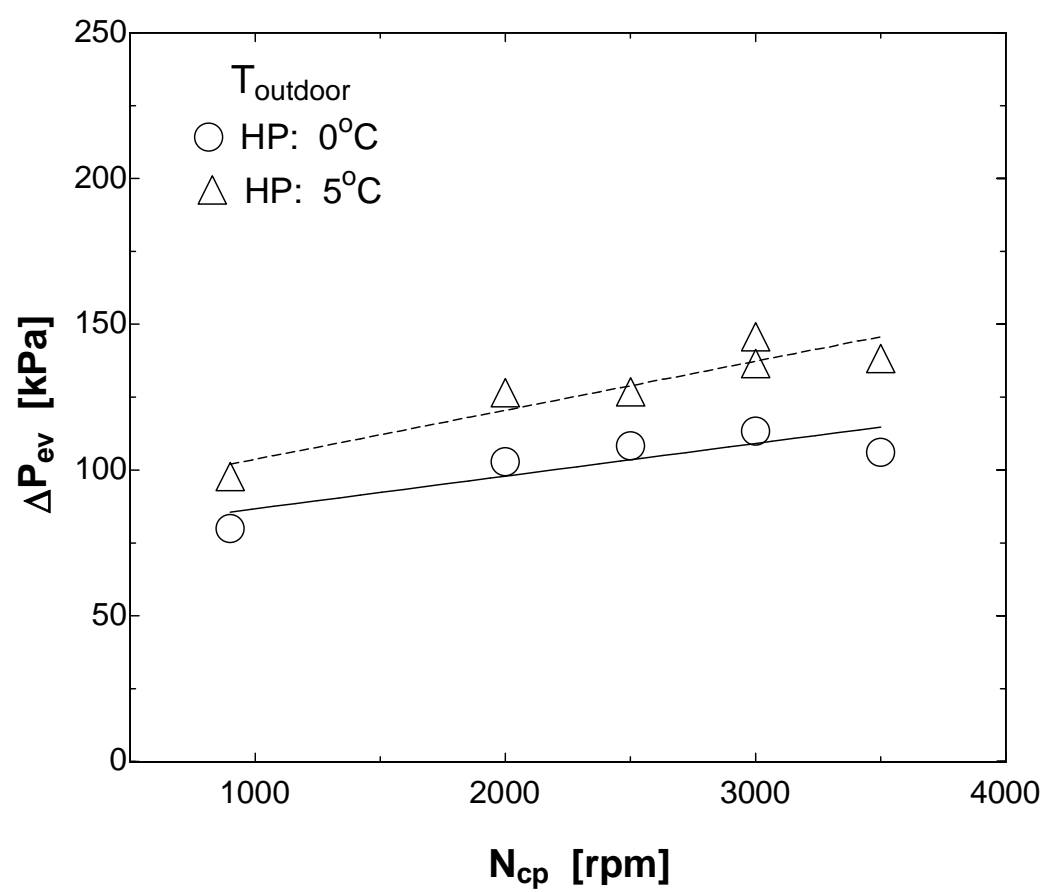

Figura 101: Variação da queda de pressão no evaporador no modo bomba de calor vs. rotação do compressor e temperatura do ambiente externo.

É possível notar que a queda de pressão neste trocador operando como condensador da bomba de calor é sensível tanto à rotação do compressor como à variação da temperatura do ambiente externo, seguindo uma tendência esperada, ou seja, sofrendo um aumento em função da rotação do compressor e da temperatura do ambiente externo, pois se trata de um trocador de calor de placa brasada e aletas, com micro canais para o fluxo do refrigerante.

A figura 102 mostra a mesma tendência de variação da queda de pressão em função da rotação do compressor e da temperatura do ambiente externo, quando o sistema opera como ar condicionado. 


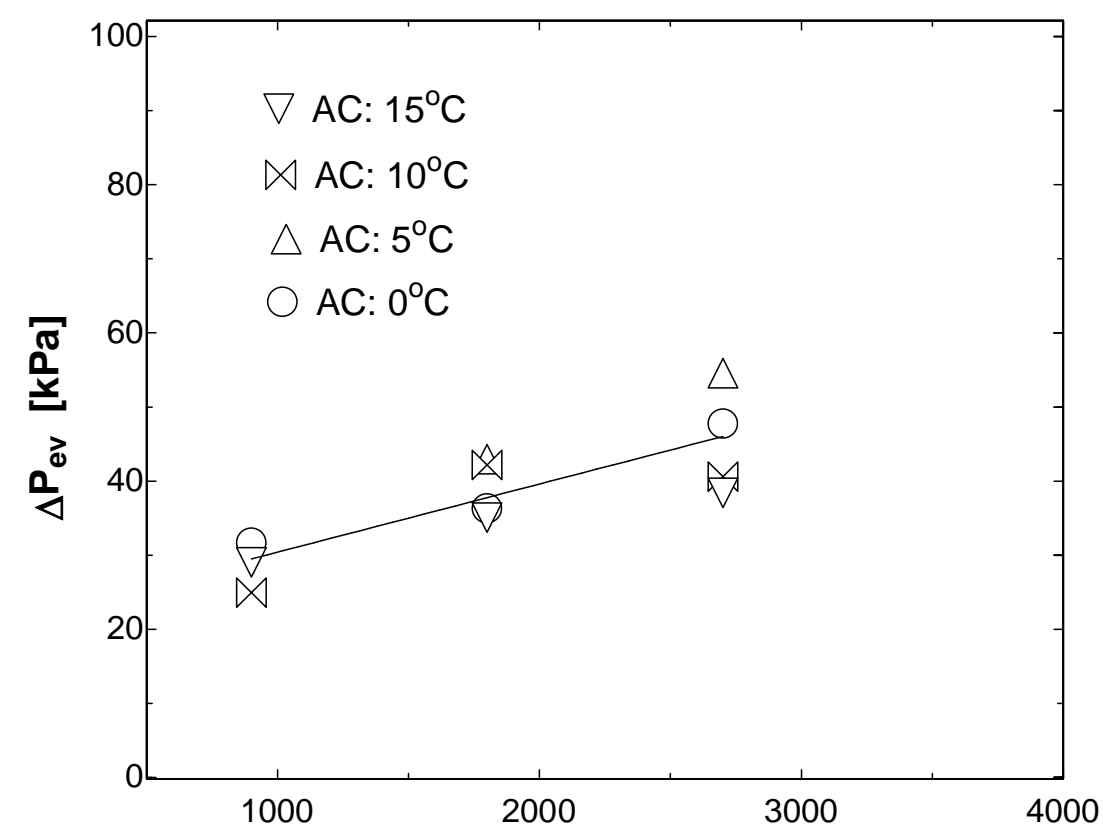

$\mathbf{N}_{\mathrm{cp}}[\mathrm{rpm}]$

Figura 102: Variação da queda de pressão no evaporador no modo ar condicionado vs. rotação do compressor e temperatura do ambiente externo.

É possível notar, como esperado, que os valores de queda apresentados são inferiores aos valores quando o sistema operou como bomba de calor, pois na função ar condicionado este trocador de calor está submetido a baixas pressões da linha de sucção do compressor. Já no caso anterior, o trocador de calor está submetido a pressões elevadas da linha de descarga do compressor.

O sistema apresentou uma variação não esperada da queda de pressão deste trocador de calor, quando trabalhou no modo bomba de calor e a temperatura do ambiente externo era de $10^{\circ} \mathrm{C}$. A figura 103 mostra a citada variação, quando foram analisados dez pontos de um período de 40 segundos de teste. 


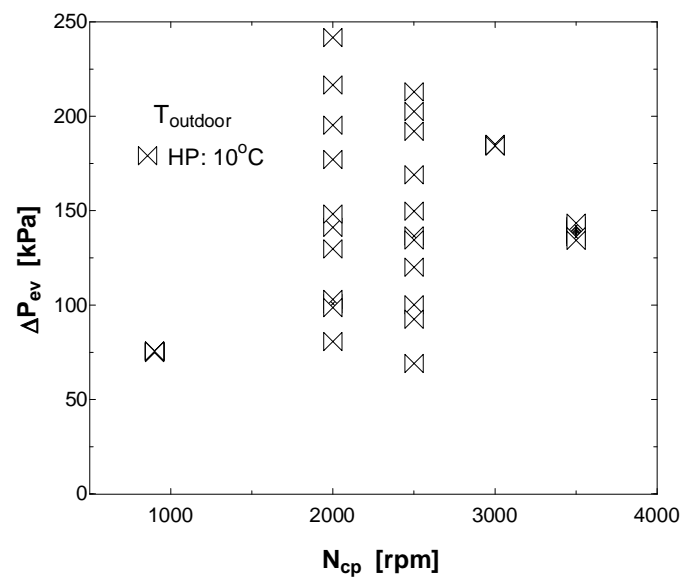

Figura 103: Variação da queda de pressão no trocador indoor vs. rotação do compressor com temperatura do ambiente externo de $10^{\circ} \mathrm{C}$.

Uma possível causa do efeito mostrado na figura 102 é a modulação da válvula TXV instalada no trocador de calor "outdoor". Tais válvulas são calibradas para operarem com um evaporador e não com um condensador que na bomba de calor, possui a função de evaporador. Imagina-se que uma válvula de expansão termostática de controle eletrônico venha atenuar satisfatoriamente este efeito apresentado.

Com o sistema operando como ar condicionado, as pressões de entrada no evaporador P4, (representada como P8) a de saída do evaporador P3, (representada como P10) e a sucção do compressor P1, foram plotadas contra o tempo. A figura 104 mostra a variação das pressões mencionadas contra o tempo. Uma possível causa das pressões apresentarem uma variação independente e defasada é o acúmulo de líquido no trocador de calor.

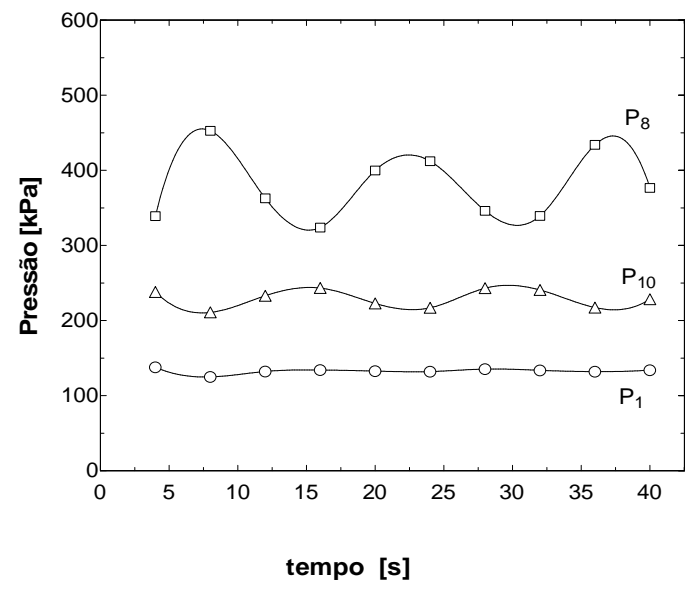

Figura 104: Variação das pressões vs. tempo de ensaio em segundos. 
A figura 105 mostra as variações das pressões na entrada e saída do condensador e sucção do compressor, quando o sistema operou nas mesmas condições do caso anterior. É possível verificar que apesar das pressões sofrerem variação, descaracterizando um regime permanente, as variações das pressões possuem um mesmo comportamento. Neste caso pode-se inferir que não houve acumulo de liquido no interior do trocador de calor, ou seja, o trocador trabalhou em melhores condições de desempenho.

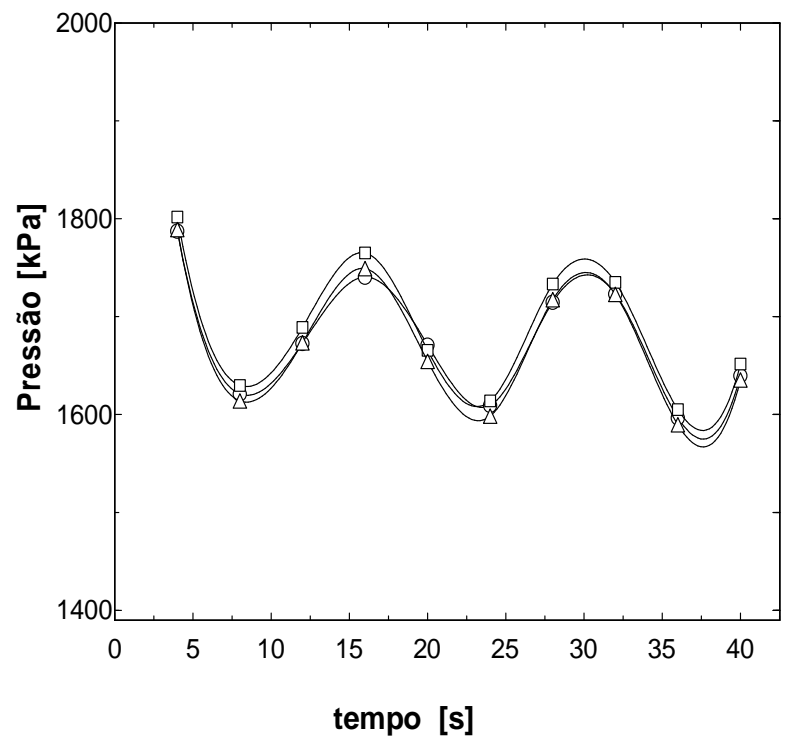

Figura 105: Variação das pressões vs. tempo de ensaio em segundos.

Diante dos resultados alcançados neste trabalho, conclui-se que o sistema, apesar de ter sido montado com componentes de um sistema condicionador de ar automotivo convencional, surpreendentemente, apresentou melhor desempenho nos testes de bomba de calor, diante das condições estabelecidas pelas duas câmaras. 


\section{7 CONCLUSÕES E SUGESTÕES PARA FUTUROS TRABALHOS}

Desenvolveu-se, na presente tese, o estudo experimental e teórico de nova tecnologia para sistemas condicionadores de ar automotivos, aplicada a veículos elétricos, visando aquecimento e refrigeração. Para tal foi projetado, com inspiração na norma SAE J2765, e montado, no Laboratório de Refrigeração, Condicionamento de Ar e Criogenia da PUCRio, um aparato experimental para ensaio de sistemas automotivos de condicionamento de ar. Igualmente, foi realizada uma simulação numérica do sistema estudado a fim de ampliar o conhecimento adquirido com os dados experimentais.

\section{1 \\ Conclusão}

São as seguintes as principais conclusões da presente tese:

- O sistema demonstrou funcionar como esperado, tanto para o modo de ar condicionado (refrigeração da cabine) como para o modo de bomba de calor (aquecimento), para uma ampla faixa de condições externas $\left(30^{\circ} \mathrm{C}\right.$ a $45^{\circ} \mathrm{C}$, para ar condicionado, e $0^{\circ} \mathrm{C}$ a $10^{\circ} \mathrm{C}$, para aquecimento);

- A capacidade térmica da bomba de calor decresce à medida que a temperatura externa cai, isto é, quanto mais se precisar de aquecimento;

- A capacidade térmica do ciclo, frio ou aquecimento, cresce com a velocidade angular do compressor, e esta pode tornar-se uma efetiva variável de controle da capacidade do sistema;

- O coeficiente de desempenho da bomba de calor manteve-se, ao longo de toda a faixa de operação, superior à unidade, mostrando sua superioridade, do ponto de vista energético, sobre a resistência elétrica convencional;

- A construção do aparato experimental utilizando câmaras climatizadas para a simulação dos ambientes, interno e externo, mostrou-se eficaz;

- A pressão de descarga do compressor e as de entrada e saída do condensador apresentaram uma variação diretamente proporcional à variação da temperatura de entrada do ar.

- A utilização de câmaras climatizadas foi importante no que diz respeito à manutenção, o mais próximo possível de um regime permanente, das temperaturas do ambiente externo e da cabine, buscando o regime permanente; 
- A aquisição de grande número de dados brutos, obtidos com a instrumentação utilizada, resultou em grande complexidade no momento da redução destes;

- Ambos os trocadores de calor necessitam de adaptação visando melhorar sua efetividade e desempenho na dupla função que terão (condensador e evaporador);

- A válvula de expansão apresentou instabilidades, principalmente quando o sistema operou como bomba de calor;

- O aparato experimental apresentou, por questões de construção, uma queda de pressão elevada na linha de sucção.

\section{2 \\ Sugestões para futuros trabalhos}

Para trabalhos futuros sugere-se o seguinte:

- $\quad$ Medição direta da vazão de refrigerante de forma a se obter dados mais precisos para a caracterização dos diferentes componentes do referido sistema;

- Uma melhoria da instrumentação utilizada, garantindo assim uma melhor repetitividade nas medições;

- $\quad$ Modelagem dos trocadores de calor utilizando o método de multizona;

- A utilização de novos refrigerantes.

Foram motivos de estudo, na presente tese, as variáveis que mais influenciam o desempenho do sistema operando nos modos de ar condicionado e de bomba de calor.

Espera-se que a grande quantidade de dados obtidos através dos diferentes testes contribua para um melhor entendimento dos processos que ocorrem em um sistema automotivo de ar condicionado e bomba de calor de compressão de vapor.

Os dados aqui estudados terão, dentre outras, a finalidade de servir como marco de comparação para sistemas de capacidade equivalente que utilizem técnicas e/ou configurações distintas. 


\section{REFERÊNCIAS BIBLIOGRÁFICAS}

ANTONIJEVIC D., HECKT R. Heat pump supplemental heating for motor vehicles proceedings of the institution of mechanical engineers part journal, (2004);

BÁRBARA TORREGROSSA-JAIME; JORGE PAYÁ; JOSE CORBERAN; Design of Efficient Air-Conditioning Systems for Electric Vehicles, SAE 2013-010864.

BHATTI, M.S (a); Evolution of Automotive Air Conditioning - Riding in Comfort: Part I, ASHRAE, (1999)

BHATTI, M.S (b); Evolution of Automotive Air Conditioning - Riding in Comfort: Part II, ASHRAE, (1999);

DIDACTA; Manual de Operação do Equipamento T66-D, 2003

ENGINEERING EQUATION SOLVER (EES), version V7, 258-3D, F-Chart

Software, LLC, 2004.

F-GAS LEGISLATION, Conselho e Parlamento Europeu regulamento (CE), 17/05/2006.

GALLAS, M. R. Análise de incertezas IF - UFRGS(1998)

JOHN MEYER; GEORGE YANG; EVANGELOS PAPOULIS; R134a Heat Pump for Improved Passenger Comfort; SAE 2004-01-1379.

Journal, 41(9), Set. 1999.

LAWRENCE P. SCHERER; MAHMOUD GHODBANE; JAMES A. BAKER; PRASAD S. KADLE; On-Vehicle Performance Comparison of an R-152a and R-134a Heat Pump System; SAE 2003-01-0733.

M. DIREK; M. HOSOZ; K.S. YIGIT; M. CANAKC; A. TURKCAN; E. ALPTEKIN; A. SANLI; A.F. OZGUC; Experimental Performance of R134a Automotive Heat Pump Coupled to the Passenger Compartment, World Renewable Energy Congress 2011 - Sweden 8-13 May 2011, Linköping, Sweden.

M. HOSOZ; M. DIREK; Performance Avaluation of an Integrade Automotive Air Conditioning and Heat Pump, Energy Conversion and Management 47 (2006) 545-559.

PAYÁ, J.; CORBERÁN, J.M.; TORREGROSA-JAIME, B. VASILE-MÜLLER, C.; Innovative Air-Conditioning Systems for Conventional e Electric Vehicles; 2011.

SAE: Norma J2765, outubro 1999.

SEONGKOOK SHIN; CHANGHOON YUN; SEOK-JOO LIM; JUNG-HOON; YOUNGDOO CHO; TAEWOO KOO; SANGGON LEE; $R$ 134a Heat Pump 
Application for the Buses by Using Engine Coolant as a Heat Source; SAE 2008-01-2697.

TAKAHISA SUZUKI; KATSUYA ISHIL; Air Conditioning System for Electric Vehicle; SAE 960688, 1996.

TOSHIHISA KONDO ${ }^{1}$; AKIRA KATAYAMA ${ }^{1}$; HIDEKI SUETAKE ${ }^{1}$; MASATOSHI MORISHITA ${ }^{2}$; Development of Automotive Air-Conditioning Systems by Heat Pump Technology, 2011,

VICENTE POMMÉ; Reversible Heat Pump System for an Electrical Vehicle, Valeo Thermal System, SAE 971772, 2012. 